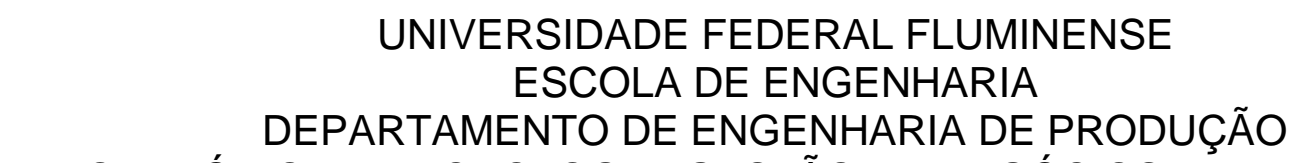

LABORATÓRIO DE TECNOLOGIA, GESTÃO DE NEGÓCIOS E MEIO AMBIENTE MESTRADO PROFISSIONAL EM SISTEMAS DE GESTÃO

VLADIMIR STEFFEN PINTO

\title{
DESENVOLVIMENTO DE SOLUÇÃO CRISP-DM PARA CLASSIFICAÇÃO DO EVENTO PRISÃO DE COLUNA NO PROCESSO DE PERFURAÇÃO DE POÇOS OFFSHORE
}

Dissertação apresentada ao Curso de Mestrado em Sistema de Gestão da Universidade Federal Fluminense como requisito parcial para obtenção do Grau de Mestre em Sistemas de Gestão. Área de concentração: Organizações e Estratégia. Linha de Pesquisa: Sistema de Gestão pela Qualidade Total.

Orientador:

Prof. Gilson Brito Alves Lima, D.Sc

Niterói

2018 
Ficha catalográfica automática - SDC/BEE Gerada com informações fornecidas pelo autor

P659d Pinto, Vladimir Steffen

DESENVOLVIMENTO DE SOLUÇÃO CRISP-DM PARA CLASSIFICAČ̃O DO EVENTO PRISÃO DE COLUNA NO PROCESSO DE PERFURAÇÃO DE POÇOS OFFSHORE / Vladimir Steffen Pinto ; Gilson Lima, orientador. Niterói, 2018.

121 f. : il.

Dissertação (mestrado profissional)-Universidade Federal Fluminense, Niterói, 2018.

DOI: http://dx.doi.org/10.22409/PSG.2018.mp.68310390068

1. Perfuração de Poços. 2. Prisão de Coluna. 3. CRISPDM. 4. Regressão Logística. 5. Produção intelectual. I. Lima, Gilson, orientador. II. Universidade Federal Fluminense. Escola de Engenharia. III. Título.

Bibliotecária responsável: Fabiana Menezes Santos da Silva - CRB7/5274 


\title{
DESENVOLVIMENTO DE SOLUCÃO CRISP-DM PARA CLASSIFICACÃO DO EVENTOPRISAOO DE COLUNA NO PROCESSO DE PERFURACÃODE POCOS OFFSHORE.
}

\begin{abstract}
Dissertaçũo apresentada ao Curso de Mestrado em Sistemas de Gestāo da Universidade Federal Fluminense como requisito parcial para obtençũo do Grau de Mestre em Sistemas de Gestào. Area de Concentração: Organizaçōes e Fstratégia. Linha de Pesquisa: Sistema de Gestão pela Qualidade Total.
\end{abstract}

Aprovada em 17 de dezembro de 2018.
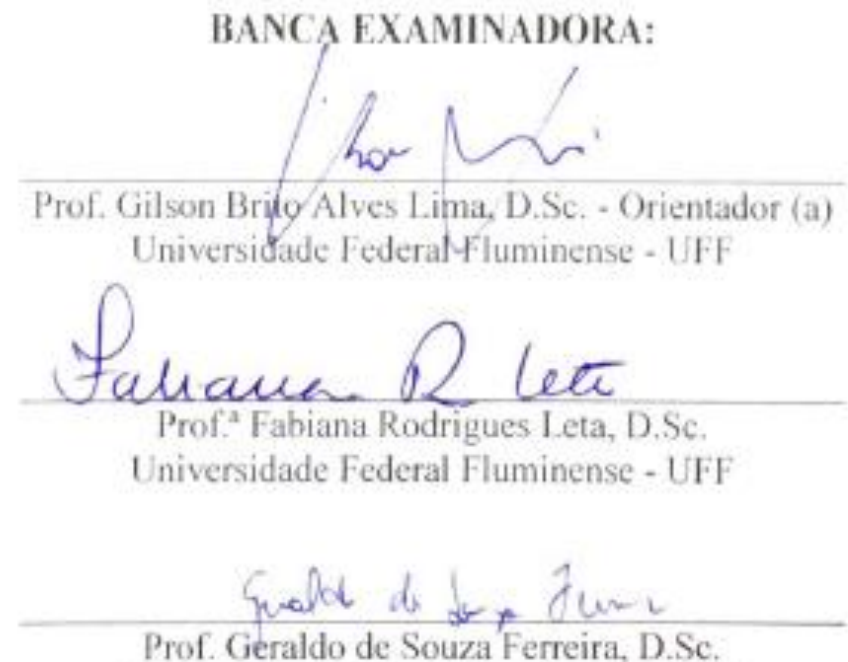

Universidade Federal Fluminense - UFF

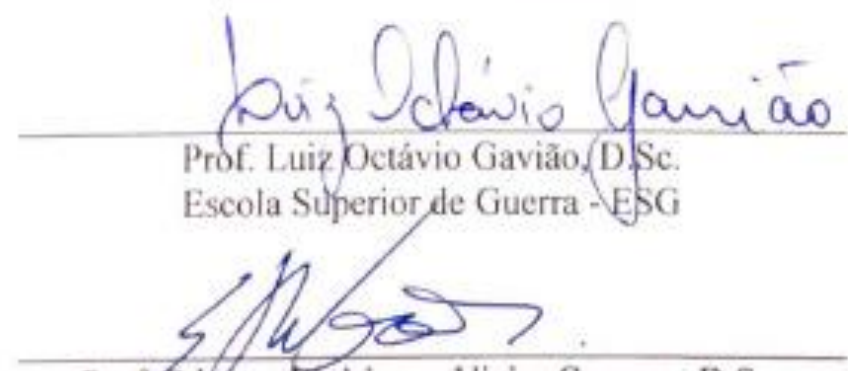

Prof. Sthener Rodrigues Vieira Campos, D.Sc.

Centro de Pesquisa da Petrobras - CENPES 
Dedico esta dissertação

a minha esposa Paloma e meu filho Nicolas. 


\section{AGRADECIMENTOS}

Agradeço à Agência Nacional do Petróleo, Gás Natural e Biocombustíveis (ANP) e a Petrobras que forneceu recursos, por meio de projeto de pesquisa desenvolvimento e inovação (PD\&I), para que esta dissertação pudesse ser realizada.

Aos meus colegas do curso de mestrado e participantes dos projetos de pesquisa (PD\&l) que me proporcionaram uma oportunidade de troca de conhecimentos e apoio durante toda a jornada.

Meus sinceros agradecimentos aos colegas de trabalho Claudio Lima, Jonas Maciel e Miguel Galiza, que além do apoio moral, participaram de discussões valiosas contribuindo para a elaboração dessa dissertação.

Agradeço também à minha família e amigos por entender os meus momentos de recolhimento e ausência.

Um agradecimento especial ao meu orientador, Gilson Brito Alves Lima, por todo o apoio durante a condução desta pesquisa que me proporcionou a descoberta de novas linhas de conhecimento.

Agradeço, finalmente, a minha esposa Paloma e meu filho Nicolas, que constituem a minha base, e sem os quais nenhuma das minhas conquistas seria possível.

Obrigado a todos! 
Eu acredito demais na sorte.

E tenho constatado que, quanto mais duro eu trabalho, mais sorte eu tenho.

Thomas Jefferson 


\section{LISTA DE ILUSTRAÇÕES}

Figura 1 - Evolução do Preço do Petróleo 2015.

Figura 2 - Prisão de coluna de perfuração por (a) diferencial de pressão e por prisão mecânica: (b) desmoronamento, (c) embuchamento e (d) inchamento de argila. 21

Figura 3 - Estrutura geológica do Pré-Sal.

Figura 4 - Fluxo de desenvolvimento da pesquisa baseado na metodologia CRISP-DM.

Figura 5 - Cadeia de valor da exploração e produção.

Figura 6 - Transporte dos resíduos pelo fluido de perfuração.

Figura 7 - Classificação das sondas de perfuração rotativa

Figura 8 - Tipo de sondas marítimas.

Figura 9 - Sistema de sustentação e movimentação de cargas.

Figura 10 - Top Drive.

Figura 11 - Painel do sondador

Figura 12 - Sistemas Integrados de Controle de Perfuração.

Figura 13 - Drill collars, C- Drill pipes e heavy weight drill pipes.

Figura 14 - Brocas de perfuração.

Figura 15 - Sistema de Superfície e poço (downhole).

Figura 16 - Fluxo de trabalho de engenharia de perfuração.

Figura 17 - Transformação Digital no E\&P

Figura 18 - Artificial Intelligence - Machine Learning - Deep Learning.

Figura 19 - Algoritmos de aprendizado de máquina.

Figura 20 - Etapas do processo KDD.

Figura 21 - Processo do Big Data.

Figura 22 - Metodologia CRISP-DM.

Figura 23 - Metodologia SEMMA.

Figura 24 - Publicações pelo mundo.

Figura 25 - Quantidade de registro da amostra.

Figura 26 - Análise de dados nulos e faltantes.

Figura 27 - Análise de balanceamento da variável alvo. 
Figura 28 - Boxplot de análise de distribuição dos dados.

Figura 29 - Seleção de variáveis.

Figura 30 - Boxplot das variáveis selecionadas (desvio padrão).

Figura 31 - Sumarização do método de regressão logística.

Figura 32 - Interpretação útil da área.

Figura 33 - Diretório com dataset.

Figura 34 - Seleção dos dados.

Figura 35 - Seleção dos dados para Treinamento.

Figura 36 - Seleção dos dados para Teste

Figura 37 - Análise dos dados.

Figura 38 - Seleção das variáveis.

Figura 39 - Análise de resultados. 


\section{LISTA DE ABREVIAÇÕES}

$\begin{array}{ll}\text { ALARP } & \text { As Low as Reasonably Practicable } \\ \text { BHA } & \text { Button hole assembly } \\ \text { BOP } & \text { Blowout Preventer } \\ \text { CAPEX } & \text { Capital expenditure } \\ \text { CPS } & \text { Cyber-physical systems } \\ \text { CSD } & \text { Centro de Suporte a Decisão } \\ \text { DC } & \text { Drill Collars } \\ \text { DL } & \text { Deep Learning } \\ \text { DP } & \text { Drill Pipers } \\ \text { E\&P } & \text { Exploração e Produção } \\ \text { ESCP } & \text { Equip. de Segurança de Cabeça de Poço } \\ \text { GOM } & \text { Gulf of Mexico } \\ \text { GUI } & \text { Graphical user interface } \\ \text { HWDP } & \text { Heavy- Weight } \\ \text { IA } & \text { Inteligência Artificial } \\ \text { IOT } & \text { Internet of Things } \\ \text { KDD } & \text { Knowledge Discovery in Databases } \\ \text { LDA } & \text { Lâmina d'água } \\ \text { LWD } & \text { Logging while drilling } \\ \text { M2M } & \text { Machine-to-machine } \\ \text { ML } & \text { Machine Learning } \\ \text { MWD } & \text { Measurement while drilling } \\ \text { NPT } & \text { Non-productive time } \\ \text { OPEX } & \text { Operational Expenditure } \\ \text { PDW } & \text { Pressure-While-Drilling } \\ \text { RTOC } & \text { Real-time Operational Center } \\ \text { SCADA } & \text { Supervisory Control and Data Acquisition } \\ \text { SMS } & \text { Segurança, Meio Ambiente e Saúde } \\ \text { VPL } & \text { Valor Presente Líquidos } \\ & \end{array}$




\section{QUADROS}

Quadro 1 - Processo de desenvolvimento da dissertação. 26

Quadro 2 - Sistemas Geradores de Dados de Perfuração - Superfície. 41

Quadro 3 - Sistemas Geradores de Dados de Perfuração - Poço (Downhole). 44

Quadro 4 - Os sintomas de instabilidade do poço. 45

Quadro 5 - Problemas na perfuração. 49

Quadro 6 - Publicações relacionadas a regressão em Perfuração de Poços. 71

Quadro 7 - Processo no desenvolvimento da solução. 76

Quadro 8 - Descrição das variáveis da amostra. $\quad 80$

Quadro 9 - Variáveis relevantes selecionados. 88

Quadro 10 - Matriz de confusão. $\quad 94$ 


\section{RESUMO}

A indústria de Exploração e Produção (E\&P), com o intuito de melhorar a produtividade e reduzir custos, tem buscado, ao longo dos anos, o uso de tecnologias digitais para mitigar os efeitos das sazonalidades dos preços do petróleo, a escassez de profissionais, o aumento da concorrência e operações mais seguras. Atualmente, a iniciativa de transformação digital, referenciada como a nova revolução industrial, vem impulsionando o uso de tecnologias disruptivas e provocando mudanças culturais na sociedade e na indústria. No centro desta revolução está o crescimento exponencial e a disponibilidade de dados. Neste cenário é necessária uma mudança na forma como estes são coletados, armazenados, analisados e acessados para suportar inteligência e ciclos de tomada de decisão das organizações. Esta dissertação visa abordar o processo de descoberta de conhecimento em dados, através do desenvolvimento de uma solução computacional com suporte da metodologia CRISPDM (Cross Industry Standard Process for Data Mining) para análise de anomalias no processo de perfuração de poços em águas ultra profundas. A perfuração de poços é uma das fases mais demandantes de recursos financeiros. Assim, entender e antecipar problemas, avaliar suas causas e soluções de planejamento são necessários para o controle global de custos e para garantir a integridade e estabilidade do poço, evitando tempos não produtivos. Esta pesquisa foi delimitada ao evento de prisão de coluna de perfuração e ao uso do método de regressão logística no desenvolvimento da etapa de modelagem. Os dados utilizados foram disponibilizados pela Agência Nacional do Petróleo, Gás Natural e Biocombustíveis (ANP), por meio de um projeto de pesquisa de desenvolvimento e inovação (PD\&l), contendo um conjunto de dados reais de perfuração de poços de petróleo do polígono do Pré-sal, na costa brasileira. Ao final do processo de avaliação, foi possível analisar a aplicabilidade do modelo escolhido e dos resultados obtidos com o objetivo do negócio propriamente dito, ou seja, que os resultados fiquem adequados para apoiar a tomada de decisões da organização. Os resultados alcançados para exemplificar o modelo demonstram uma acurácia de $89 \%$ e uma taxa de precisão de $99 \%$. Outro resultado importante do trabalho é a contribuição para profissionais e empresas que necessitem aplicar métodos de ciência de dados em casos semelhantes ou com outras características. Algumas limitações, como a baixa qualidade dos dados e o tamanho da amostra também são destacadas durante o processo de descoberta de conhecimento. Adicionalmente, foram incluídos os códigos de linguagem de programação, utilizados para o entendimento e tratamento de dados e geração dos resultados. Estes podem servir como uma versão inicial para outras análises.

Palavras-Chaves: Perfuração de Poços. Prisão de Coluna. CRISP-DM. Regressão Logística. 


\begin{abstract}
Over the years, the Exploration and Production (E\&P) industry, in order to improve productivity and reduce costs, has sought the use of digital technologies to mitigate the effects of seasonal oil prices, the shortage of professionals, increased competition and to promote safer operations. Today the digital transformation initiative - referred to as the new industrial revolution - has been driving the use of disruptive technologies and provoking cultural changes, both in society and industry. At the heart of this revolution is the exponential growth and data availability. In this scenario, a change is needed in the way these data are collected, stored, analyzed and accessed to support organizations intelligence and decision-making cycles. This dissertation addresses the process of knowledge discovery in data, through the development of a computational solution with support of the methodology CRISP-DM (Cross Industry Standard process for data Mining) for analysis of anomalies in the process of Drilling of wells in ultra-deep waters. Well drilling is one of the stages that most demand financial resources. Thus, understanding and anticipating problems, evaluating their causes and planning solutions are necessary for global cost control, in order to ensure the well integrity and stability, avoiding non-productive times. This research was delimited to the stuck pipe event and the use of the logistic regression method in the development of the modeling step. The data used were made available by the Brazilian National Agency of Petroleum, Natural Gas and Biofuels (ANP), through a development and innovation research Project (PD\&I), containing a set of real data for drilling oil wells of the Pre-salt polygon on the Brazilian coast. At the end of the evaluation process, it was possible to analyze the applicability of the chosen model and the results obtained with the business perspective, that is, that the results are adequate to support the decision-making of the organization. The results obtained to exemplify the model demonstrate an accuracy of $89 \%$ with a rate of $99 \%$. Another important result of the work is the contribution to professionals and companies that need to apply methods of data science in similar cases or with other characteristics. Some limitations with low data quality and sample size are also highlighted during the knowledge discovery process. Additionally, programming language codes were included, used for understanding and processing data and generating results. These can serve as an initial version for other analyses.
\end{abstract}

Key-Words: Well Drilling. Stuck Pipe. CRISP-DM. Logistic Regression. 
1. INTRODUÇÃO

1.1. O PROBLEMA DA PESQUISA 19

1.2. OBJETIVOS DA PESQUISA 22

1.2.1. Objetivos específicos 22

1.3. DELIMITAÇÃO DA PESQUISA 23

1.4. CONTRIBUIÇÃO E RELEVÂNCIA 24

1.5. MATERIAIS E MÉTODOS 25

1.6. ORGANIZAÇÃO DA DISSERTAÇÃO 26

2. REFERENCIAL TEÓRICO $\mathbf{2 8}$

2.1. CADEIA DE VALOR DO E\&P 28

2.2. PERFURAÇÃO DE POÇOS OFFSHORE 29

2.3. MÉTODOS E SONDAS DE PERFURAÇÃO 29

2.4. SISTEMAS DA SONDA DE PERFURAÇÃO 32

2.4.1. Sistema de sustentação e movimentação de cargas 33

2.4.2. Sistema de geração e transmissão de energia 34

2.4.3. Sistema de rotação $\quad 34$

2.4.4. Sistema de circulação $\quad 35$

2.4.5. Sistema de segurança do poço 36

2.4.6. Sistema de monitoramento da sonda 36

2.4.7. Sistemas de subsuperfície - Coluna de Perfuração 38

2.4.8. Sistemas de subsuperfície - Brocas 39

2.5. SISTEMA GERADORES DE DADOS DE PERFURAÇÃO 40

2.5.1. Outros sistemas 44

2.6. PROBLEMAS NA PERFURAÇÃO (INSTABILIDADE NO POÇO) 45

2.7. TEMPO NÃO PRODUTIVO (NPT - NON PRODUCTIVE TIME) 50

3. A TRANSFORMAÇÃO DIGITAL NO E\&P $\mathbf{5 4}$

3.1. BIG DATA NO E\&P 56

3.2. QUALIDADE DE DADOS (DATA QUALITY) 57

3.3. INTELIGÊNCIA ARTIFICIAL 58

3.3.1. Aprendizado de Máquina - Machine Learning 60

3.3.2. Aprendizagem Profunda - Deep Learning 62

3.4. PRODUÇÃO DE CONHECIMENTO A PARTIRDE DADOS 62 
4. REVISÃO DA LITERATURA 69

5. DESENVOLVIMENTO DA SOLUÇÃO CRISP-DM 75

5.1. COMPREENSÃO DO NEGÓCIO 77

5.2. COMPREENSÃO DOS DADOS

$\begin{array}{ll}\text { 5.2.1. Fontes de Dados } & 78\end{array}$

5.2.2. Limpeza dos dados faltantes $\quad 79$

5.2.3. Identificação do dado de estudo (variável alvo) 79

5.2.4. Análise qualitativa da amostra 80

5.2.5. Análise quantitativa da amostra 82

5.2.6. Análise exploratória dos dados 83

5.2.6.1. Análise de variáveis nulas e faltantes 83

5.2.6.2. Análise de balanceamento da variável alvo 84

5.2.6.3. Análise de distribuição dos dados $\quad 85$

5.3. PREPARAÇÃO DOS DADOS 86

5.3.1. Seleção de variáveis $\quad 87$

5.3.2. Tratamento para dados nulos e faltantes 89

5.3.3. Tratamento para dispersão de valores $\quad 89$

$\begin{array}{ll}\text { 5.3.4. Tratamento da variável alvo } & 90\end{array}$

5.4. MODELAGEM 90

5.5. AVALIAÇÃO 93

5.6. IMPLANTAÇÃO 96

5.6.1. Solução computacional (protótipo) 97

5.6.1.1. Seleção da Amostra 97

5.6.1.2. Análise dos dados 100

5.6.1.3. Seleção das variáveis 100

5.6.1.4. Análise dos resultados 101

6. CONCLUSÕES 103

6.1. TRABALHOS FUTUROS $\quad 104$

$\begin{array}{ll}\text { BIBLIOGRAFIA } & 106\end{array}$

APÊNDICE A - Códigos da análise exploratória 113

APÊNDICE B - Códigos da preparação dos dados $\quad 115$

APÊNDICE C - Códigos da modelagem e avaliação 116

APÊNDICE D - Códigos da solução (protótipo) 118 


\section{INTRODUÇÃO}

Nos últimos anos a exploração de petróleo no mar desenvolveu-se substancialmente. O aprimoramento das técnicas de perfuração tem levado à exploração de hidrocarbonetos em ambientes cada vez mais profundos. A adoção de novas tecnologias, assim como as pesquisas e desenvolvimentos, tem um custo elevado. A indústria de petróleo, em função da demanda de sua fase de Exploração e Produção (E\&P) é notadamente umas das que mais investem recursos financeiros em pesquisas e desenvolvimento de novas tecnologias, porém, isto possui uma forte dependência em relação às variações no valor da commodity (GALLAGHER et al., 2011).

Conforme Holdaway e Irving (2017), a indústria do petróleo possui natureza cíclica, com variações históricas nos preços do barril. Esta última desaceleração do preço do barril em 2015, como nas recessões anteriores, abalou a indústria drasticamente com a redução de OPEX ${ }^{1}$ e CAPEX ${ }^{2}$. Segundo a publicação de Damodaran (2014), a combinação da redução da demanda e o aumento da oferta de petróleo no mercado contribuíram para a queda de preços, cerca de 40\%, em 2014. Mas, de acordo com a OPEC (2015), esta redução foi maior ainda conforme apresentado na Figura 1.

Figura 1 - Evolução do Preço do Petróleo 2015.

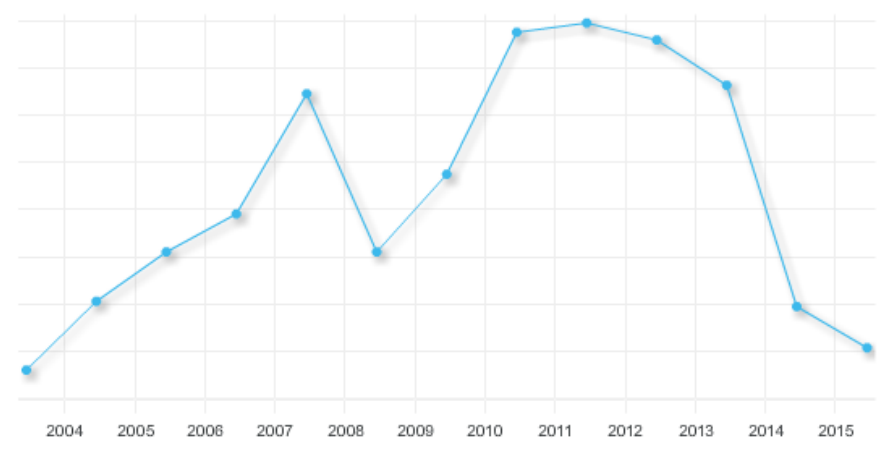

Fonte: OPEC (2015)

Como consequência, a redução de custos operacionais (OPEX) levou à diminuição na contratação de recursos humanos e no uso de materiais, como

\footnotetext{
${ }^{1}$ OPEX - sigla inglesa para operational expenditure e em português, despesas operacionais

2 CAPEX - sigla inglesa para capital expenditure e em português, despesas de capital
} 
provocou o cancelamento de projetos de exploração (CAPEX). Os portfólios de projetos de investimentos das empresas, que são planejados em longo prazo e com ordem de grandeza de bilhões de dólares, foram os primeiros a serem impactados. Projetos anteriormente com seu Valor Presente Líquidos (VPLs) exuberantes foram submetidos ao extremo, ou seja, mais próximo do zero (VPL $=0)$. Neste cenário, a carteira mundial de projetos diminuiu drasticamente, deixando para segundo plano projetos menos lucrativos e não lucrativos nesta atual conjuntura (MOREIRA, 2017). Porém, existem casos de projetos em andamento que entraram em uma árdua tarefa de replanejamento, para a redução dos seus custos. Este contexto restritivo agrega à realização destas tarefas a mudança cultural e organizacional nas operadoras e nas prestadoras de serviços. Estas últimas impactadas diretamente pela diminuição nas carteiras de seus clientes.

Durante períodos de transição, as empresas buscam melhores práticas de trabalho, com processos mais eficiêntes. Isto leva, inevitavelmente, à adoção de novas tecnologias, não necessariamente novas em outras indústrias.

Na busca por eficiência, Holdaway (2014) ressalta que um bem primordial de qualquer operação de petróleo e gás são os dados, e o mais importante é manter os muitos anos de experiência por meio do desenvolvimento de centros analíticos de excelência colaborativos, que incorporem habilidades e conhecimentos especializados. Seguindo a linha de raciocínio do autor, a história indica que, a partir da década de 1980, houve um aumento na quantidade de informação gerada durante a perfuração de um poço. Isto se deu através da evolução tecnológica, com o desenvolvimento de sensores e de sistemas de processamento de dados, corroborando e permitindo a medição e o registro de informações que abrangem desde os paramentos operacionais das sondas de perfuração, os dados de equipamentos instalados nos poços até as características geológicas das formações perfuradas. Como acelerador deste ambiente, agregou-se nos últimos anos a evolução dos meios de transmissão de dados, possibilitando a análise em tempo real das informações em qualquer parte do mundo, uma atividade que antes estava circunscrita, com a obtenção de dados no ambiente das sondas e sua posterior consolidação na base das empresas.

Também no contexto de busca pela eficiência, Boman (2015) indica que as abordagens habituais para a otimização da produção precisam ser aprimoradas para incluir modelos baseados em dados. Esta otimização tem como suporte a 
disponibilização de um ciclo de tomada de decisão mais eficiente, utilizando metodologias para garantir a colaboração e o dimensionamento de uma força de trabalho mais experiente. Pessoas, processos e tecnologias compreendem o tripé de uma efetiva excelência organizacional.

Nesta linha de busca pela eficiência, integrando pessoas, processos e tecnologia, e compreendendo os dados e informações, a indústria do petróleo já vinha conduzindo iniciativas que visavam operações mais enxutas, devido à escassez de recursos. Os principais direcionadores dessas atividades eram: a otimização em seus processos de trabalho, a redução do tempo de operações e a melhora na qualidade da tomada de decisão. São exemplos de destaque dessas iniciativas as Operações Integradas (Integrated Operations) e os Campos Inteligentes (Digital Oilfield) (CRAMER et al., 2012; LIMA, 2013). Estas iniciativas são ainda mais catalisadas em cenários de crises, possibilitando, em alguns casos, a viabilidade econômica de projetos.

Atualmente, a Transformação Digital é a expressão em destaque nas empresas de todos os setores ao redor do mundo. É um processo no qual as empresas concentram o esforço na mudança da estrutura organizacional da empresa, colocando a área de TI (Tecnologia de Informação) como um papel estratégico, e não mais como apenas uma área de apoio.

De acordo com Frank Gens et al. (2016):

\footnotetext{
Estamos em um ponto de inflexão. Nos próximos três a quatro anos, os esforços de transformação digital não serão mais "projetos", "iniciativas", ou "unidades de negócios especiais" para a maioria. Com efeito, cada empresa (em crescimento) - não importa sua idade ou indústria - se tornará um "nativo digital" na forma como seus executivos e funcionários pensam e como funcionam.
}

As iniciativas anteriores de Digital Oilfield, e semelhantes, tinham como objetivo o aumento da produtividade e da eficiência nas operações, mas, conforme Kane et al. (2015), as empresas precisarão alinhar seus domínios de tecnologia da informação e organização para completar a Transformação Digital. $O$ autor destaca também o aspecto humano para esta transição. Reforça a necessidade de reformular a força de trabalho de petróleo e gás, pontuando que os especialistas atuais precisam ser trazidos para um mundo mais virtual, onde eles possam trabalhar em um ambiente 
central e orientar as pessoas, usando a tecnologia e conhecimentos especializados para cruzar distâncias.

No centro desta evolução estão os dados a serem utilizados pelos cientistas de dados, com o uso de metodologias analíticas avançadas, permitindo a realização de gerenciamento e análise de dados exploratórios e a operacionalização de modelos preditivos com resultados em tempo real. Sendo assim, o acesso aos dados disponíveis e a qualidade desses são fundamentais neste contexto.

A expressão Big Data é utilizada para representar este conjunto grande e complexo de dados, que não são passíveis de gerenciamento e tratamento pelos sistemas tradicionais de processamento de dados, de acordo com as necessidades de negócios. O Big Data é baseado em: Volume, Velocidade e Variedade, conhecido com os 3V's. De acordo com Marr (2017), por intermédio do Big Data é que uma organização será capaz de analisar as métricas corretas e conseguirá atingir os objetivos da Transformação Digital.

Outro fator importante na Transformação Digital, brevemente mencionado anteriormente, está relacionado com a área de Data Science (ciência de dados), a área de atuação dos cientistas de dados. Data Science é a área responsável pelo estudo das informações, o processo de captura, transformação, geração e, por fim, a análise de dados propriamente dita. Esta área é composta por diversas disciplinas como computação, estatística, matemática e, fundamentalmente, conhecimento do negócio. O profissional, cientista de dados, é multidisciplinar, responsável por conduzir o processo citado anteriormente. À medida que a força de trabalhar, com anos de experiente adquirida, se retira da indústria do petróleo a nova geração de profissionais chega com conhecimentos avançados em estatística e Soft Computing (HOLDAWAY, 2014).

Dentro deste contexto, vale ressaltar que uma das áreas que mais consomem recursos financeiros no processo de disponibilização de um campo de petróleo para a produção é a perfuração de poços (englobando a perfuração propriamente dita, a avaliação e a completação), sejam os poços pioneiros, presentes nas fases de prospecção, sejam os poços produtores e injetores, nas fases de desenvolvimento e produção de um campo de petróleo. É possível encontrar algumas iniciativas de integração e otimização das disciplinas envolvidas na construção de poços, por meio da disponibilização dos centros de perfuração, chamados de Drilling Centers (LIMA et al., 2016). De acordo com os autores, estes centros, que funcionam como áreas de 
integração de diversas disciplinas, também são suportados por tecnologias que visam a mais eficaz tomada de decisão operacional no tempo mais adequado possível. Existem algumas tecnologias já utilizadas, e alinhadas ao conceito da Transformação Digital, como as análises de dados históricos e de tempo real, com intuito de remediação de problemas operacionais, que podem ser consideradas preditivas (GHILARDI et al., 2013).

Os tempos perdidos nas operações de construção de poços são oriundos, na maioria das vezes, de complexidades não previstas durante o processo de construção de poços. Estes mesmos processos geram centenas de gigabytes de informações durante a perfuração do poço e podem estar disponíveis nos ambientes onshore. Assim, a chamada Transformação Digital abre um leque de oportunidades para a indústria do petróleo, com o uso de ferramentas e técnicas de Inteligência Artificial, buscando a predição de eventos não desejados.

Em um cenário de margens de lucro mais baixas, como o apresentado atualmente, as operadoras estão empenhando esforços para a redução de custos mediante a diminuição dos chamados Tempos Não Produtivos - NPT (Non-productive time), seja fazendo uso de novas tecnologias e melhoras nos processos de trabalho, seja priorizando operações cada vez mais seguras, pois qualquer evento não desejável pode ter impactos irreversíveis para a organização. Exemplos recentes mostram que eventos de blowout (escoamento descontrolado dos fluidos contidos nas rochas-reservatórios para dentro do poço, eventualmente atingindo a superfície de forma catastrófica) podem levar a perdas de vida e custos de recuperações (multas, custos indenizatórios, etc.) de bilhões de dólares, como o caso do poço de Macondo (GPO, 2011).

\subsection{O PROBLEMA DA PESQUISA}

A perfuração de poços de petróleo exige diversos equipamentos, associados a processos distintos. Destaca-se, especificamente, a coluna de perfuração, composta por tubos de perfuração, tubos pesados e comandos, a qual normalmente recebe 0 torque de equipamentos localizados na superfície. Estes equipamentos geram a energia necessária para que a coluna possa girar a broca e fornecer o peso necessário para perfurar a formação geológica em subsuperfície (NASCIMENTO et al., 2010). 
Como a perfuração de poços se trata de uma das fases mais demandantes de recursos financeiros, a manutenção de prazos dos projetos é primordial. Porém, com grande frequência, esta configuração de equipamentos que forma a coluna de perfuração pode ficar presa dentro do poço que está sendo perfurado, impossibilitando e evolução da perfuração e repercutindo negativamente no chamado tempo não produtivo (NPT non-productive time). Segundo estudo de Muqeen, Weekse e Al-Hajji (2012) este tipo de ocorrência é responsável por até $25 \%$ do NPT, pois são necessárias diversas manobras não planejadas para tentar liberar a coluna, assim como equipamentos e serviços especiais.

A presente dissertação foca a questão da prisão de coluna de perfuração, evento não desejável que pode ocorrer na perfuração, causando atrasos e custos extras, devido às tentativas de sua liberação e, em casos mais extremos, inclusive a necessidade de abandono do poço definitivamente. Ademais, alguns autores relacionam um percentual de ocorrências de blowout como sendo iniciados com uma prisão de coluna (CARTER; VAN OORT; BARENDRECHT, 2014).

O problema de prisão de coluna é classificado normalmente em duas categorias: a prisão mecânica e prisão diferencial (BUSHNELL-WATSON; PANESAR, 1991).

- Prisão diferencial: causada quando, em uma formação permeável, o fluido de perfuração existente no poço exerce pressão excessiva na coluna de perfuração pressionando-a sobre o reboco. A circulação do fluido é mantida, nesta categoria, porém, a tubulação fica impossibilitada de mobilidade. Este fato pode ser ocasionado por uma formulação errônea dos fluidos e/ou a não consideração de existência de formações permeáveis, Figura 2 (a);

- Prisão mecânica: causada por obstruções ou restrições físicas, impedindo o fluido de perfuração de circular. Nesta categoria de prisão de coluna os principais fatores podem ser: a limpeza do poço, desmoronamentos e sedimentação de partículas carregadas no poço pelo fluido, Figura 2 (b), (c) e (d). 
Figura 2 - Prisão de coluna de perfuração por (a) diferencial de pressão e por prisão mecânica: (b) desmoronamento, (c) embuchamento e (d) inchamento de argila.

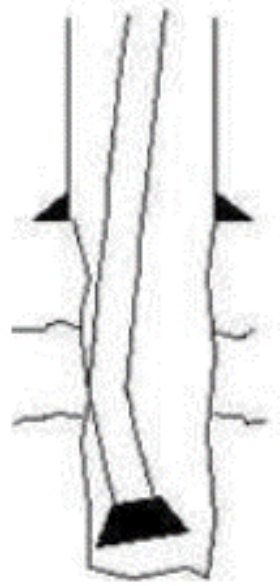

(a)

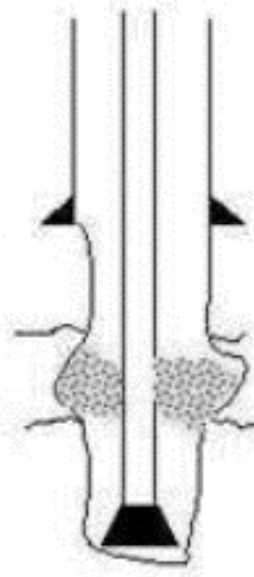

(b)

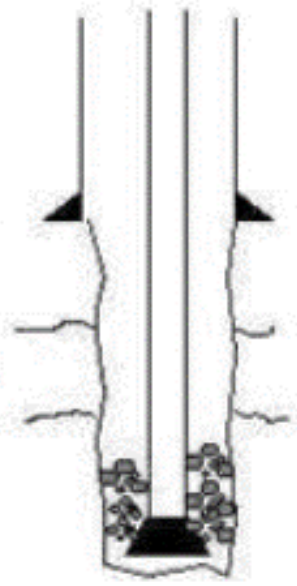

(c)

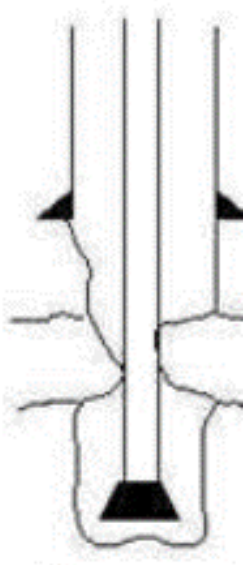

(d)

Fonte: Nascimento et al. (2010).

O desenvolvimento de novas tecnologias, nas últimas duas décadas, transformou sensivelmente o cenário na atividade de perfuração de poços marítimos. Estas tecnologias têm proporcionado um melhor controle das operações e disponibilizado um volume de dados cada vez maior. O crescente aumento de trabalhos publicados, sobre a atividade da área de Exploração e Produção de Petróleo, também ressalta a importância do processo de análise de dados.

Segundo Holdaway (2014), para impedir impactos adversos nas metas dos programas de perfuração, é imperativo que sejam utilizadas metodologias analíticas avançadas e implementar soluções híbridas para abordar os problemas. Essas soluções híbridas são fornecidas em torno de um sistema central, onde os engenheiros tenham acesso aos mais diversos dados (históricos e em tempo real) e obtenham informações críticas e cruciais para os parâmetros que tenham impactos estatísticos importantes para um evento de prisão de coluna de perfuração. O autor também complementa que entender e antecipar problemas de perfuração, avaliar suas causas e soluções de planejamento são necessários para o controle global de custos e para garantir a integridade e estabilidade do poço.

Considerando os frequentes eventos de prisão de coluna nas operações de perfuração, em associação com o crescente número de dados disponíveis, decorrentes de sistemas cada vez mais automatizados, é importante que se busquem métodos que proporcionem previsibilidade nas ocorrências deste evento, sejam tanto as prisões mecânicas quanto as diferencias (HESS, 2016). Este autor, em seu 
trabalho, relaciona alguns estudos já realizados nessa linha, utilizando análise estatística multivariada (análise de regressão), com dados históricos, para identificar as correlações entre os parâmetros selecionados.

Por fim, a identificação e, posterior, adoção de medidas preventivas ou atenuantes, à luz dos sinais de alerta ocultos nos parâmetros operacionais e não operacionais, considerados necessários, são importantes mecanismos que podem ser aplicados para mitigar os problemas de uma prisão de coluna.

\subsection{OBJETIVOS DA PESQUISA}

A perfuração de poços marítimos é a atividade que leva uma fatia generosa dos investimentos previstos no desenvolvimento de um campo de petróleo. A atividade está cercada de riscos que, em sua grande maioria, são analisados, levando em consideração o critério ALARP (As Low As Reasonably Practicable), tão baixo quanto razoavelmente possível (CCPS, 2014).

Historicamente, a indústria do petróleo vem perfurando poços terrestres, em águas rasas e profundas, estes considerados até anos atrás como em horizontes profundos. Porém, na segunda década deste milênio, começou a surgir um novo horizonte de poços, ultraprofundos, como, por exemplo, os poços perfurados que atingem profundidades abaixo da camada pré-sal, na Bacia de Santos, e que expõem a indústria a novos desafios, carregados de novos riscos em seus processos (MORAIS, 2013).

Esta dissertação objetiva desenvolver uma solução computacional, com suporte da metodologia CRISP-DM (Cross Industry Standard Process for Data Mining), para classificação do evento de prisão de coluna de perfuração, que contribua para apoio à tomada de decisão nos Drilling Centers (Centro apoio a decisão em perfuração).

\subsubsection{Objetivos específicos}

Para fins de atendimento ao objetivo geral serão desenvolvidos os seguintes objetivos específicos:

- Identificação das principais anomalias do processo de perfuração de poços de petróleo; 
- Levantamento das principais técnicas de Inteligência Artificial utilizadas;

- Modelagem e a aplicação da técnica selecionada;

- Avaliação dos resultados do modelo;

- Construção do protótipo da solução computacional.

\subsection{DELIMITAÇÃO DA PESQUISA}

Considerando a complexidade das atividades da construção de um poço de petróleo offshore, o foco do estudo será a etapa de perfuração, onde os impactos de anormalidades podem ser mais comprometedores, de acordo com os riscos envolvidos.

O campo de estudo será delimitado aos dados oriundos dos poços perfurados no polígono do pré-sal. A camada de sal, representada esquematicamente na Figura 3, possui 2000 metros de espessura e a perfuração nesta fase é geralmente efetuada com bocas de 1711/2" (KUEHN, 2014; PASCHOA, 2013). Limitando assim, o estudo em questão, aos dados de perfuração desta fase.

Figura 3 - Estrutura geológica do Pré-Sal.

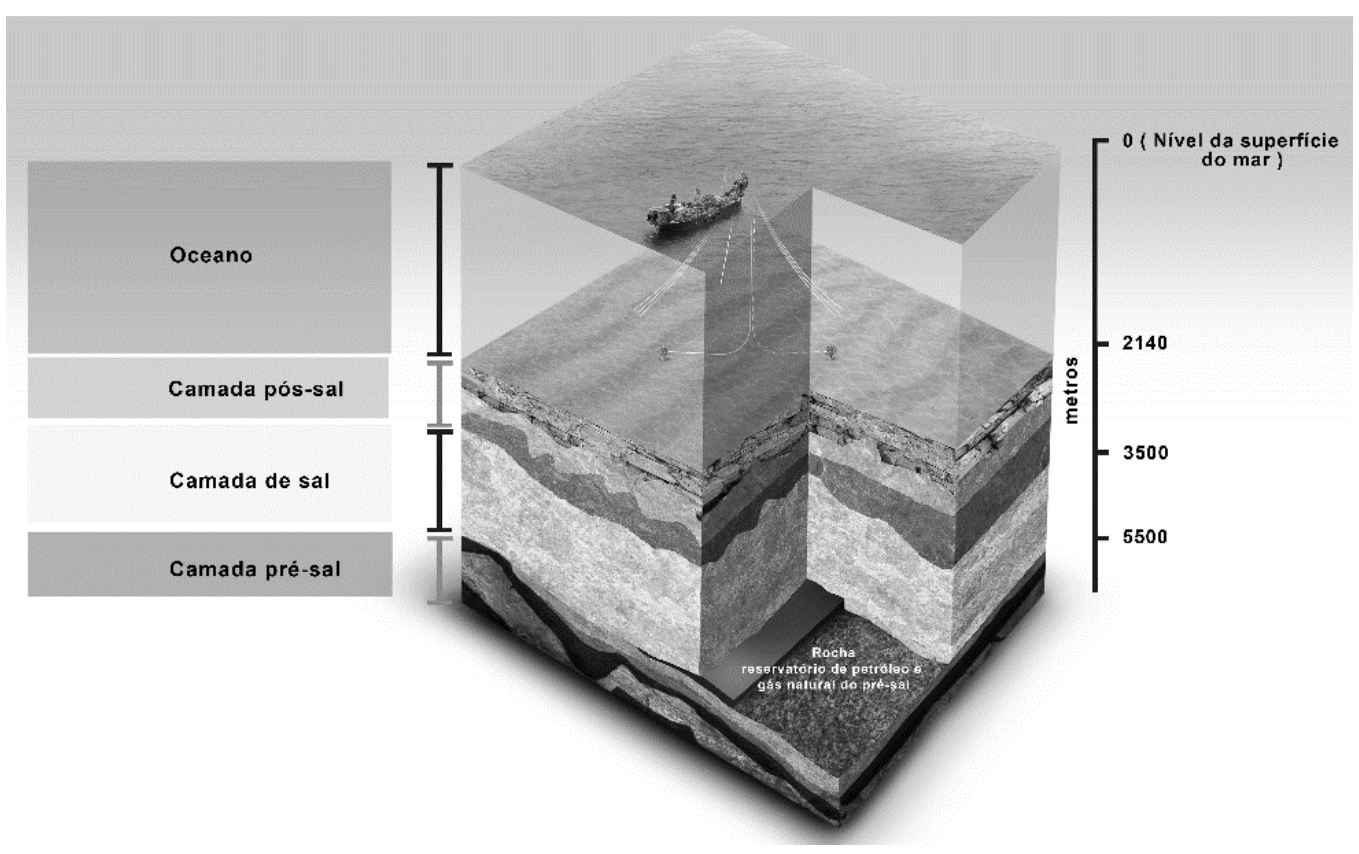

Fonte: Paschoa (2013).

Por último, no contexto das diversas técnicas de aplicação de Inteligência Artificial disponibilizadas na literatura, para análise do problema em estudo, esta 
pesquisa estará delimitada à avaliação de aplicabilidade da técnica de regressão logística na identificação de padrões de anomalias do tipo prisão de coluna de perfuração, na fase de perfuração no sal.

\subsection{CONTRIBUIÇÃO E RELEVÂNCIA}

A indústria do petróleo vem investindo fortemente para fazer com que os dados gerados nas unidades de perfuração offshore estejam disponíveis nos ambientes de apoio em terra no menor tempo possível. A medição destes dados e parâmetros em tempo real visa possibilitar o apoio nos processos operacionais e assim viabilizar análises mais aprofundadas nos históricos e ajustes nos processos de trabalho, a fim de evitar novos problemas. Conforme Ghilardi et al. (2013), a maioria das análises dos dados de perfuração em tempo real para identificar possíveis problemas operacionais é feita por um especialista em análise de perfuração, posteriormente à execução. Estes dados também permitem, com o apoio de técnicas computacionais de aprendizado de máquina, a antecipação e remediação de problemas durante a fase de perfuração (GOLA et al., 2012).

A aplicação de uma ferramenta computacional é apresentada por Ghilardi et al. (2013), para interpretar dados de perfuração (como pressão de bomba, pressão de fundo, torque e arrasto), objetivando detectar comportamentos anormais (como uma tendência crescente inesperada na pressão de fundo) e estabelecer critérios quantitativos para identificar uma possível causa, sugerindo ações corretivas e/ou preventivas. O objetivo principal é possibilitar uma tomada de decisão mais direta e rápida.

A aplicação de métodos preditivos para analisar dados de perfuração de poços de petróleo marítimos tem como objetivo proporcionar que as operadoras tomem decisões mais rápidas e precisas, redução do tempo não produtivo - NPT, redução de custos e principalmente redução dos riscos operacionais, nos casos de prisão de coluna de perfuração.

Nesta linha, Hess (2016) apresenta o uso do método de regressão múltipla com o objetivo de buscar a identificação e previsibilidade em ocorrências de prisão de coluna em um conjunto de dados de poços perfurados no Golfo do México. No conjunto de dados utilizados, especialistas buscaram identificar previamente dados 
de prisão de coluna ou sem prisão, e com o uso da estatística buscou-se obter correlações nos parâmetros selecionados.

A análise estatística de regressão múltipla é uma técnica usada para analisar a relação entre uma única variável dependente e diversas variáveis independentes (HAIR et al., 2009).

A pesquisa em questão usou um processo similar ao utilizado por Hess (2016), onde, a partir de uma amostra de dados identificados previamente por especialistas como dados de prisão de coluna ou sem prisão, foram realizadas análises, a fim de identificar correlações entre os parâmetros selecionados. Assim, nesta dissertação pretende-se fazer uso do método estatístico, que será aplicado em um cenário de dados de perfuração de poços na área de Pré-sal, com o objetivo de identificar os eventos de prisão de coluna à luz dos sinais de alerta ocultos nos parâmetros operacionais. Desta forma, medidas preventivas ou atenuantes podem ser tomadas, contribuindo para a otimização dos custos de perfuração mediante a redução do tempo perdido, NPT, e diminuição dos riscos operacionais.

\subsection{MATERIAIS E MÉTODOS}

Para obter os resultados pretendidos nesta dissertação, foi adotada a metodologia CRISP-DM (Cross-Industry Standard Process for Data Mining) para auxiliar desde a estruturação do problema até a obtenção dos resultados. A Figura 4 apresenta as etapas que constituem o processo da pesquisa.

Figura 4 - Fluxo de desenvolvimento da pesquisa baseado na metodologia CRISP-DM.

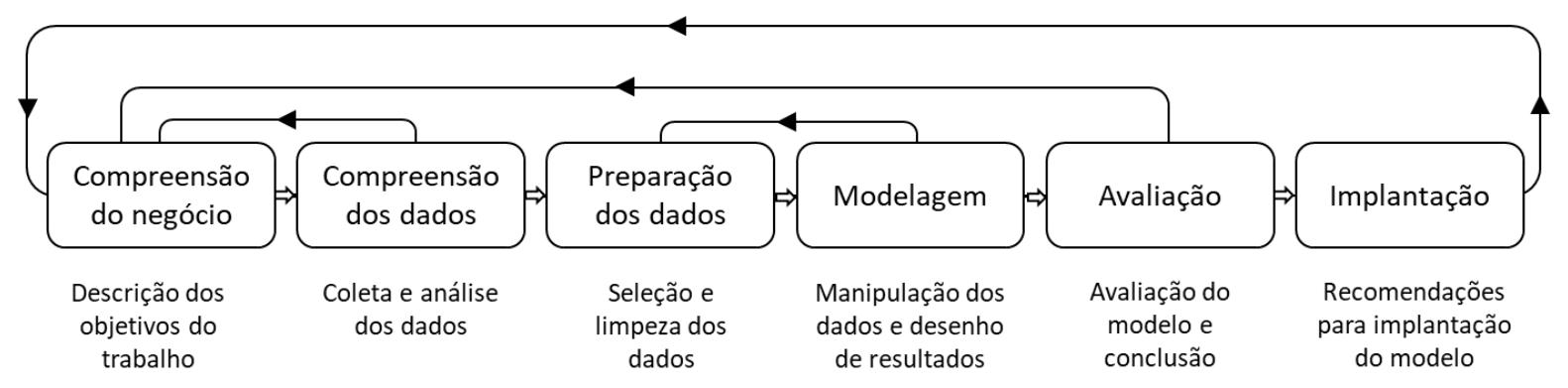

Fonte: o autor.

As etapas de compreensão, preparação, modelagem e avaliação dos dados foram executadas através do desenvolvimento de uma solução de software, utilizando 
a linguagem de programação Python ${ }^{\circledR}$, na versão 3.6. O Python ${ }^{\circledR}$ é uma linguagem de uso geral, de código aberto, e com funcionalidades adequadas para a criação de códigos e automatização de regras para a mineração de dados, principalmente com o uso de pacotes de computação científica (SciPy / NumPy), de manipulação de dados (Pandas) e geração de gráficos (Matplotlib), utilizados para os desenvolvimentos desta solução.

Os dados utilizados nesta dissertação referem-se às informações de dados de perfuração de poços de petróleo do pré-sal, no sudeste brasileiro, disponibilizados pela Agência Nacional do Petróleo, Gás Natural e Biocombustíveis (ANP), para projeto de pesquisa, desenvolvimento e inovação (PD\&I).

\subsection{ORGANIZAÇÃO DA DISSERTAÇÃO}

O desenvolvimento da dissertação foi dividido em seis capítulos, conforme apresentado no Quadro 1:

Quadro 1 - Processo de desenvolvimento da dissertação.

\begin{tabular}{c} 
Introdução \\
Referencial \\
Teórico \\
Transformação \\
Digital no E\&P \\
\hline Revisão da \\
Literatura \\
\hline Recomendações \\
\hline da Solução \\
\hline \\
\hline
\end{tabular}

-Análise do cenário atual da indústria e evolução tecnológicas;

- Descrição do objetivo da dissertação;

- Contribuição e relevância do estudo para a indústria.

- Entendimento do processo de construção de um poço de petróleo;

- Sistemas geradores de dados de Perfuração;

-Problemas na perfuração e tempo não produtivo.

- Aspectos relevantes nas iniciativas de Tranformação Digital;

- Big Data no E\&P e Qualidade de Dados ;

- Inteligencia Artificial (Machine Learning e Deep Learning);

- Processos de produção de conhecimento a partir de dados.

- Revisão da literatura referente ao metódo de regressão aplicada na perfuraçã de poços e com relação ao evento de prisão de coluna.

- Processo de desenvolvimento: compreensão do negócio, compreenção dos dados, preparação dos dados, modelagem, avaliação e implantação (versão inicial da solução).

- Análise dos resultados;

- Possibilidades de evolução e aplicação.

Fonte: 0 autor. 
O Capítulo 1, conforme visto, apresenta um resumo do cenário atual da indústria em decorrência do ciclo de variações do preço do petróleo no mercado internacional. Além disto, aborda os aspectos tecnológicos que podem ser aplicados à gestão de operações de Exploração e Produção (E\&P), focando mais especificamente nas anomalias que podem ocorrer no processo de perfuração de poços marítimos. Por fim, aborda os objetivos da dissertação e a relevância da matéria para a indústria de petróleo.

O Capítulo 2 faz uma revisão dos principais conceitos aplicados nesta dissertação. Inicia com uma visão do processo de perfuração de poços de petróleo em ambientes offshore e os principais sistemas geradores de dados e informações durante a perfuração. Além disto, são apresentados alguns aspectos fundamentais associados aos problemas de perfuração, descrevendo-se as anormalidades mais comuns, alguns dos principais fatores associados à sua ocorrência e às consequências para os projetos em decorrência de tais riscos.

O Capítulo 3 traz os aspectos relevantes sobre as iniciativas de Transformação Digital em E\&P. Faz um aprofundamento sobre a grande quantidade de dados, no Big Data, gerados atualmente pelo sistema de informação e os processos e metodologias de descoberta de conhecimento em banco de dados. O capítulo conclui com algumas questões sobre qualidade de dados e modelos estatísticos utilizados em Inteligência Artificial.

O Capítulo 4 apresenta a revisão da literatura do método estatístico de regressão, utilizado em operações de perfuração de poços de petróleo e relacionado com o evento de prisão de coluna de perfuração.

O Capítulo 5 descreve os processos da metodologia utilizada nesta dissertação, ressaltando os principais aspectos de sua aplicação. Inicia com a compreensão do negócio, compreensão dos dados, preparação dos dados, modelagem (aplicação método selecionado de regressão), avaliação dos resultados e por fim apresentação da solução computacional e os aspectos necessários para a implantação.

Finalmente, no Capítulo 6, são apresentadas as conclusões obtidas com o estudo realizado e direcionadores para novas pesquisas.

São disponibilizados alguns apêndices ao final contendo os códigos computacionais gerados para o desenvolvimento da dissertação. 


\section{REFERENCIAL TEÓRICO}

Neste Capítulo, é apresentada uma contextualização do processo de construção de um poço de petróleo marítimo, assim como, os principais dados gerados pelos sistemas utilizados na construção dos poços, relevantes a esta dissertação. Por fim, são abordadas algumas anormalidades encontradas neste processo e como elas impactam no chamado tempo não produtivo.

\subsection{CADEIA DEVALOR DO E\&P}

O processo de exploração e produção de petróleo compreende algumas fases que podem ser agregadas em exploração, avaliação, desenvolvimento, produção e aprimoramento (para manter a produção), conforme a Figura 5. Neste ciclo de vida, é envolvida uma grande quantidade de recursos financeiros e cada fase é precedida de análises de viabilidades econômicas afim de tomar a melhor decisão para o negócio (HOLDAWAY, 2014).

Figura 5 - Cadeia de valor da exploração e produção.

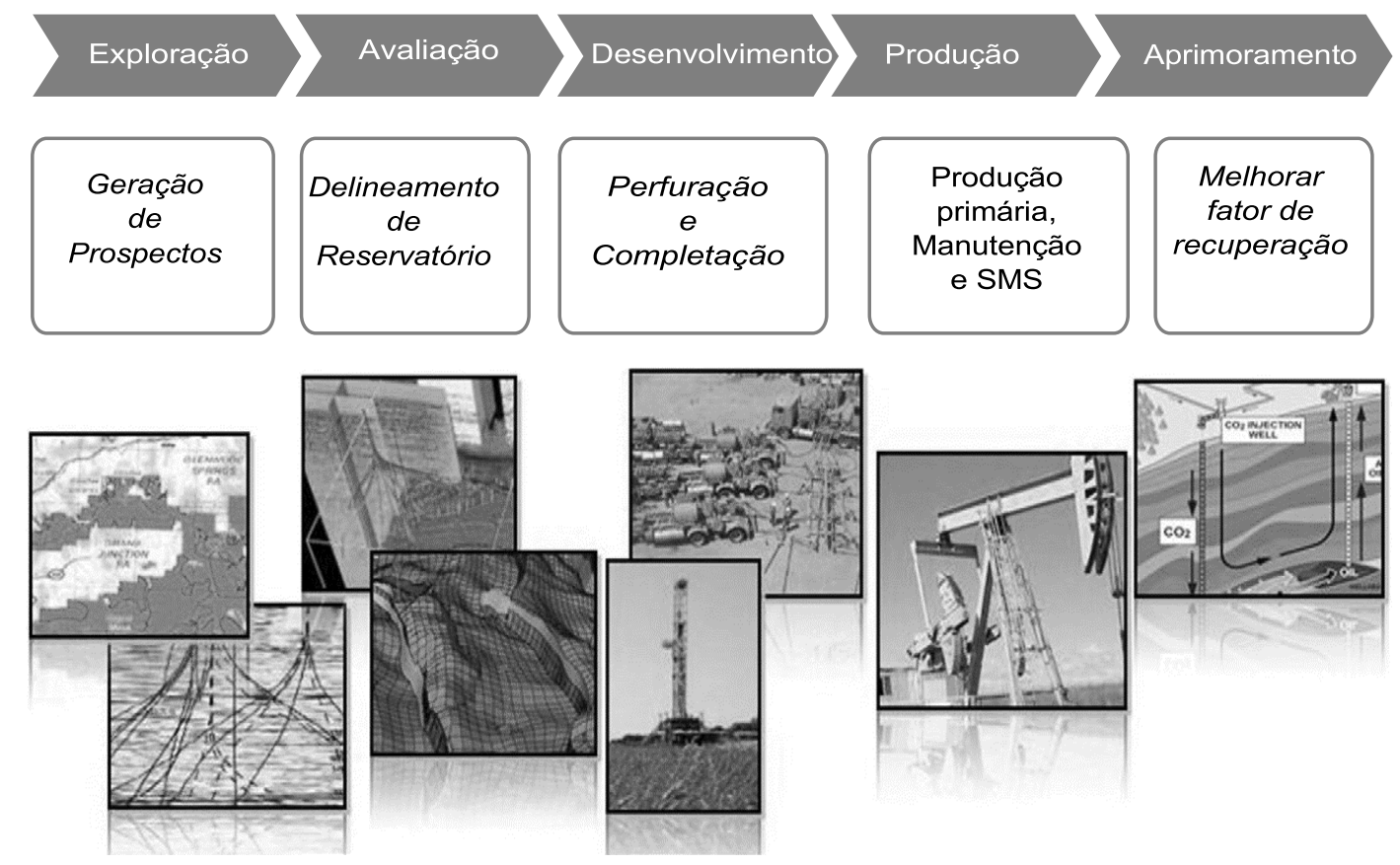

Fonte: adaptado de Holdaway (2014). 


\subsection{PERFURAÇÃO DE POÇOS OFFSHORE}

Conforme a abordagem de Holdaway (2014), na etapa de desenvolvimento se encontra a construção do poço, que, basicamente, é responsável por abrir um canal de comunicação entre o leito marinho e a subsuperfície, guardiã de potenciais reservas de hidrocarbonetos. Em poços marítimos, existe ainda a necessidade de disponibilizar infraestrutura necessária para conectar o poço às unidades de produção, quando este for entregue à próxima fase da cadeia de valor.

A presente dissertação aborda o cenário de dados gerados em poços marítimos offshore, realizados em elevados valores de profundidade do mar, ou lâmina d'água (LDA) ultraprofundas. De acordo com Bay e Bay (2016), a construção de poços submarinos pode ser caracterizada, em função da LDA, como:

- Poço em águas rasas a LDA é inferior a 300 metros. Na prática, água rasa é a LDA dentro do alcance de um mergulhador;

- Poço de águas profundas se o LDA está entre 300 metros a 1.500 metros de profundidade;

- Poço de águas ultraprofundas, aquele em que a LDA é superior a 1.500 metros de profundidade.

Com o intuito de ter um melhor entendimento do funcionamento da sonda e os processos envolvidos da construção de um poço, é indispensável ter uma visão geral dos principais sistemas utilizados nas operações de perfuração.

\subsection{MÉTODOS E SONDAS DE PERFURAÇÃO}

\section{- Métodos de perfuração}

Existem dois métodos de perfuração: o método percussivo e o método rotativo (BOURGOYNE et al., 1991):

- no método percussivo, também designado como perfuração a cabo (cable tool drilling), o avanço do poço é feito por meio de golpes sucessivos na rocha, com uma broca sustentada por um cabo de aço, causando a sua fragmentação por esmagamento. Este metódo é ultimamente pouco utilizado; 
- método rotativo consiste em descer, no poço, uma coluna de perfuração contendo em sua extremidade uma broca de aço, com um movimento de rotação e um determinado peso sobre a coluna, causando assim a fragmentação da rocha. É o método atualmente mais utilizado, sendo este quase que uma exclusividade nas sondas offshore.

Durante o processo de perfuração no método rotativo, é feito, desde a sonda de perfuração, o bombeio de um fluido ou lama de perfuração, por dentro da coluna de perfuração que após passar pelos orifícios na extremidade da broca retorna à superfície pelo espaço anular existente entre a coluna de perfuração e as paredes do poço, transportando consigo os fragmentos de rocha produzidos pela ação da broca, como pode ser observado na Figura 6.

Figura 6 - Transporte dos resíduos pelo fluido de perfuração.

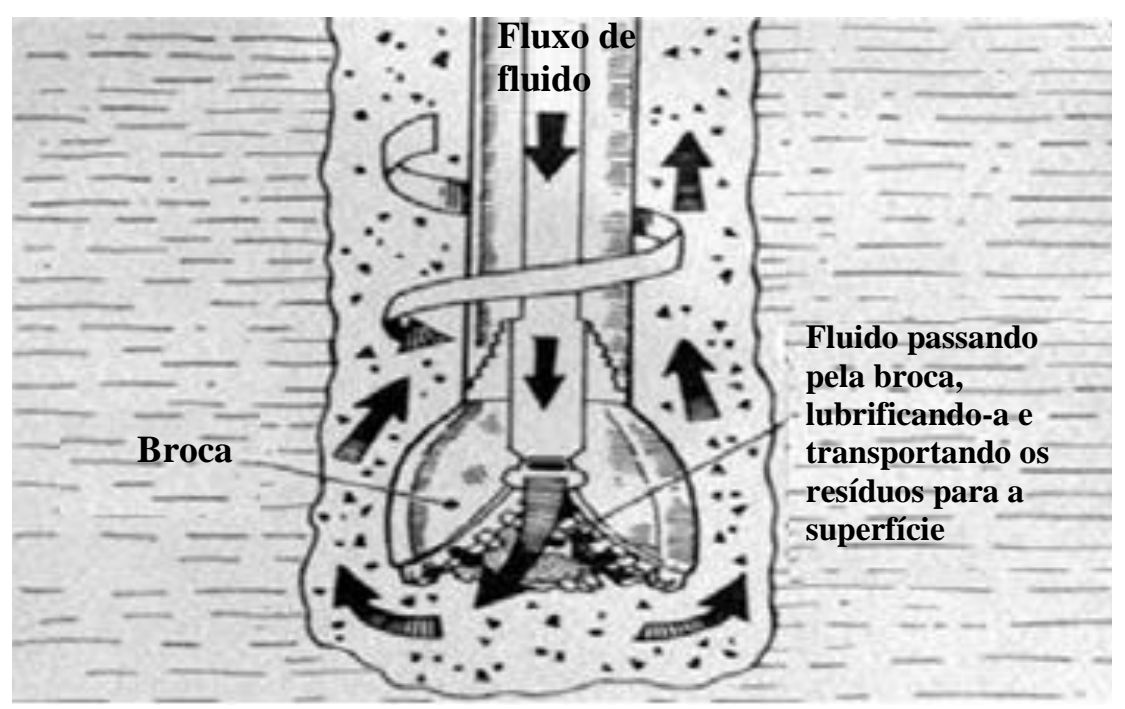

Fonte: Chipalavela (2013).

\section{- Sondas Rotativas de Perfuração Marítimas}

A estrutura que permite perfurar um poço e obter acesso aos reservatórios de petróleo é chamada de sonda ou plataforma de perfuração. As sondas são classificadas em dois tipos: onshore (terrestres) ou offshore (marítimas). Neste estudo, não serão abordadas as caraterísticas das sondas terrestres. As sondas de perfuração marítimas são, em sua grande maioria, também responsáveis pelo armazenamento de materiais e pelo alojamento do pessoal. A Figura 7 apresenta um esquema de classificação das sondas rotativas (BOURGOYNE et al., 1991). 
Figura 7 - Classificação das sondas de perfuração rotativa

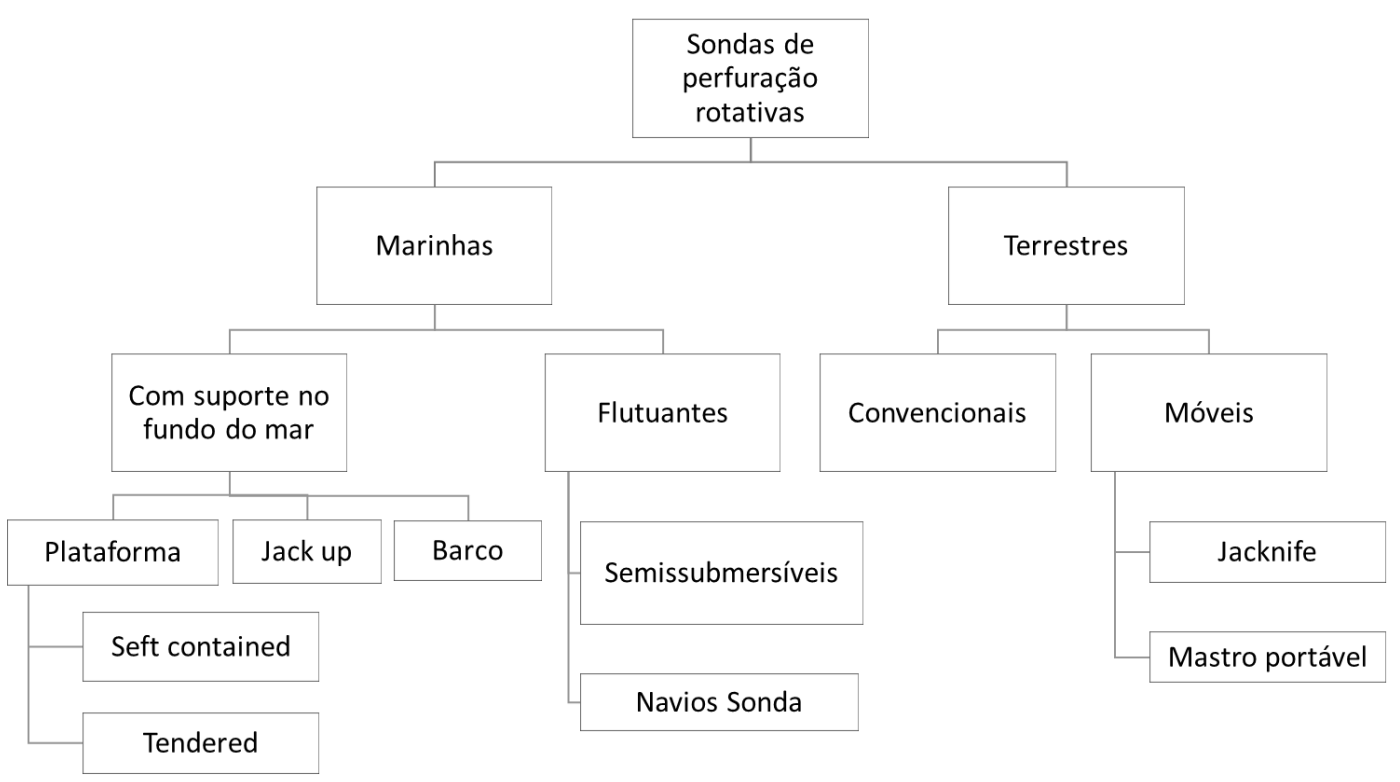

Fonte: adaptado de Bourgoyne et al. (1991).

A seleção do modelo de sonda a ser utilizada é definida previamente durante a elaboração do projeto de poço e varia, principalmente, em função da portabilidade, profundidade da lâmina de água e do relevo do leito submarino (AZUAGA; ROCHA; VIEIRA, 2012; LAKE, 2006).

As plataformas marítimas são classificadas em plataformas fixas e plataformas flutuantes, Figura 8 .

Figura 8 - Tipo de sondas marítimas.

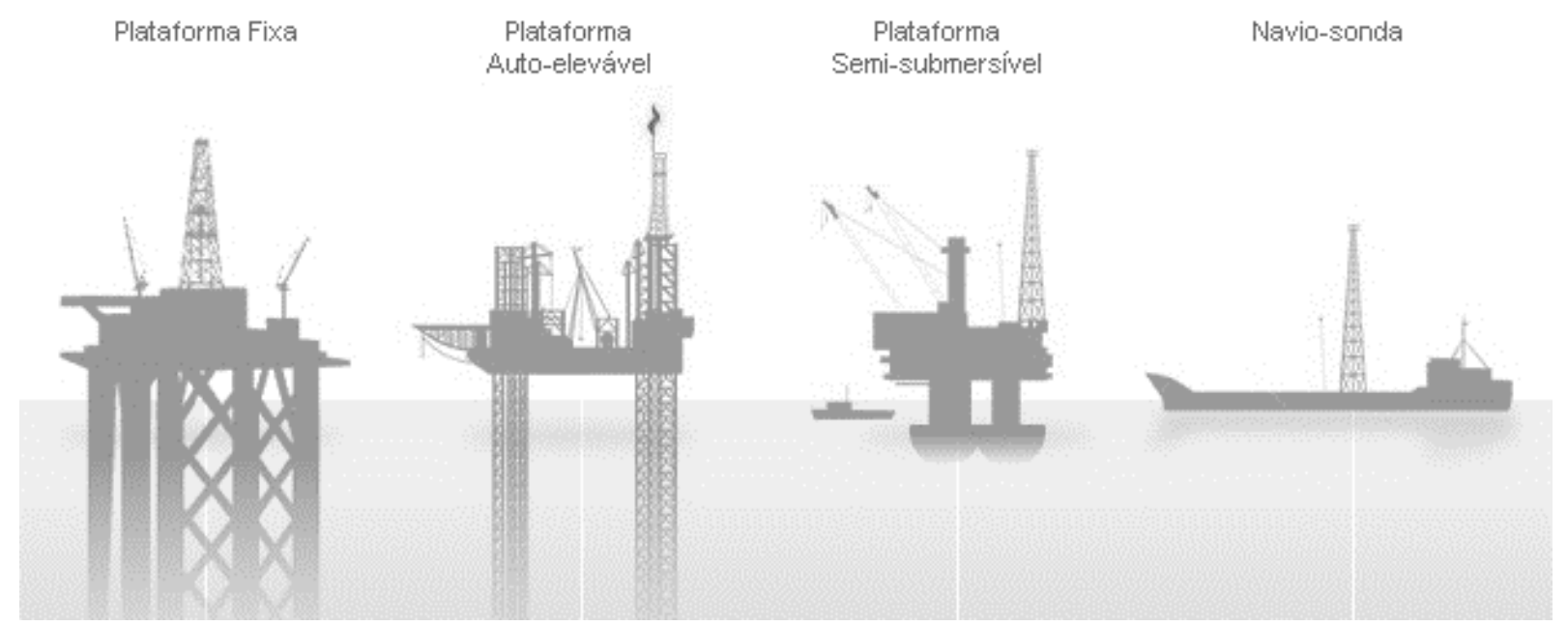

Fonte: Galp (2018) 
As plataformas fixas são estruturas apoiadas no fundo do mar, oferecendo grande estabilidade ao processo de perfuração, que se torna parecido com a perfuração realizada em terra. Essa estabilidade permite que a maioria dos equipamentos de segurança e controle do poço permaneçam no convés da sonda. $O$ fator limitante para o uso deste tipo de plataforma é a profundidade máxima da lâmina d'água de operação, de cerca de 300 metros, sendo assim, somente podem ser utilizadas em águas rasas.

As plataformas auto-eleváveis são também plataformas fixas, que utilizam estruturas de apoio que se movimentam para baixo até atingirem o leito marinho, logo após se inicia a elevação da plataforma acima do nível da água. Estão normalmente localizadas em lâminas de água que variam entre cinco e 130 metros.

No tocante às plataformas futuantes, estas podem ser classificadas em semisubmersíveis e os navios sonda. As plataformas semisubmersíveis são estruturas retangulares flutuantes, sustentadas por colunas verticais estabilizadas em flutuadores submersos, que submergem a unidade até a uma determinada profundidade. A ancoragem e o posicionamento destas estruturas podem ser controlados tanto por meio de sistemas, que podem ser utilizados em até cerca de 3000 metros de profundidade, quanto por posicionameno dinâmico, este último disponível em alguns casos. Por fim, os navios sonda são considerados os precussores tecnológicos e pioneiros na perfuração offshore ultraprofunda. Possuem grande navegabilidade, oferencendo maior mobilidade e velocidade. Seu controle de posicionamento é feito dinâmicamente por sensores de posição que determinam a deriva e acionam propulsores que restauram a posição da unidade, não existindo assim a ligação física com o fundo do mar, exceto a dos equipamentos de perfuração (BOURGOYNE et al., 1991; CHIPALAVELA, 2013; GALP, 2018; PEREIRA, 2014).

\subsection{SISTEMAS DA SONDA DE PERFURAÇÃO}

Segundo Thomas et al. (2001), os equipamentos de uma sonda rotativa podem ser agrupados nos chamados sistemas de sonda, sendo que os principais sistemas são de: sustentação e movimentação de cargas, geração e transmissão de energia, movimentação de cargas, rotação de circulação, segurança do poço, sistema de monitoramento e o sistema de subsuperfície, que envolve a coluna de perfuração e as brocas. 
Com o intuito de ter um melhor entendimento do funcionamento da sonda e dos principais sistemas envolvidos nas operações de perfuração, estes são descritos a seguir.

\subsubsection{Sistema de sustentação e movimentação de cargas}

O sistema de sustentação de cargas tem a função de sustentar e manobrar cargas, como a coluna de perfuração, revestimentos, entre outros, para dentro ou fora do poço. Entre os principais componentes deste sistema estão a torre ou mastro, o guincho, o bloco de coroamento(polias fixas) e a catarina (polias móveis). O mastro ou a torre é uma estrutura que fornece altura vertical necessária para elevar ou abaixar a coluna de perfuração, além de sustentar polias e cabos. A coluna de perfuração é formada por seções de tubos rígidos, que necessitam de espaço vertical livre disponível para serem "içados" do poço. A movimentação da coluna de perfuração e demais equipamentos é realizada com o auxílio de um guincho, que compreende basicamente o bloco de coroamento e a catarina, com a função de içar e deslocar cargas pesadas (THOMAS et al., 2001).

Além disto o sistema como um todo fornece a energia de peso necessário para que a broca utilize seus "dentes" e avance nas perfurações rochosas (DEVEREUX, 2012). A Figura 9 apresenta o sistema de sustentação de cargas.

Figura 9 - Sistema de sustentação e movimentação de cargas.

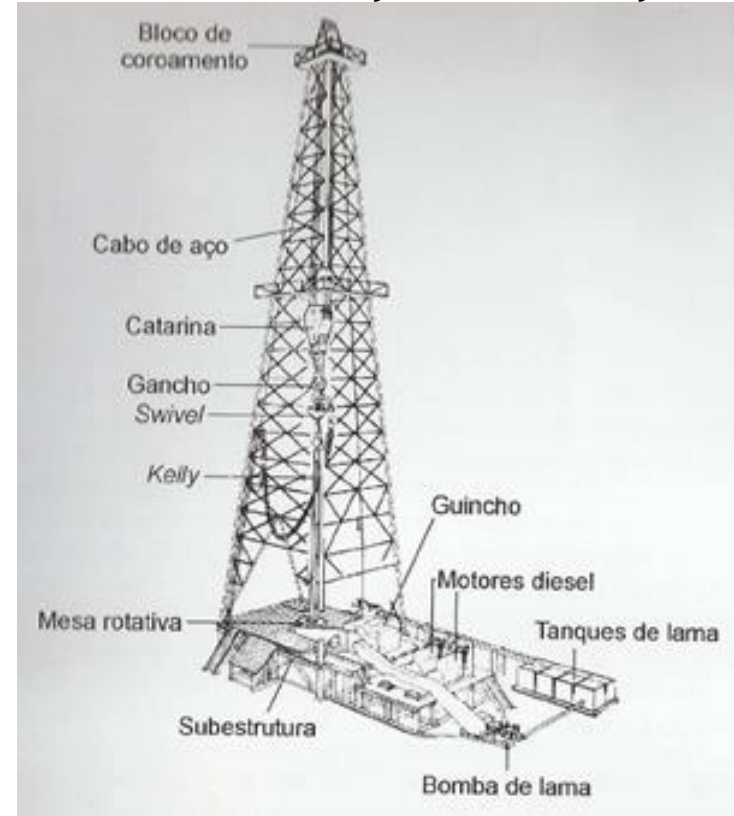

Fonte: Thomas et al. (2001). 


\subsubsection{Sistema de geração e transmissão de energia}

O sistema de geração de energia das sondas modernas são geralmente compostos por motores a diesel. As sondas marítimas costumam aproveitar a geração de gás para acionar turbinas e gerar energia para a plataforma. A maior parte da energia fornecida é utilizada nos sistemas de elevação e circulação de fluido. Os equipamentos auxiliares da sonda ou platafoma a iluminação e a hotelaria, que utilizam corrente alternada, recebem a energia do barramento após esta passar por um transformador (THOMAS et al., 2001).

\subsubsection{Sistema de rotação}

O sistema de rotação é constituído por todos os equipamentos da sonda responsáveis por transmitirem o movimento de rotação à coluna de perfuração e à broca que the encontra solidária, permitindo que esta efetue a fragmentação e consequente perfuração da formação rochosa. Os principais equipamentos constituintes do sistema de rotação em uma sonda convencional são a mesa rotativa, a kelly, e o swivel, ou cabeça de injeção. A kelly tem formato de haste poligonal e constitui a parte da coluna de perfuração localizada na superfície que recebe o torque da mesa rotativa e o transmite ao resto da coluna. A cabeça de injeção é um equipamento que sustenta o peso da coluna de perfuração e permite seu giro, constituindo o elemento de ligação entre as partes móveis e as fixas. O swive/ possui também um dispositivo que permite a injeção de fluido de perfuração no interior da coluna de perfuração (AZAR; SAMUEL, 2007).

O sistema mais utilizado atualmente é equipado com o top drive, representado na Figura 10, que dispensa a mesa rotativa e a kelly. Neste sistema um motor acoplado à catarina transmite a rotação diretamente ao topo da coluna de perfuração. Com o top drive, ganha-se mais espaço e torna-se possível perfurar o poço de três em três tubos ao invés de um a um, como na mesa rotativa.

Os sistemas de rotação modernos podem possuir motores de fundo, similares a turbinas, que transmitem giro à coluna. Estes motores são posicionados acima da broca e seu torque é gerado pela passagem do fluido de perfuração a uma determinada vazão de bombeio no seu interior (AZAR; SAMUEL, 2007). 


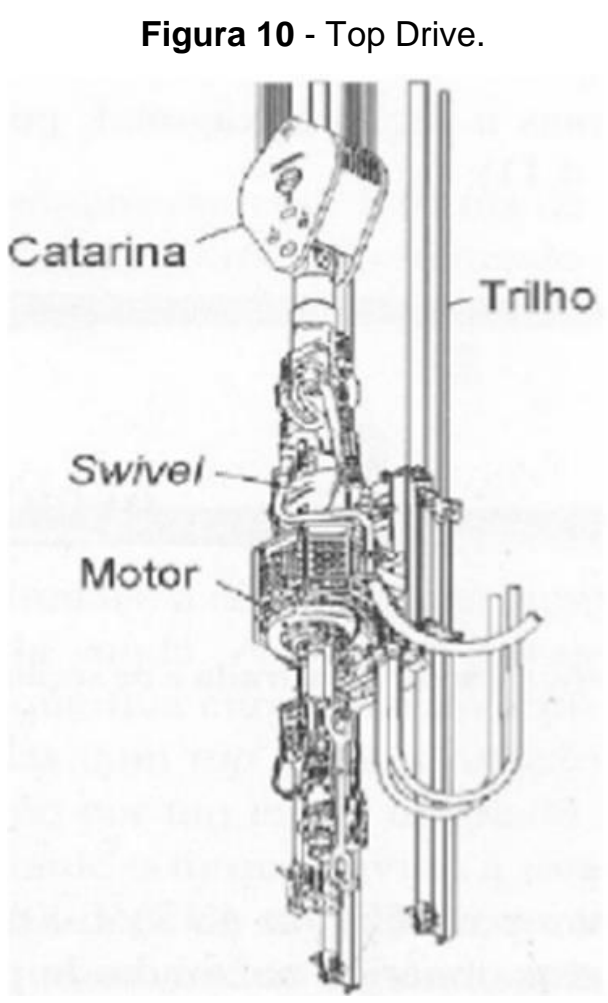

Fonte: Thomas et al. (2001).

\subsubsection{Sistema de circulação}

O sistema de circulação abrange todos os equipamentos que permitem a circulação e o tratamento do fluido de perfuração. O fluido pode ser à base de água, óleo ou gás comprimido. Em uma situação de circulação normal, o fluido de perfuração é bombeado através da coluna de perfuração até à broca, retornando pelo espaço anular até à superfície, trazendo consigo os cascalhos, fragmentos de rocha, cortados pela broca, além de qualquer fluido liberado pelo reservatório (água, óleo ou gás).

Na superfície, o fluido permanece dentro de tanques, após receber o tratamento adequado. Além de transportar os detritos, o fluido também possui outras finalidades, como por exemplo, proporciona o resfriamento da coluna de perfuração e é responsável pela formação de uma camada impermeável na parede do poço, chamada de mudcake. O mudcake previne a infiltração de fluidos das zonas rochosas mais permeáveis para o interior do poço (THOMAS et al., 2001).

Outra característica muito importante é a densidade do fluido, que é controlada visando manter uma pressão hidrostática positiva superior à pressão do reservatório (overbalanced drilling), mas menor que a pressão de fratura da formação rochosa (BOURGOYNE et al., 1991), auxiliando na contenção da pressão do reservatório. Se 
a pressão do reservatório for maior que a pressão hidrostática da coluna, pode acontecer uma infiltração ou influxo descontrolado de fluidos - água, óleo e gás - dos reservatórios até à superfície. Esse fenômeno é conhecido como blowout do poço (GOMES et al., 2011; THOMAS et al., 2001). Este assunto será tratado detalhadamente no subitem seguinte.

\subsubsection{Sistema de segurança do poço}

O sistema de segurança do poço é constituído dos Equipamentos de Segurança de Cabeça de Poço (ESCP) e de equipamentos complementares que possibilitam o fechamento e controle do poço em caso de situações de sinistro.

O equipamento mais importante neste conjunto é o Blowout Preventer (BOP), composto por um conjunto de válvulas com capacidade de fechamento do poço em caso de fluxo descontrolado de hidrocarbonetos da formação rochosa para o interior do poço (THOMAS et al., 2001). Os principais elementos desse sistema são: a cabeça de poço, constituída por diversos equipamentos que permitem a vedação e a ancoragem das colunas de revestimento, e os preventores, do tipo preventor anular e de gaveta, que permitem o fechamento do espaço anular.

Os preventores são acionados para controlar e combater o fluxo indesejável do fluido da formação para dentro do poço, fenômeno conhecido como kick. Em caso de ocorrência de kicks durante a construção do poço, estes devem ser controlados eficientemente pois poderão se transformar em um blowout. $\mathrm{O}$ fluxo descontrolado pode criar uma série de consequências desagradáveis, para pessoas, equipamentos, reservatório e meio ambiente.

\subsubsection{Sistema de monitoramento da sonda}

O sistema de monitoramento é composto por equipamentos necessários ao controle da perfuração: manômetros, indicador de peso sobre a broca, indicador de torque, tacômetro, etc. Um dos registradores mais importantes é o que mostra a taxa de penetração da broca, pois esta é uma informação importante para se avaliarem as mudanças de propriedades das formações perfuradas, o desgaste da broca e a adequação dos parâmetros de perfuração (THOMAS et al., 2001). 
O sistema de monitoramento da sonda, disposto na cabine do sondador Figura 11, contempla o acesso às informações dos equipamentos que são usados para monitorar parâmetros importantes da perfuração. Estes equipamentos podem ser analógicos ou digitais, sendo que as sondas mais modernas e automatizadas possuem sistema digitais.

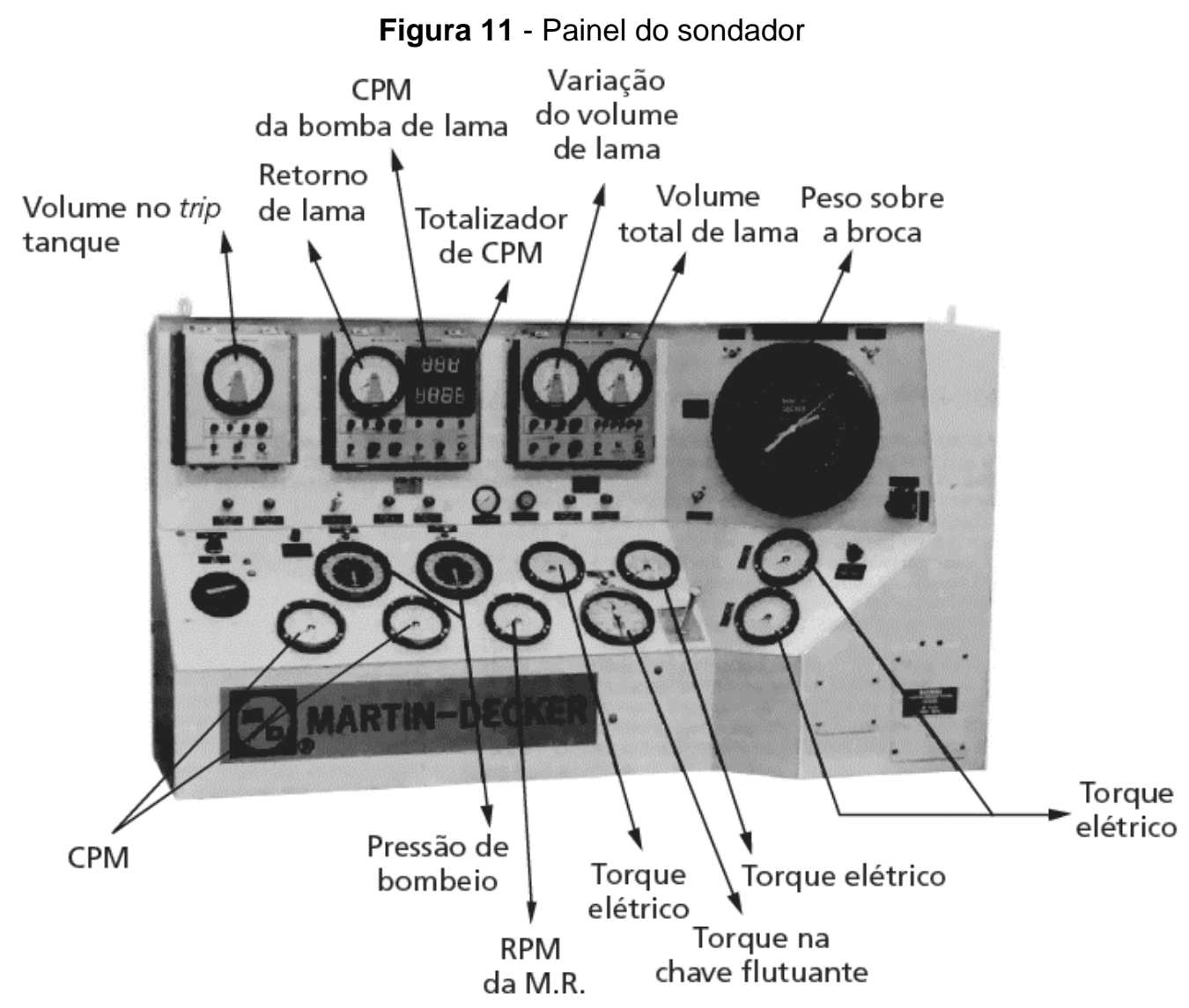

Fonte: Silva et al. (2012).

Nos últimos, anos houve um aumento significativo de sistemas de monitoramento e de controle remoto nas sondas de perfuração. Os sistemas integrados de controle de perfuração aprimoram o controle do operador sobre os equipamentos da sonda, melhorando a eficiência e segurança no processo. As plataformas de perfuração continuam adicionando cada vez mais equipamentos automatizados e mais funcionalidades. Sistemas de controle integrados, Figura 12, vêm sendo implantados para otimizar a interface homem-máquina, utilizando soluções gráficas de interface de usuário (GUI) que tornam mais fácil o controle de uma ampla gama de equipamentos de perfuração (NOV, 2018). 
Figura 12 - Sistemas Integrados de Controle de Perfuração.

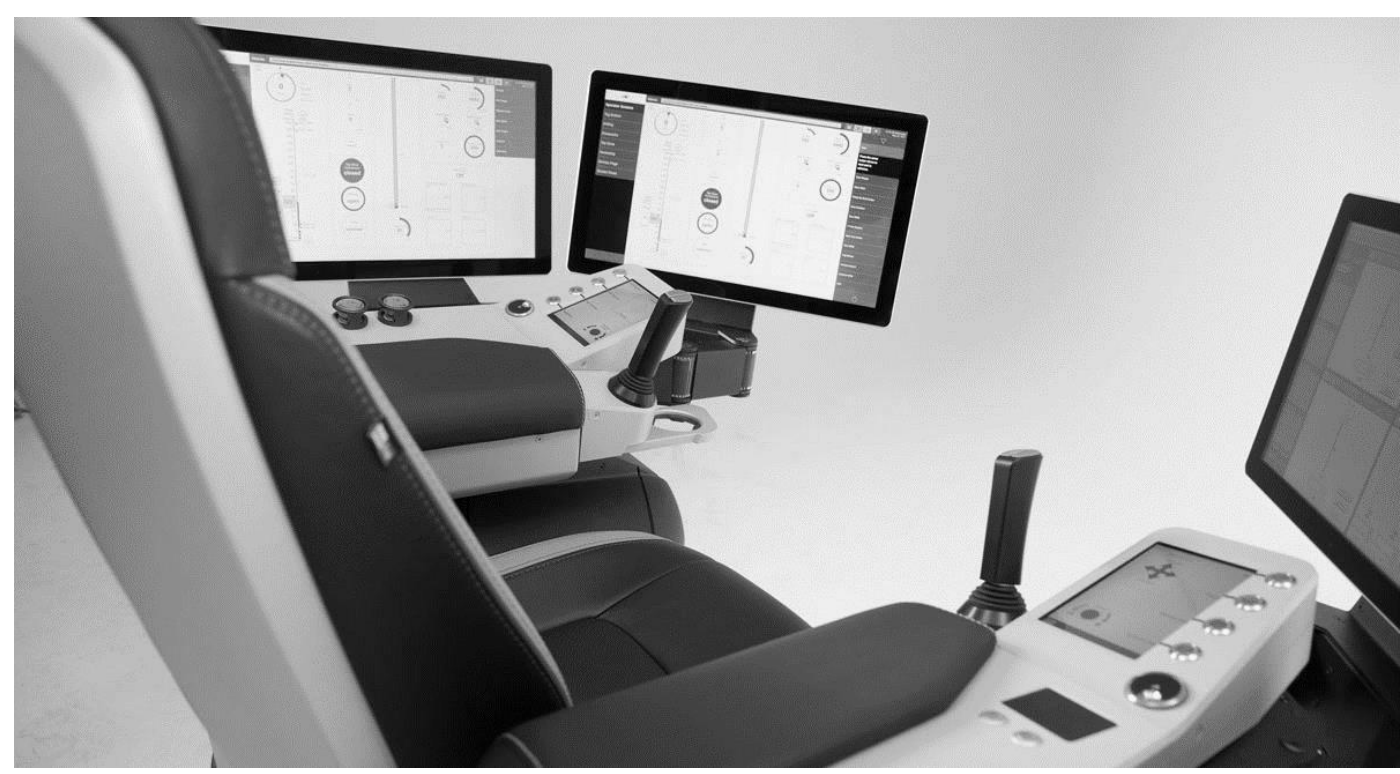

Fonte: NOV (2018).

\subsubsection{Sistemas de subsuperfície - Coluna de Perfuração}

A perfuração rotativa é um processo que exige uma grande quantidade de energia. Parte desta energia é transmitida mecanicamente à broca em forma de rotação e a outra em forma de peso, sendo este o princípio da perfuração (BOURGOYNE et al., 1991).

A coluna de perfuração é responsável por concentrar grande quantidade de energia na broca para que ela possa cortar as diversas formações rochosas. Esta energia, em forma de rotação e peso aplicados sobre a broca, é transferida às rochas, fazendo com que as formações sejam rompidas e desagregadas em forma de pequenas lascas, ou cascalho, que, por sua vez, são removidos do fundo do poço e carregados até a superfície pelo fluido de perfuração.

Conforme a Figura 13, a coluna é composta pelos seguintes equipamentos: comandos (Drill Collars - DC), tubos pesados (heavy- weight drill pipes - HWDP) e tubos de perfuração (Drill Pipers - DP) (AZUAGA; ROCHA; VIEIRA, 2012; MANSANO, 2004; THOMAS et al., 2001). 
Figura 13 - Drill collars, C-Drill pipes e heavy weight drill pipes.

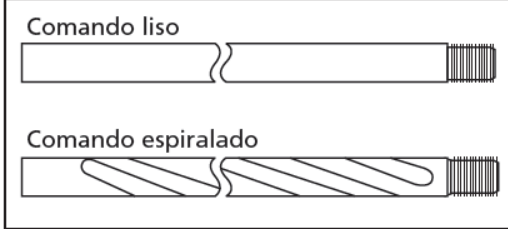

Comando de perfuração (Drill Collar)

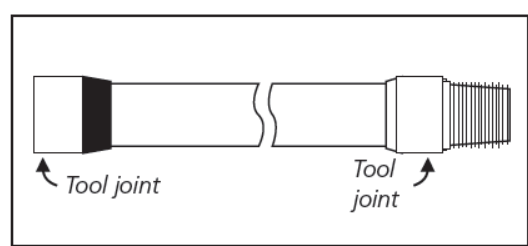

Tubo de perfuração (Drill Pipe)

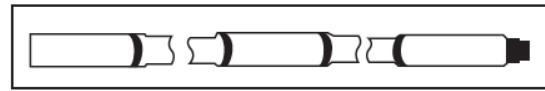

Tubo de perfuração pesado (HW)

Fonte: adaptado de Mansano (2004).

Os drill collars são elementos tubulares fabricados em aço forjado. São tubos pesados que têm como função fornecer peso sobre a broca e prover rigidez à coluna, permitindo melhor controle da trajetória do poço. Os heavy-weight drill pipes, comumente designados por HW são os tubos colocados acima dos drill collars, suas conexões são semelhantes, porém mais leves. Os HW têm como principal função formar uma transição de rigidez mais amena na coluna de perfuração, entre os drill collars e os drill pipes. Os drill pipes são os tubos colocados acima dos HW. Têm como função fornecer à coluna de perfuração o comprimento desejado, possuem menos rigidez que os $\mathrm{HW}$ e DC e possuem também conexões semelhantes.

\subsubsection{Sistemas de subsuperfície - Brocas}

As brocas são equipamentos que têm a finalidade de fragmentar - perfurar, lascar, quebrar e triturar - as formações rochosas. São colocadas na extremidade da coluna de perfuração e podem ser de vários tipos e tamanhos. São selecionadas na fase de projeto, dependendo da profundidade e do tipo de rocha a ser perfurada.

O desempenho da broca de perfuração está condicionado ao funcionamento em conjunto dos sistemas de sustentação, movimentação, coluna de perfuração e rotação, apresentados anteriormente. A perfuração provocada pela broca decorre da combinação do tipo de broca, com o peso transferido e o movimento rotativo.

Existem disponíveis uma grande variedade de brocas para diferentes formações e situações encontradas durante a perfuração. As brocas de perfuração, dependendo do modelo, possuem partes móveis e, de uma forma geral, são constituídas pelo corpo, estrutura cortante que pode ser de aço, carbureto de 
tungstênio, diamante natural ou diamante sintético, e canais preferenciais que permitem o escoamento do fluido de perfuração e a limpeza do fundo do poço à medida que este é perfurado. A aplicação da broca é determinada pela sua estrutura cortante, seja para formações mais duras ou mais brandas (AZUAGA; ROCHA; VIEIRA, 2012; CHIPALAVELA, 2013; THOMAS et al., 2001).

A Figura 14 apresenta alguns exemplos de brocas.

Figura 14 - Brocas de perfuração.

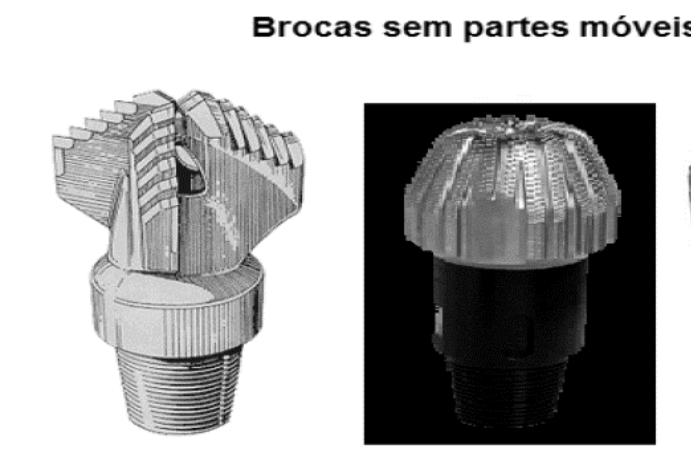

Broca de lâmina de aço

Broca diamantada

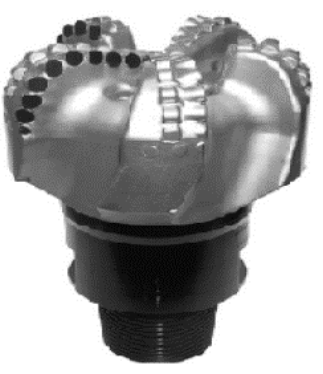

Broca PDC

\section{Broca com partes móveis}

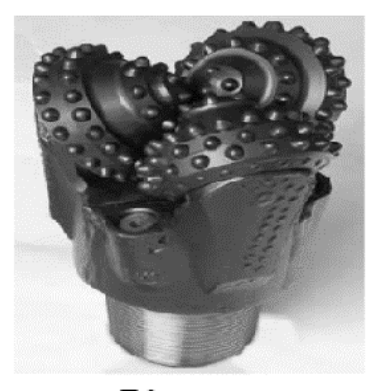

Tricone

Fonte: adaptado de Chipalavela (2013).

\subsection{SISTEMA GERADORES DE DADOS DE PERFURAÇÃO}

Uma sonda de perfuração possui diversos sistemas geradores de dados necessários para a tomada de decisão e para o controle da perfuração, dados estes dispostos na cabine do sondador.

Existe também uma infinidade de dados da perfuração de poços provenientes de sensores e equipamentos existentes ao longo da coluna de perfuração. Esses dados resultam de medidas realizadas na superfície ou a milhares de metros de profundidade e são enviadas para sensores localizados na superfície, ou no poço (downhole), a fim de subsidiar a tomada de decisão em tempo real.

A Figura 15 apresenta como estes sistemas de Superfície, compostos por sensores de Sondagem, MWD (Measuring While Drilling) e Mudloggin e sensores de poço (downhole) MWD e LWD (Logging While Drilling) são distribuídos. A partir destes dados é possível também calcular outros parâmetros como, por exemplo, o torque na broca e a taxa de penetração (CHIEZA, 2011). 
Figura 15 - Sistema de Superfície e poço (downhole).

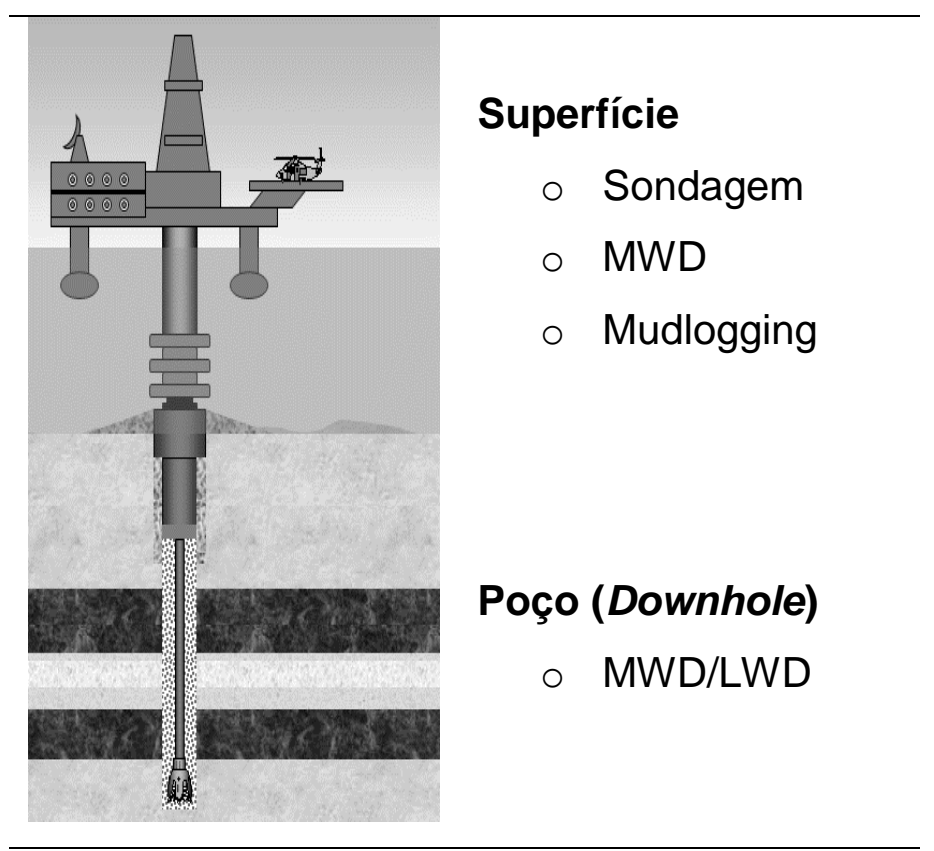

Fonte: adaptado de ASLAN (2015).

A distribuição dos principais dados e sensores de superfície é apresentada no Quadro 2. Um aspecto importante apresentado é a existência de dados redundantes entre os sistemas, sendo a configuração (paridade) destes essenciais para garantir a integridade dos dados gerados.

Quadro 2 - Sistemas Geradores de Dados de Perfuração - Superfície.

\begin{tabular}{|c|c|c|}
\hline Sondagem & MWD & Mudlogging \\
\hline $\begin{array}{l}\text { Controle de data e hora } \\
\text { (Time / Depth })\end{array}$ & $\begin{array}{l}\text { Controle de data e hora } \\
\text { (Time / Depth) }\end{array}$ & $\begin{array}{l}\text { Controle de data e hora } \\
\text { (Time / Depth) }\end{array}$ \\
\hline $\begin{array}{c}\text { Comprimento do tally } \\
\text { (Comprimento da seção de tubo de } \\
\text { perfuração, drill pipe - Stand Length) }\end{array}$ & $\begin{array}{l}\text { Altura do bloco/gancho } \\
\text { (Block / Hook Height) }\end{array}$ & $\begin{array}{l}\text { Altura do bloco/gancho } \\
\text { (Block / Hook Height) }\end{array}$ \\
\hline $\begin{array}{l}\text { Altura do bloco/gancho } \\
\text { (Block / Hook Height) }\end{array}$ & $\begin{array}{c}\text { Profundidade medida da broca } \\
\text { compensada pelo heave } \\
\text { (Heave Compensator) }\end{array}$ & $\begin{array}{c}\text { Profundidade medida da broca compensada } \\
\text { pelo heave } \\
\text { (Heave Compensator) }\end{array}$ \\
\hline $\begin{array}{l}\text { Profundidade medida da broca } \\
\text { compensada pelo heave } \\
\text { (Heave Compensator) }\end{array}$ & $\begin{array}{l}\text { Status de acunhamento da coluna } \\
\text { (In-Slips Status) }\end{array}$ & $\begin{array}{l}\text { Status de acunhamento da coluna } \\
\text { (In-Slips Status) }\end{array}$ \\
\hline $\begin{array}{l}\text { Status de acunhamento da coluna } \\
\text { (In-Slips Status) }\end{array}$ & $\begin{array}{l}\text { Profundidade medida do poço } \\
\text { (MD - Measured Depth) }\end{array}$ & $\begin{array}{l}\text { Profundidade medida do poço } \\
\text { (MD - Measured Depth) }\end{array}$ \\
\hline $\begin{array}{l}\text { Profundidade medida do poço } \\
\text { (MD - Measured Depth) }\end{array}$ & $\begin{array}{c}\text { Profundidade vertical do poço } \\
\text { (TVD - Total Vertical Depth) }\end{array}$ & $\begin{array}{l}\text { Profundidade medida da broca } \\
\text { (Bit Depth) }\end{array}$ \\
\hline $\begin{array}{l}\text { Profundidade medida da broca } \\
\text { (Bit Depth) }\end{array}$ & $\begin{array}{c}\text { Profundidade medida da broca } \\
\text { (Bit Depth) }\end{array}$ & $\begin{array}{c}\text { Taxa de penetração } \\
(R O P \text { - Rate of Penetration) }\end{array}$ \\
\hline $\begin{array}{c}\text { Taxa de penetração } \\
\text { (ROP - Rate of Penetration) }\end{array}$ & $\begin{array}{c}\text { Taxa de penetração } \\
\text { (ROP - Rate of Penetration) }\end{array}$ & $\begin{array}{c}\text { Peso no gancho } \\
\text { (Hook load) }\end{array}$ \\
\hline
\end{tabular}

Fonte: adaptado de Ablard et al. (2012), Eren (2010), Hess (2016), Martin (1986), Tavares (2006) e Whittaker (1987). 
Quadro 2 - Sistemas Geradores de Dados de Perfuração - Superfície. Continuação.

\begin{tabular}{|c|c|c|}
\hline Sondagem & MWD & Mudlogging \\
\hline $\begin{array}{l}\text { Peso no gancho } \\
\text { (Hook load) }\end{array}$ & $\begin{array}{l}\text { Peso no gancho } \\
\text { (Hook load) }\end{array}$ & $\begin{array}{l}\text { Peso na broca } \\
\text { (WOB) }\end{array}$ \\
\hline $\begin{array}{l}\text { Peso na broca } \\
\text { (WOB) }\end{array}$ & $\begin{array}{l}\text { Peso na broca } \\
\text { (WOB) }\end{array}$ & $\begin{array}{l}\text { Pressão nas linhas de superfície } \\
\text { (SPP - Stand Pipe Pressure) }\end{array}$ \\
\hline Torque na superfície & $\begin{array}{l}\text { Pressão nas linhas de superfície } \\
\text { (SPP - Stand Pipe Pressure) }\end{array}$ & $\begin{array}{c}\text { Pressão no choke } \\
\text { (Choke Line Pressure) }\end{array}$ \\
\hline $\begin{array}{c}\text { Frequência de rotação da coluna de } \\
\text { perfuração } \\
(R P M-\text { Rotation per minute })\end{array}$ & $\begin{array}{l}\text { Pressão no choke } \\
\text { (Choke Line Pressure) }\end{array}$ & $\begin{array}{c}\text { Número de ciclos de } \\
\text { bombeio por minuto } \\
\text { (SPM - Stroke per minute) }\end{array}$ \\
\hline $\begin{array}{l}\text { Arraste } \\
(\text { Drag) }\end{array}$ & $\begin{array}{c}\text { Número de ciclos de } \\
\text { bombeio por minuto } \\
\text { (SPM - Stroke per minute) }\end{array}$ & Contador de pulsos da bomba \\
\hline $\begin{array}{l}\text { Pressão de bombeio do fluido de } \\
\text { perfuração (Pump Pressure) }\end{array}$ & Contador de pulsos da bomba & Vazão total \\
\hline $\begin{array}{l}\text { Pressão nas linhas de superfície } \\
\text { (SPP - Stand Pipe Pressure) }\end{array}$ & Vazão total & $\begin{array}{l}\text { Volume de fluido de perfuração nos tanques } \\
\text { (Mud Pit) }\end{array}$ \\
\hline $\begin{array}{l}\text { Pressão no choke } \\
\text { (Choke Line Pressure) }\end{array}$ & & $\begin{array}{l}\text { Vazão de entrada de fluido de perfuração } \\
\text { (Mud Flow in and out) }\end{array}$ \\
\hline $\begin{array}{c}\text { Número de ciclos de } \\
\text { bombeio por minuto } \\
\text { (SPM - Stroke per minute) }\end{array}$ & & $\begin{array}{l}\text { Concentração de gás no fluido de perfuração } \\
\text { (Total Gás) }\end{array}$ \\
\hline $\begin{array}{l}\text { SICP (Shut in casing pressure) and } \\
\text { SIDPP (Shut in drill pipe pressure) }\end{array}$ & & Detecção de H2S nas peneiras \\
\hline Contador de pulsos da bomba & & $\begin{array}{c}\text { Temperatura do fluido de perfuração na } \\
\text { entrada e na saída do poço } \\
\text { (Temperature inlet and outlet) }\end{array}$ \\
\hline Vazão total & & $\begin{array}{l}\text { Densidade do fluido de perfuração na entrada } \\
\text { e na saída do poço } \\
\text { (MW - mud weight in and out). }\end{array}$ \\
\hline & & $\begin{array}{c}\text { Tempo de retorno do fluido de perfuração ( } L a g \\
\text { Time) }\end{array}$ \\
\hline & & Distribuição da concentração de gás \\
\hline
\end{tabular}

Fonte: adaptado de Ablard et al. (2012), Eren (2010), Hess (2016), Martin (1986), Tavares (2006) e Whittaker (1987).

Cada coluna do quando apresenta o conjunto de dados oriundos dos sistemas de Sondagem, MDW e Mudlogging.

A coluna Sondagem apresenta o sistema de controle da operação na superfície, responsável pelo desempenho e sequenciamento das atividades de perfuração. monitoramento dos parâmetros e a execução das rotinas são realizadas a partir da cabine do sondador, suportada pelos profissionais plataformistas que auxiliam nos procedimentos, rotinas, manutenção e manipulação desse sistema. As operações de movimentação e rotação de coluna, mobilização e desmobilização de equipamentos, bombeio de fluidos, atuação das linhas de pressão e de equipamentos de controle de poço fazem parte desse serviço (EREN, 2010; HESS, 2016). 
A coluna Mudlogging descreve o sistema de monitoramento dos parâmetros mecânicos e hidráulicos da lama, e parâmetros litológicos dos cascalhos que retornam do poço durante a atividade de perfuração. Esse trabalho é realizado pelo mudlogger através de sensores instalados nas peneiras e nos tanques de fluidos, bem como pela realização de coleta e análise de amostras de fluidos e cascalhos. Todavia, para realizar a disponibilização e integração desses dados com a operação, o serviço de mudlogging compreende também a instalação de sensores similares aos de sondagem no que se refere ao controle de profundidade, pressão nas linhas de superfície e volume de bombeio de fluidos. Vale ressaltar que na perfuração de um poço marítimo, o sistema de mudlogging só está disponível nas fases em que houver retorno do fluido de perfuração para a superfície (ABLARD et al., 2012; TAVARES, 2006).

Na coluna MWD (Measuring While Drilling) são apresentados os dados do sistema de monitoramento de parâmetros operacionais do poço, medidos no fundo, durante a atividade de perfuração. Esse trabalho é realizado por um engenheiro de operações MWD, mediante o uso de sensores instalados na coluna próximos à broca, essa composição é chamada de BHA (Bottom Hole Assembly).

Os principais serviços compreendidos por esse sistema são: monitoramento da pressão, temperatura, diâmetro, trajetória do poço, monitoramento de esforços e vibração na coluna, e telemetria de dados em tempo real. Todavia, para realizar a disponibilização e integração desses dados com a operação, o serviço de MWD compreende também a instalação de sensores similares aos de sondagem no que se refere ao controle de profundidade, pressão nas linhas de superfície e volume de bombeio de fluidos (MARTIN, 1986; TAVARES, 2006; WHITTAKER, 1987).

Os dados dos sensores localizados no poço (downhole) são oriundos dos sistemas MWD e LWD, conforme distribuídos no

Quadro 3. O sistema MWD também está presente na superfície e no poço, porém é responsável pela medição de outros sensores relativos ao poço.

O LWD (Logging While Drilling) é o sistema de monitoramento de parâmetros litológicos (perfilagem) do poço, medidos no fundo, durante a atividade de perfuração. Esse trabalho é realizado por um engenheiro de operações LWD através de sensores instalados na coluna BHA próximos a broca.

Os principais serviços compreendidos por esse sistema são: exposição da formação a raios gama, resistividade, densidade-neutrão, sônico, ressonância magnética, testes 
de formação e coleta de amostras no fundo. A disponibilização e integração desses dados com a operação é realizada concomitantemente ao serviço de MWD (EREN, 2010; HESS, 2016; TAVARES, 2006).

Quadro 3 - Sistemas Geradores de Dados de Perfuração - Poço (Downhole).

\begin{tabular}{|c|c|c|}
\hline \multicolumn{2}{|c|}{ MWD } & LWD \\
\hline Inclinação do poço & Pressão diferencial & Raios gama \\
\hline Azimute do poço & $\begin{array}{l}\text { Densidade equivalente Estática } \\
\text { (EMW - Equivalent Static Density) }\end{array}$ & Resistividade \\
\hline Vibração axial & $\begin{array}{l}\text { Densidade equivalente durante circulação } \\
(E C D \text { - Equivalent Circulating Density) }\end{array}$ & Densidade \\
\hline Vibração lateral & $\begin{array}{c}\text { Torque no fundo } \\
\text { (TOB - Torque on Bottom) }\end{array}$ & Porosidade \\
\hline Vibração stick slip & $\begin{array}{l}\text { Peso sobre a broca no fundo } \\
\text { (WOB - Weight on Bit) }\end{array}$ & Caliper \\
\hline $\begin{array}{c}\text { Temperatura do fluido de perfuração } \\
\text { no fundo do poço }\end{array}$ & $\begin{array}{l}\text { Frequência de rotação da turbina } \\
\text { (RPM - Rotation per minute) }\end{array}$ & Sônico \\
\hline Pressão no anular & $\begin{array}{l}\text { Frequência de rotação da broca } \\
\text { (RPM - Rotation per minute) }\end{array}$ & Teste de formação \\
\hline Pressão interna & Energia específica na broca & Ressonância magnética \\
\hline
\end{tabular}

Fonte: adaptado de Hess (2016), Martin (1986),Tavares (2006) e Whittaker (1987).

\subsubsection{Outros sistemas}

Além dos sistemas citados anteriormente, existem também outros elementos igualmente importantes na geração de dados de perfuração: o serviço direcional, a otimização de pressão e o boletim diário de perfuração são exemplos desses elementos.

- Sistema direcional: Esse serviço é realizado por um engenheiro direcional e compreende o acompanhamento dos parâmetros de perfuração, visando melhoria de desempenho, execução da trajetória conforme projeto, integridade da coluna, integridade e limpeza do poço e anti-colisão;

- Otimização de pressão: Esse serviço é realizado por um engenheiro MPD (Managed Pressure Drilling) e compreende a otimização do regime de pressões em cenários complexos durante a perfuração, onde os métodos tradicionais de controle da pressão são difíceis ou impossíveis;

- Boletim diário de perfuração: Relatório diário preenchido na sonda pelo representante da empresa operadora, apresenta uma descrição textual das operações realizadas nas últimas 24 horas. $O$ boletim de perfuração é um dos documentos gerados diariamente durante a operação, contendo 
informações sobre todas as atividades executadas em um dia de operação. O documento contém a sequência de atividades executadas em ordem cronológica para perfuração do poço, com a duração de cada uma delas (HALLIBURTON, 2017).

\subsection{PROBLEMAS NA PERFURAÇÃO (INSTABILIDADE NO POÇO)}

De acordo com Gaurina-Medjimurec e Pasic (2014), a E\&P é uma das partes mais importantes da indústria do petróleo, onde geralmente é encontrada a maior parte dos problemas que podem gerar tempo não produtivo e gastos adicionais aos projetos. O problema mais comum está relacionado com a instabilidade nas paredes do poço e diversos problemas conexos. Estas adversidades, geralmente, aparecem nas operações da perfuração, mas também podem estar presentes durante a completação e manutenção do poço. A etapa de construção do poço é uma das mais caras, pois exige técnicas que usam tecnologias e conhecimentos de engenharia muito específicas. Pequenos desvios do planejado podem causar aumentos de custos para os projetos.

MacLellan (1996) classificou os sintomas de instabilidade do poço, em dois grupos: diretos e indiretos, conforme

Quadro 4, sendo de se ressaltar que as instabilidades do poço têm suas causas primárias no colapso das paredes do poço.

Quadro 4 - Os sintomas de instabilidade do poço.

\begin{tabular}{|c|c|c|}
\hline $\begin{array}{l}\text { SINTOMAS DIRETOS } \\
\text { - Oversized hole }\end{array}$ & \multicolumn{2}{|c|}{ SINTOMAS INDIRETOS } \\
\hline 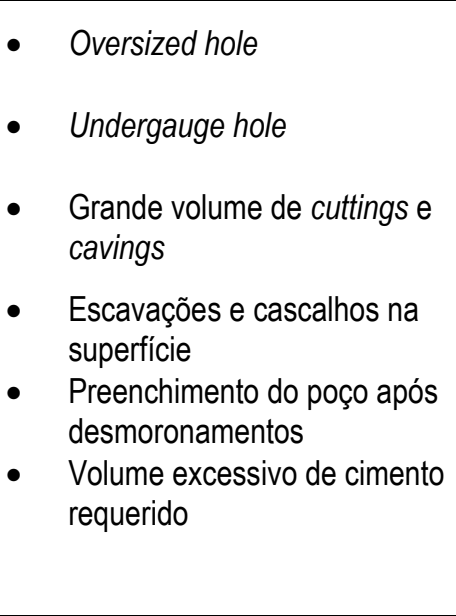 & $\begin{array}{l}\text { - } \quad \text { Alto torque e fricção } \\
\text { - } \quad \text { Aprisionamento da coluna de } \\
\text { - } \quad \text { Susperfuração } \\
\text { perfuração, revestimento ou } \\
\text { outra tubulação } \\
\text { - } \quad \text { Aumento das pressões de } \\
\text { circulação } \\
\text { - } \quad \text { Vibrações excessivas na coluna } \\
\text { - } \text { de perfuração } \\
\text { - } \quad \text { Palha na coluna de perfuração } \\
\text { Problemas no controle de } \\
\text { desvios }\end{array}$ & $\begin{array}{ll}\text { - } & \text { Inclinações excessivas } \\
\text { - } & \text { Asoglegs) } \\
\text { - } & \text { } \quad \text { Verfuraçãamento da coluna de } \\
\text { anular devido a fraca } \\
\text { cimentação } \\
\text { - } \quad \text { Fraca reposta das } \\
\text { - ferramentas de perfilagem } \\
\text { Impossibilidade de gerar } \\
\text { perfis } \\
\text { Problemas no controle de } \\
\text { desvios }\end{array}$ \\
\hline
\end{tabular}

Fonte: McLellan (1996). 
Conforme MacLellan (1996), os sintomas diretos incluem observações do diâmetro alcançado na perfuração, o chamado oversized hole (o poço fica com diâmetro maior que o programado), gauge hole e undergauge hole (quando os diâmetros do poço têm o mesmo tamanho e um tamanho menor que o diâmetro da broca, respectivamente). A existência de escavações (cavings) na superfície também é uma evidência de que há problemas de instabilidade na parede do poço, pois pode estar ocorrendo um processo de desmoronamento das paredes do mesmo. O volume de fragmentos de rocha em excesso, comparado ao que seria o volume normal (gauge hole) em poço com o mesmo diâmetro da broca usada na perfuração, também atesta a ampliação no tamanho do poço. O volume de cimento requerido sendo maior que o volume calculado, de acordo com a perfuração, também é um indicador direto de que o alargamento aconteceu.

Já os sintomas indiretos podem ser diversos, tais como: vibração excessiva na coluna de perfuração, alto torque e fricção, problemas no controle dos desvios, entre outros; estes sintomas podem ser derivados de uma instabilidade nas paredes do poço, bem como também podem ser resultantes de um programa de perfuração inadequado, por falha de equipamentos ou erros operacionais. Um exemplo são os problemas na coluna de perfuração resultantes da instabilidade no poço, fadiga dos materiais ou um planejamento mal feito no design da coluna, (MCLELLAN, 1996).

Segundo Chieza (2011), problemas operacionais podem ser muito difíceis de serem identificados preventivamente e acabam gerando tempos extras da operação para serem resolvidos. A autora descreve alguns problemas operacionais e suas possíveis causas:

- Influxo de fluidos indesejados (Kick) - O kick é o influxo indesejado de fluidos presentes na formação (água, gás ou óleo) para dentro do poço, devido à existência de uma pressão hidrostática no interior do mesmo insuficiente para conter a pressão da formação. A ocorrência deste evento de maneira descontrolada que atinge a superfície chamase blowout. Como possíveis causas estão: o pistoneio, a perda de circulação, pressão da formação anormalmente alta, cimentação deficiente, falta de ataque ao poço. Além disto, eventos de kicks podem provocar instabilidade no poço, como: desmoronamentos, 
alargamentos, fechamento do poço, contaminações do fluido de perfuração, entre outros.

- Perda de circulação - A perda de circulação ocorre quando há invasão de fluido de perfuração para dentro da formação através de fraturas existentes ou provocadas em formações com alta permo-porosidade (devido à presença de formação inconsolidada, existência de falhas, fraturas naturais, cavernas, entre outros) ou em zonas depletadas. A perda pode ser total ou parcial, respectivamente, quando não há retorno de fluido ou quando há retorno parcial de fluido para a superfície. Uma perda de circulação provoca instabilidade mecânica no poço (devido à redução da pressão hidrostática com a queda do nível de fluido de perfuração no anular). Pode provocar o desmoronamento das camadas superiores ou inferiores da zona de perda e gerar influxos de fluidos da formação para dentro do poço (kick) pondo em risco a segurança do mesmo. As possíveis causas podem ser naturais (formações naturalmente fraturadas, formações inconsolidadas e formações cavernosas ou com falhas) e causas induzidas (elevada velocidade de descida da coluna (surge), elevado peso de fluido de perfuração e má limpeza de poço).

- Prisão da coluna de perfuração - A prisão da coluna de perfuração pode ocorrer devido a problemas operacionais (capacidade dos sondadores na identificação dos sintomas emitidos pelo poço), durante a parada da coluna de perfuração ou durante as manobras. Também podem ocorrer em situações de condições oceano-meteorológicas de severo heave (movimento vertical de subida e descida das ondas). Durante a retirada da coluna de perfuração pode ocorrer prisão da coluna por acunhamento. As anormalidades que podem acarretar a prisão de uma coluna de perfuração estão descritas posteriormente nos problemas operacionais de dificuldade de avanço e manobra.

- Dificuldade de manobra - Dificuldade de manobra são as anormalidades que podem ocorrer durante as operações de descida e 
retirada da coluna de perfuração para efetuar conexões ou troca de equipamentos. Podem ter causas devido à litologia (batente - variações no diâmetro interno do poço, prisão por diferencial de pressão, fechamento do poço devido ao inchamento das argilas, fechamento do poço devido à fluência do sal, fechamento do poço devido ao desgaste da broca em formações abrasivas, fechamento do poço por espessamento do reboco e desmoronamento das formações) ou operacionais (limpeza deficiente do poço, dogleg severo - ângulo maiores que 5\%/30m e chavetas (Key Seats) - cavidades abertas na formação devido ao constante atrito da coluna de perfuração com a parede do poço).

- Dificuldade de avanço da perfuração - São dificuldades de avanço todas as anormalidades que ocorrem durante a perfuração do poço e suas causas estão relacionadas à: litologia (enceramento do BHA bottom hole assembly - e da broca - pela aderência total ou parcial de material argiloso, cobrindo componentes da coluna de perfuração; fechamento do poço - devido ao inchamento das argilas, à fluência do sal, à abrasividade de formações e à formação de rebocos; formações abrasivas - que geram desgaste dos equipamentos da coluna de perfuração e formações duras - com uma baixa, ou quase nula, taxa de perfuração), falhas operacionais (má limpeza do poço; dogleg severo e chavetas) e vibrações (são detectadas por meio da observação das oscilações das medidas na superfície de torque e rotação da coluna de perfuração. A ocorrência de vibração pode causar falhas à coluna de perfuração, desvio da trajetória do poço, alargamento do poço e danos aos equipamentos do BHA - broca, estabilizadores, juntas, MWD, LWD, PWD, motor de fundo, RSS, entre outros).

A seguir, no Quadro 5 , são apresentados alguns problemas comuns na perfuração, muitos deles propiciados pela instabilidade do poço (RABELO, 2008; SCHLUMBERGER, 1999). 
Quadro 5 - Problemas na perfuração.

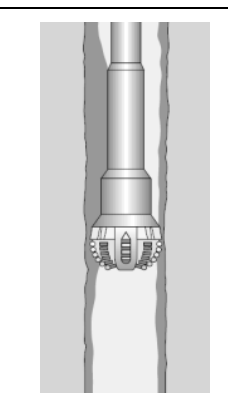

Diferencial de pressão: ocorre quando intensas forças de contato, resultantes da diferença entre as pressões do poço e do reservatório, são exercidas sobre uma grande área da coluna de perfuração
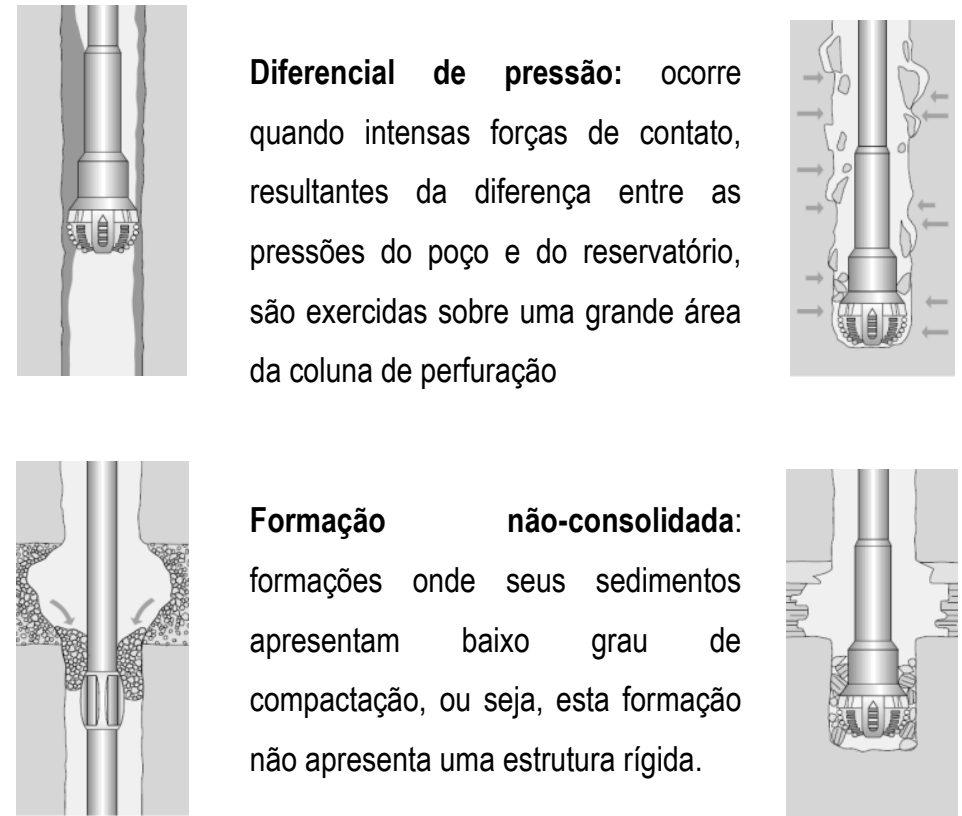

Formação não-consolidada: formações onde seus sedimentos apresentam baixo grau de compactação, ou seja, esta formação não apresenta uma estrutura rígida.

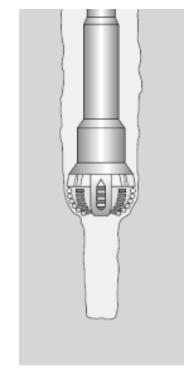

Poço com diâmetro reduzido: ocorre em formações extremamente duras e abrasivas, que podem prender a broca desgastada, consequentemente, a coluna, no ato de seu movimento para dentro do poço.

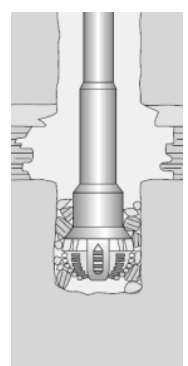

Pressão geostática: é quando a pressão da formação é maior em certo ponto do que a esperada pelo gradiente de pressão, podendo assim causar um kick, ou se tornar um grande problema durante a perfuração.

Zonas fraturadas ou com falhas: as falhas são descontinuidades geológicas naturais que ao longo do tempo e com 0 movimento das rochas podem provocar fraturas nas formações. Podendo assim, ocorrer perda de circulação do fluído de perfuração para formação, gerando má limpeza do poço.

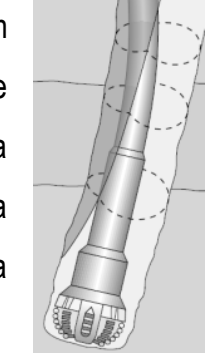

Aprisionamento por chaveta: acontecem em formações com variação em sua dureza, em perfurações direcionais, no momento em que é feito um desvio, os elementos da coluna de perfuração com diâmetros maiores podem ficar presos.

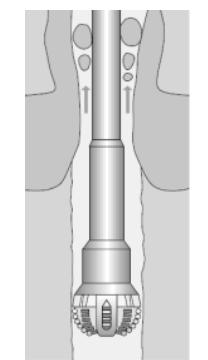

Formação reativa: formações como por exemplo o folhelho, que pode reagir com uma lama a base de água e fazer com que a formação "inche", fechando o poço.

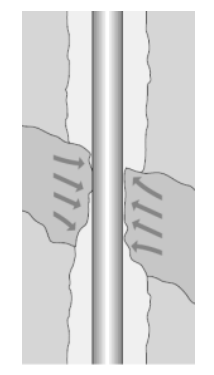

Formação móvel: formações como o sal, que possui uma alta mobilidade, o que faz com que a formação tenda a se movimentar para dentro do poço, causando um grande risco de prisão de coluna, principalmente se a formação for muito espessa.

Colapso do revestimento: ocorre quando o revestimento não é resistente 0 suficiente para aguentar a pressão exercida pela formação, causando seu colapso ou deformação.
Lixo - Fraca limpeza: a implementação de um fluido de perfuração inadequado pode gerar problemas de limpeza caso ele não esteja exercendo seu papel de levar cascalhos e fragmentos da formação para a superfície.

Fonte: adaptado de Schlumberger (1999) e Mattos e Campos (2017) 
Quadro 5. Problemas na perfuração (continuação).

\begin{tabular}{l|l|l|l} 
Problemas com Cimentação: uma & $\begin{array}{l}\text { Vibração da coluna: uma vibração elevada } \\
\text { cimentação feita incorretamente pode } \\
\text { permitir a passagem de gás pelo anular ou } \\
\text { não conferir uma estabilidade adequada } \\
\text { para o poço. }\end{array}$ & $\begin{array}{l}\text { da coluna pode gerar problemas de } \\
\text { instabilidade devido a impactos com a } \\
\text { parede do poço }\end{array}$ \\
\hline &
\end{tabular}

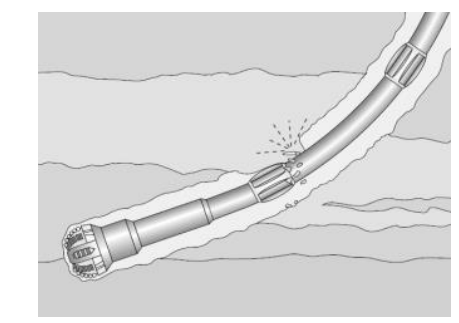

Geometria do poço: Um raio de curvatura muito elevado durante a construção de poços direcionais pode ocasionar a dificuldade de passagem de ferramentas, ou até mesmo aprisionamento, devido a restrições de flexibilidade de alguns materiais presentes na coluna.

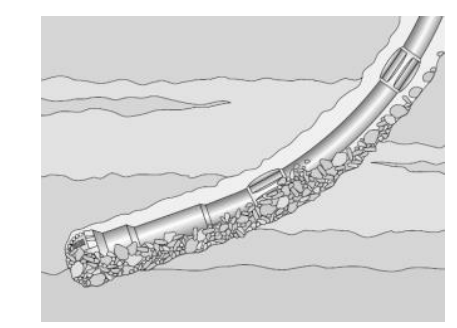

Fraca limpeza do poço: 0 acumulo excessivo de cascalhos por decantação, durante a construção de poços direcionais, pode ocasionar aprisionamento devido à dificuldade de movimentar a coluna nessas condições

Fonte: adaptado de Schlumberger (1999) e Mattos e Campos (2017).

\subsection{TEMPO NÃO PRODUTIVO (NPT - NON PRODUCTIVE TIME)}

A instabilidade nas paredes do poço pode resultar em muitos tipos de problemas, conforme visto no tópico anterior. Em alguns casos, os problemas de instabilidade do poço podem causar o abandono de uma parte do poço e, em casos extremos, é necessário o abandono do poço inteiro. A consequência mais importante dos problemas de instabilidade do poço diz respeito ao tempo não produtivo (NPT Non productive time) e às despesas adicionais (não programadas), oriundas destas ocorrências (GAURINA-MEDJIMUREC, 2014).

Tavares (2006) reforça que, durante a perfuração, problemas de instabilidade do poço e a quebra de equipamentos são fontes muito comuns de NPT. Os custos diários da sonda representam uma parcela considerável do gasto total na construção de um poço, principalmente em operações offshore. Desta forma a eliminação ou a minimização do tempo não produtivo é algo desejável em todas as operações.

O mesmo autor, em seu estudo em 2006, informa que a identificação precoce de problemas já foi objeto de diversos estudos, principalmente relacionados a kick e 
prisão de coluna. Esses estudos resultaram em sistemas de detecção antecipada de problemas. Porém, estes sistemas não foram aplicados em campo, devida duas razões básicas: o excesso de complexidade dos sistemas e o alto índice de alarmes falsos produzidos. Estes excessos de complexidade dizem respeito à falta de praticidade. Além disto, conforme o autor, alguns sistemas exigiam processos extensos de entrada de dados e de calibração. Com o alto índice de alarmes falsos, esses sistemas perdiam a credibilidade e, no decorrer do tempo, eram ignorados pela equipe de sonda.

O fator mais crítico no desempenho da construção de um poço é confirmar o menor custo por seção realizada, definindo previamente estratégias e soluções operacionais. Desta forma, as fontes de tempo não produtivos (NPT) devem ser analisadas em detalhes (HOLDAWAY, 2014).

Em sua publicação, Holdaway (2014) introduz a ideia que a performance do processo de perfuração deve ser descrita de forma analítica, assim como a identificação de todos os fatores contribuintes críticos para o desempenho da perfuração. Os diversos indicadores de desempenho não devem ser analisados isoladamente porque estão inter-relacionados. Consequentemente, a maximização de qualquer indicador, sem identificar e abordar os efeitos que o esforço tem nos outros indicadores, pode comprometer a eficiência da perfuração. Processos analíticos avançados podem estabelecer e avaliar direcionadores de desempenho que são fundamentais para a identificação e redução de tempo não produtivo (NPT) durante a perfuração. Ao realizar análise multivariada em fontes de dados de tempo real, fluxos de trabalho analíticos podem determinar padrões desconhecidos para identificar tendências em um sistema de perfuração.

A Figura 16 ilustra alguns dos principais estágios de um fluxo de trabalho de engenharia de perfuração, encapsulando o fluxo de informações geradas que suporta um ciclo efetivo de tomada de decisão (HOLDAWAY, 2014). 
Figura 16 - Fluxo de trabalho de engenharia de perfuração.

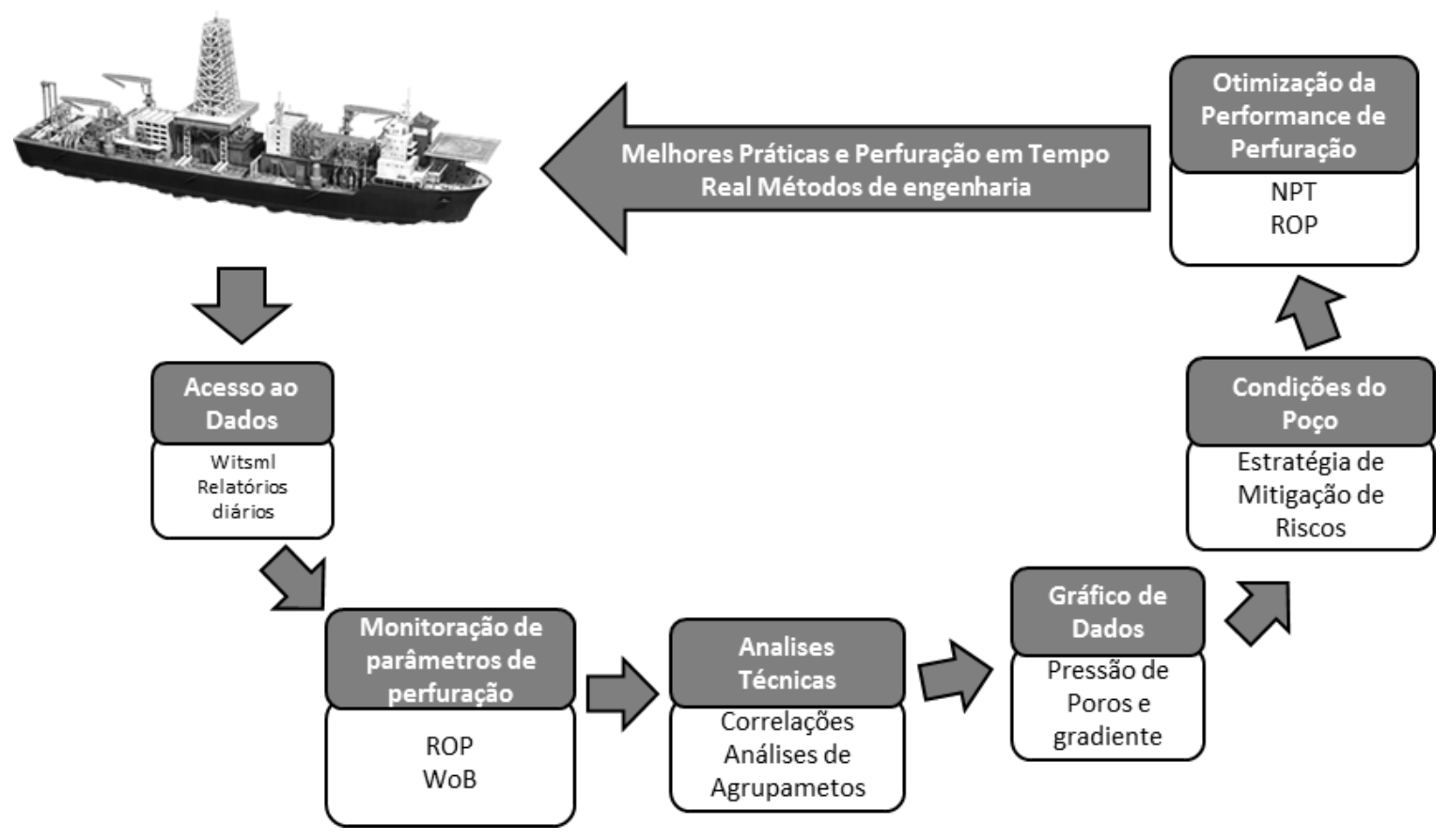

Fonte: adaptado de Holdaway (2014).

Holdaway (2014), apresenta no processo o fluxo de trabalho de engenharia de perfuração a disponibilização de dados das sondas para a monitoração dos principais parâmetros operacionais e análises técnicas. $O$ processo segue com a avaliação e correlação de dados com ferramentas gráficas, a análise mitigatória de problemas operacionais no poço tendo por fim o resultado esperado de mitigação de problemas operacionais aplicando as melhores práticas na operação.

A implementação destes processo de otimização é efetuada através da disponibilização de Centros de Operação em Tempo Real (RTOC), Drilling Centers e CSDs (Centros de Suporte à Decisão), endereçando a crescente complexidade inerente ao volume e variedade de dados de perfuração, atualmente coletados de sensores no poço, parâmetros de superfície, LWD, MWD, PWD e dados de mudlogging. Estes centros, além de fornecerem os dados necessários para o processo, concentram os especialistas das disciplinas (Holdaway 2014; Lima et al. 2016; Chieza 2011).

Além de dados de tempo real, é necessário possuir uma base de dados histórica, mantendo definições consistentes de tempo não produtivo (NPT) (realizados com planejados). Além disto, é fundamental reanalisar os dados históricos de NPT dos relatórios de perfuração diários (ADAMS; GIBSON; SMITH, 2010). 
Por fim, corroborando com a importância dos dados históricos, os autores Cristofaro et al. (2017) apresentam uma abordagem para minimizar o NPT relacionada à perda de fluidos na perfuração. O estudo propõe a aplicação de uma metodologia para definir o melhor material de controle de perda, utilizando uma estratégia de Inteligência Artificial baseada em aprendizagem supervisionada, a partir de uma base histórica de 3 anos. 


\section{A TRANSFORMAÇÃO DIGITAL NO E\&P}

A Transformação Digital é um termo que vem tendo a atenção de empresas de todos os setores ao redor do mundo. Relaciona-se a uma mudança nos processos, na qual, as organizações, executam mudanças estruturais, dando à tecnologia um papel essencial para melhorar o desempenho de seus processos, aumentar a atuação e garantir melhores resultados econômicos.

A Transformação Digital na indústria vem sendo relacionada a uma nova revolução, ou seja, à quarta revolução industrial. A primeira foi baseada no carvão como fonte de energia, impulsionando, assim, as máquinas a vapor e transformando o trabalho artesanal em automatizado. A segunda, baseada em conceitos de eletricidade para atingir a produção em massa e, a terceira, baseou-se em sistemas eletrônicos e computacionais, tendo como o seu maior expoente os sistemas Supervisory Control and Data Aquisition (SCADA), que foram utilizados para aprimoramento e eficiência da linha de produção. Esta quarta revolução industrial se apoia fortemente nas tecnologias habilitadoras de trabalho cooperativo, tais como: Internet of Things (IOT), machine learning, big data, data analytics, cyber-physical systems (CPS), machine-to-machine (M2M) e cloud computing. Outros termos e visões relacionadas neste contexto e que se destacam são: Industry 4.0, Industrial Internet Consortium e Manufatura Avançada (AZEVEDO, 2017) .

A indústria de E\&P, com o intuito de melhorar a produtividade e reduzir custos, tem buscado o uso de tecnologias digitais para mitigar ou combater os efeitos das sazonalidades dos preços do petróleo, a escassez de profissionais e o aumento da concorrência substitutiva - fontes renováveis. Além disto, executivos da E\&P apontam a necessidade de mudanças radicais no modelo operacional da indústria, sustentadas por uma maior adoção de tecnologias digitais. Corroborando com esta ideia, o relatório sobre a Transformação Digital do Fórum Econômico Mundial identifica Big Data, Data Analytics, Internet of Things, Mobility, Cloud e Artificial Intelligence como as principais prioridades para o investimento em tecnologia no setor de petróleo e gás (KUMAR, 2017; WORLD ECONOMIC FORUM, 2017).

A utilização de tecnologias digitais não é um assunto novo para o setor de petróleo e gás. Iniciativas de DOF - campos inteligentes (Digital Oil Field), operações integradas (Integrated Operations) e semelhantes, que começaram na década de 1990, viu empresas da E\&P fazer investimentos significativos em instrumentação, 
análise, visualização e tecnologias de automação de fluxo de trabalho (KUMAR, 2017; LIMA et al., 2016; LIMA, 2013).

As lições aprendidas, práticas de gestão obtidas e infraestrutura disponibilizadas nestas iniciativas citadas servem como base para a Transformação Digital no E\&P.

Esta ideia é reforçada por Priyadarshy (2017), para quem a Transformação Digital para a indústria upstream é um novo paradigma para transformar a indústria, utilizando os produtos dos campos petrolíferos digitais (DOF), colocando-a dentro do ecossistema de uma empresa, tendo um impacto profundo sobre a evolução da indústria de E\&P, para enfrentar os desafios futuros e melhorar a lucratividade.

Diversas lacunas tecnológicas foram superadas nos últimos anos, pois, hoje, armazenar e analisar dados de qualquer tamanho não apresenta tantas restrições de processamento quanto nas décadas passadas. Assim, à medida que se tem mais conhecimento de um determinado silo (departamento, setor, disciplina ou área), a demanda por inteligência aumenta dentro deste silo e principalmente entre os silos. Desta forma, a quebra destes chamados silos surge como um fator determinante para que a Transformação Digital aconteça nas empresas (PRIYADARSHY, 2018).

Nesta linha, Holdaway (2014) ressalta que os dados são um ativo estratégico de qualquer empresa de petróleo, não pertencente a uma disciplina ou área (silo) que gera e colhe os dados. A integração de dados e o gerenciamento de dados são fundamentais para o conhecimento da empresa. Outro ponto destacado por Holdaway e Irving (2017) está relacionado à atual e rápida proliferação de adoção de técnicas de Inteligência Artificial como um caminho para resolver problemas críticos de negócios de exploração e produção (E\&P), com o uso de análise de dados. O autor ressalta que esta adoção está relacionada à explosão do volume de dados, de suas variedades e que tem vindo em maiores velocidades, em resumo se tratando Big Data.

Sendo assim, o Big Data e as técnicas de Inteligência Artificial se posicionam no centro da transformação digital, ao gerar novas idéias (insights) para traçar estratégias e otimizar ações para todos os setores.

Para entender melhor estes componentes, os próximos tópicos abordam a gestão de dados do Big Data, questões relacionadas a qualidade das informações (data quality), técnicas de Inteligência Artificial utilizadas na indústria e por fim os processos de produção de conhecimento a partir de dados, Figura 17. 
Figura 17 - Transformação Digital no E\&P

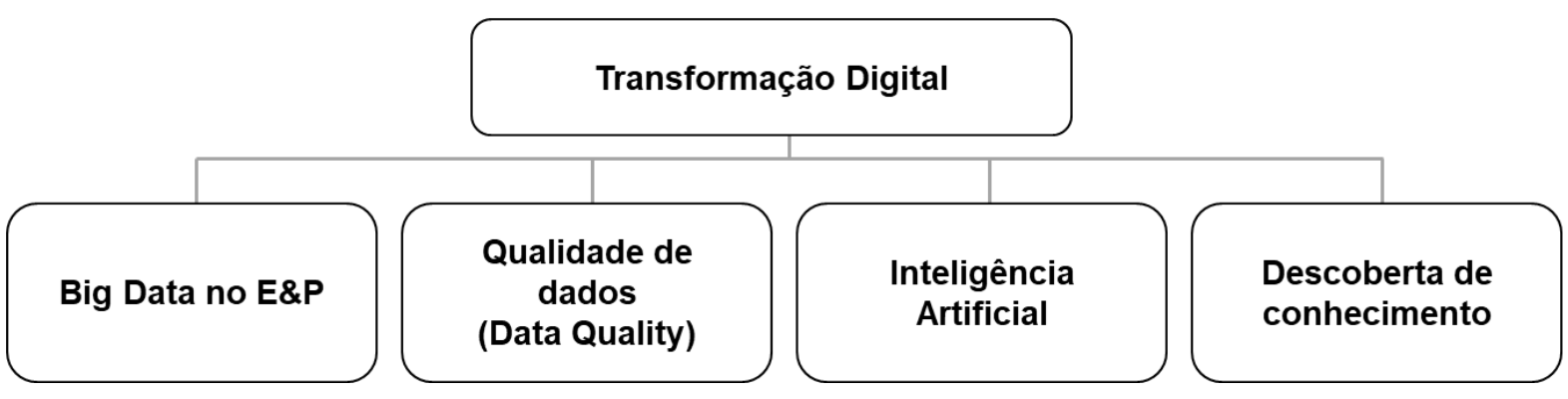

Fonte: o autor

\subsection{BIG DATA NO E\&P}

À medida que os rendimentos dos ativos da indústria de E\&P se tornam mais difíceis de serem atingidos e ainda mais difíceis de serem antecipados, é imperativo que a indústria esteja coletando e mantendo os seus dados de forma eficaz.

A iniciativa de Transformação Digital na indústria petróleo e gás vem impulsionando a necessidade da integração de tipos de dados diferentes daqueles das disciplinas de engenharia, anteriormente isoladas em seus silos, para serem resolvidos problemas críticos de negócios em toda a cadeia de valor de exploração e produção (E\&P), com análises e previsões mais precisas. A indústria de petróleo está coletando considerável quantidade de dados de sensores de operações que abrangem exploração, perfuração e produção. Velocidade de atualização dos dados e crescimento do volume dos dados colocaram uma enorme pressão sobre o desempenho dos aplicativos e dos bancos de dados. Esse crescimento rápido requer uma mudança fundamental na forma como os dados são coletados, armazenados, analisados e acessados para suportar inteligência e ciclos de tomada de decisão em tempo real (HOLDAWAY, 2014).

Big Data é um termo popular usado para descrever o crescimento exponencial e a disponibilidade de dados, estruturados e desestruturados. Mais dados podem levar a análises mais precisas. Análises mais precisas podem levar a uma tomada de decisão mais confiável. E melhores decisões podem significar maior eficiência operacional, redução de custos e risco reduzido (HOLDAWAY, 2014).

Segundo Davenport (2014), existem variações sobre a definição do Big Data com relação ao número de Vs, geralmente relacionado ao Volume, Variedade e Velocidade, porém existem variações que acrescentam Veracidade, Valor, entre 
outros. Nesta linha, Holdaway (2014), apresenta a definição dos 3Vs relacionados a indústria do petróleo e gás:

- Volume: a indústria de E\&P gera muito dados, desde as fases de exploração, desenvolvimento, produção até o abandono dos ativos de produção. Estes dados, baseados em transações, são armazenados ao longo dos anos. Além disto, com as inovações tecnológicas, novos tipos de dados estão sendo requisitados para armazenamento para processamento futuro, como, por exemplo, imagens e vídeos são considerados não estruturados. No passado, o volume de dados excessivo era um problema de armazenamento, porém com a diminuição dos custos de armazenamento, emergem outras questões, incluindo como determinar a importância de determinados dados em grandes volumes de dados e como usar análises para criar valor a partir de dados relacionados;

- Velocidade: os dados são transmitidos em frequência cada vez mais altas e devem ser tratados de forma oportuna, como, por exemplo, dados transmitidos em tempo real na fase de construção de poços oriundos dos mais diversos sensores da sonda e do poço (downhole). Reagir rapidamente para lidar com a velocidade dos dados é um desafio para a maioria das organizações;

- Variedade: os dados são disponibilizados em diversos formatos. As bases de dados tradicionais possuem dados alfanuméricos estruturados. Há informações criadas a partir de aplicativos de linha de negócios. Os documentos de texto não estruturados na forma de relatórios diários de perfuração, e-mail, vídeo, áudio e transações financeiras proliferam à medida que o campo petrolífero é desenvolvido. Gerenciar variedade de dados é uma tarefa onerosa, para a maioria das empresas de E\&P.

\subsection{QUALIDADE DE DADOS (DATA QUALITY)}

A qualidade de dados é de vital importância para obter um bom resultado em um projeto de Big Data, sendo este um problema da indústria em geral, e não seria diferente na indústria de petróleo. Segundo Mehta (2016), a qualidade de dados na indústria de petróleo (especialmente os dados históricos) carece de precisão, completude, integridade e consistência, para análises em tempo real. Acrescenta que 
menos de $50 \%$ dos usuários encontra dados, de fontes coorporativas, em um formato pronto para o uso. Além disto, o problema só tende a aumentar com a contínua disponibilidade de novas fontes de dados.

Neste cenário, pouca qualidade, e observado o princípio de Pareto (80/20), segundo a qual, $20 \%$ e vital e $80 \%$ é trivial. Aplicando este princípio ao tempo consumido ao resolver um problema de negócios em E\&P, gasta-se $80 \%$ do tempo no gerenciamento e preparação de dados, antes de se abordar o problema propriamente. Uma solução de dados deve reverter esse paradigma e garantir que $80 \%$ do tempo dos especialistas seja consumido para a interpretação dos dados (HOLDAWAY, 2014).

Uma etapa de qualidade de dados suporta a correção de todos os problemas de qualidade descobertos durante a seleção das fontes de origem. Isso, geralmente, inclui a eliminação de diferenças semânticas encontradas nos dados de origem, quebrando os campos de múltiplos valores em elementos discretos, movendo a informação para o local apropriado, padrões de normalização e assim por diante. Uma solução proposta por Holdaway (2014) para fornecer dados agregados e robustos em um ambiente de E\&P, deve cumprir alguns objetivos básicos:

- Interface perfeita com todas as fontes de dados identificadas no E\&P;

- Mecanismos para facilitar a transferência de dados em tempo real e histórico;

- Automação de fluxos de trabalho para análise de dados exploratórios, para: identificar outliers; executar transformações; incluir dados faltantes; limpar dados; identificar padrões ocultos; identificar tendências e correlações;

○ Desenvolver Metadados;

- Relatórios de avaliação da qualidade dos dados: destacar os problemas de qualidade de dados e auditorias de mudanças de valor;

- Atualizar e/ou sincronizar os valores com as diretrizes atuais do negócio.

\subsection{INTELIGÊNCIA ARTIFICIAL}

A Inteligência Artificial (IA), tenta não apenas entender um problema, mas também construir entidades inteligentes. IA é um dos mais novos campos em ciência e engenharia. A IA abrange uma grande variedade de subcampos, que vão do geral (aprendizagem e percepção) ao específico, como desempenhar tarefas mais simples (jogar xadrez, provar teoremas matemáticos, escrever poesia, dirigir um carro em uma 
rua lotada e diagnosticar doenças). IA é relevante para qualquer tarefa intelectual, é verdadeiramente um campo universal (RUSSELL; NORVIG, 2010).

Atualmente, com o avanço das tecnologias, diversas tarefas rotineiras podem ser conectadas (IoT - Internet of Things). Smartphones, carros, assistentes virtuais, entre outras máquinas podem se comportar de maneira inteligente, através de IA. Juntamente com a IA estão ligados o aprendizado de máquina ( $M L$ - Machine Learning) e Aprendizado Profundo (DL - Deep Learning).

A maneira mais fácil de pensar em seu relacionamento é visualizá-los como círculos concêntricos com a Inteligência Artificial (Artificial Intelligence), sendo a ideia que veio primeiro - a maior, o aprendizado de máquina (Machine Learning), que surgiu mais tarde e, finalmente, o aprendizado profundo (Deep Learning), que está gerando a explosão da IA atualmente, conforme a Figura 18.

Figura 18 - Artificial Intelligence - Machine Learning - Deep Learning.

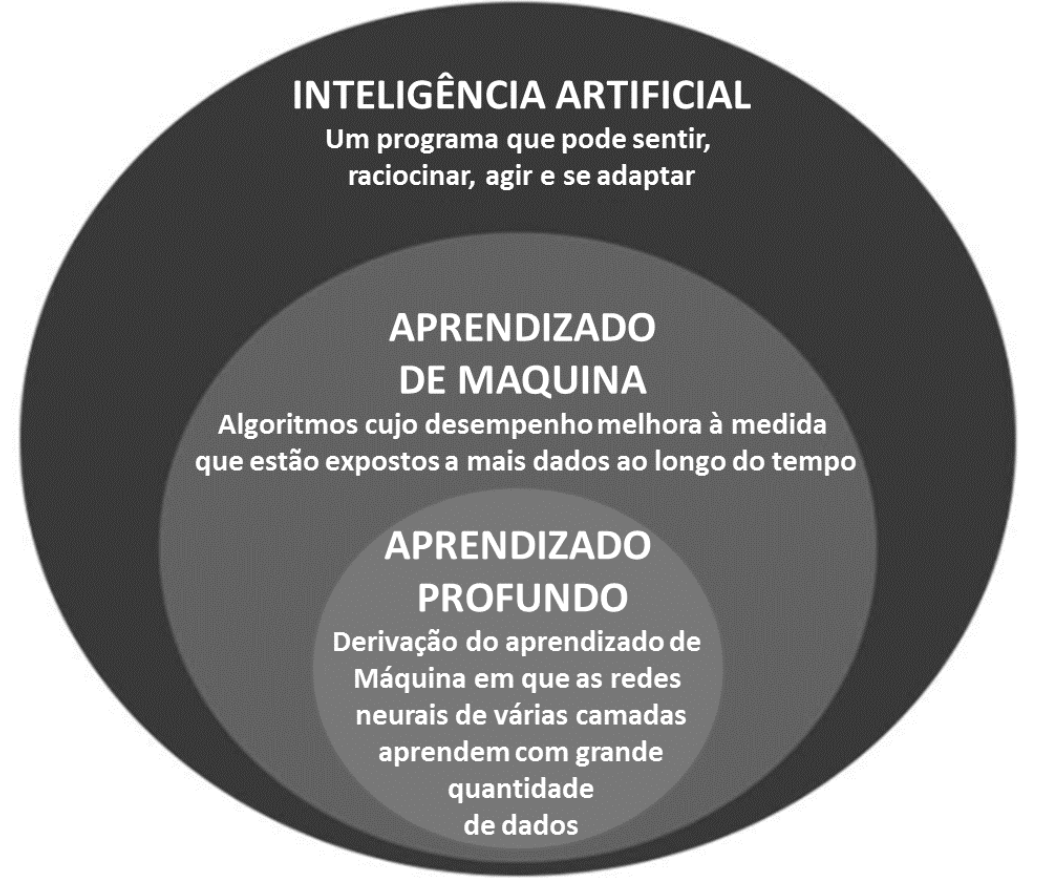

Fonte: adaptado de Saleschoice (2017).

De forma resumida, pode se considerar que qualquer atividade computacional que envolve o comportamento humano é Inteligência Artificial. Como subconjunto desta existe o Aprendizado de Máquina, que trata da extração de padrões de conjuntos de dados. A máquina pode encontrar regras para um comportamento ótimo, mas também pode se adaptar às mudanças. Muitos dos algoritmos envolvidos são conhecidos há décadas, porém, graças aos avanços tecnológicos em ciência da 
computação e computação paralela, pode-se fazer uso destes e obter o melhor resultado com grandes quantidades de informações disponíveis. Por fim, o Aprendizado Profundo (Deep Learning), é uma classe específica de algoritmos de Aprendizado de Máquinas que utilizam redes neurais complexas.

Atualmente, verifica-se a proliferação de modelos de IA e Aprendizagem de Máquinas nos negócios, nos mais diversos processos de trabalho. A IA tem o objetivo de acrescentar inteligência à automação em todas as indústrias.

Fluxos de trabalhos manuais foram mudados para fluxos de trabalhos automatizados e agora a IA fornece diferentes possibilidades na E\&P para abordar sistemas automáticos complexos. Os grupos tradicionais de engenharia de E\&P são compartimentados, em silos, e, mesmo que os limites estejam gradualmente entrando em esgotamento, a adoção da IA acelera um fluxo de trabalho interdisciplinar mais eficiente. Neste novo cenário interdisciplinar Holdaway (2014) acrescenta a importância do papel do cientista de dados, que atuará em Machine Learning e Deep Learning, podendo ser oriundo de várias indústrias.

Holdaway (2014) descreve que a indústria de petróleo, durante muitas décadas, já testemunhou a adoção de processos e metodologias automatizadas, como, mais recentemente pelos programas de Digital Oilfield, Smartfield, e similares na E\&P. O autor argumenta que estas automações não são consideradas inteligentes, pelo menos, não até que se apliquem técnicas de IA para educar estes programas implantados, com processamento de sinais, estatísticas, matemática, física e neurociência.

\subsubsection{Aprendizado de Máquina - Machine Learning}

Existem diversos métodos utilizados em Aprendizado de Máquina. A Figura 19 apresenta alguns dos algoritmos mais comuns na aprendizagem supervisionada, não supervisionada e semi-supervisionada (HALL et al., 2014). 
Figura 19 - Algoritmos de aprendizado de máquina.

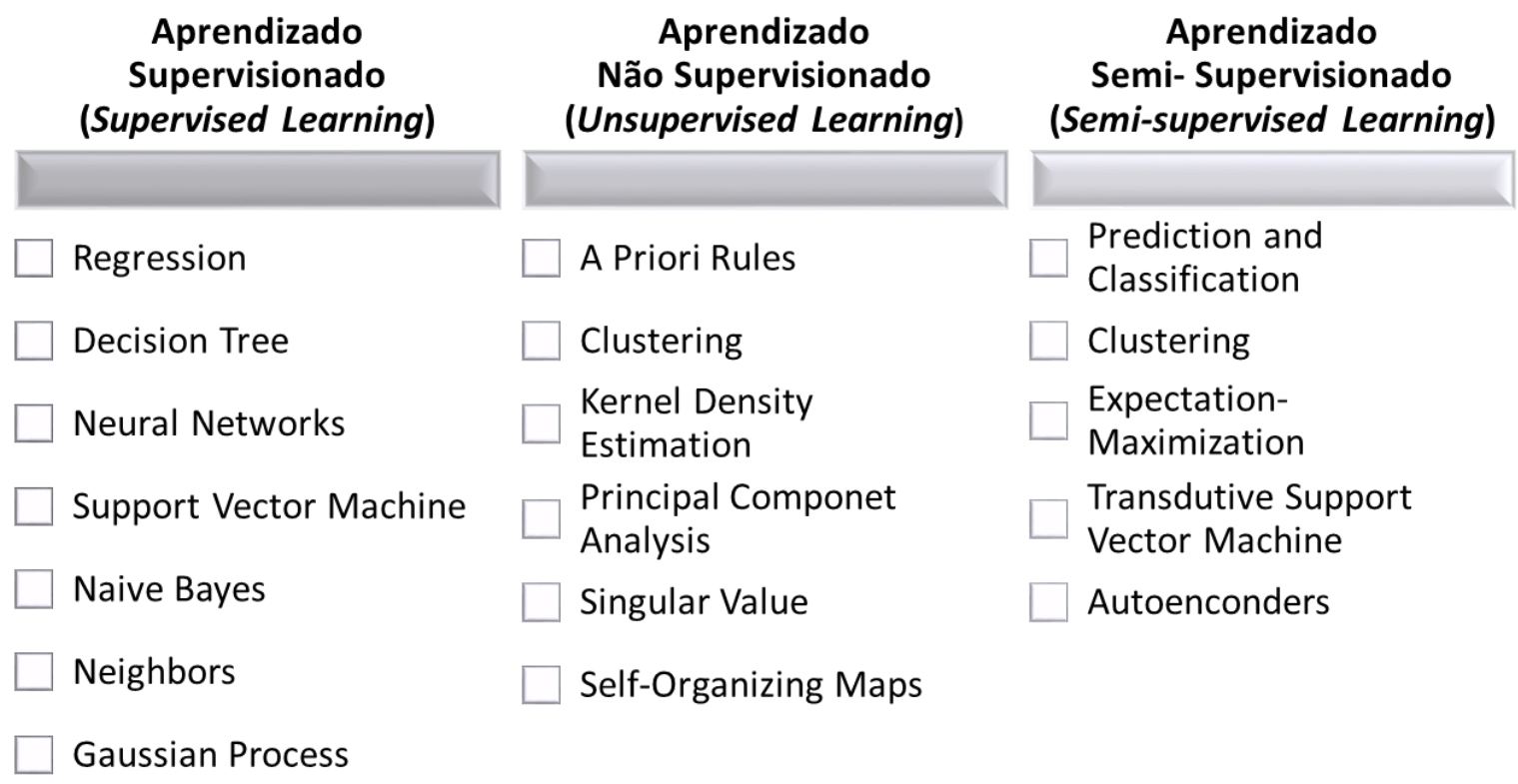

Fonte: adaptado de Hall et al. (2014).

A seguir uma descrição dos métodos utilizados em Aprendizado de Máquina, (HALL et al., 2014; HOLDAWAY, 2014):

- Aprendizagem supervisionada: Algoritmos que se enquadram neste grupo são treinados com conjuntos de dados rotulados. Rotulado refere-se ao conhecimento prévio da saída desejada de uma determinada entrada. $O$ algoritmo é treinado a partir de um conjunto de dados de entrada e dados de saída já conhecidos ou esperados. Técnicas de aprendizagem supervisionadas adotam um fluxo de trabalho de identificação de padrão para prever os valores do rótulo em dados não-rotulados.

- Aprendizagem não supervisionada: A aprendizagem não supervisionada ocorre quando um modelo é treinado em dados não marcados, não rotulados. Os algoritmos de aprendizagem não supervisionados habitualmente segmentam dados em grupos, "clusters". O algoritmo é deixado no escuro e não conhece as respostas corretas. O algoritmo deve determinar a saída para si mesmo sem orientação a priori. O objetivo é descobrir alguma estrutura escondida para todas as observações que compõem o espaço de entrada. 
- Aprendizagem semi-supervisionada: Os algoritmos de aprendizagem semisupervisionados geralmente treinam em pequenas porções de dados rotulados que são então combinados com quantidades maiores de dados não marcados, associados aprendizagem supervisionada e não supervisionada em situações onde os dados rotulados são difíceis ou dispendiosos de se adquirir.

\subsubsection{Aprendizagem Profunda - Deep Learning}

O aprendizado profundo ( $D L$ - Deep Learning) é um subconjunto de Aprendizado de Máquina ( $M L$ - Machine Learning). O DL implementa grandes redes neurais que suportam várias camadas ocultas para identificar recursos nos dados de entrada que têm capacidades preditivas robustas. As redes neurais DL evoluíram a partir das redes neurais básicas, aproveitando as técnicas não supervisionadas e semi-supervisionadas. A evolução testemunhou a adoção de algoritmos de otimização eruditos e plataformas computacionais inovadoras para alcançar a precisão do estado da arte (HALL et al., 2014; HOLDAWAY, 2014).

\subsection{PRODUÇÃO DE CONHECIMENTO A PARTIR DE DADOS}

As atividades operacionais nas organizações geram cada vez mais dados com informações vitais para continuidade operacional das empresas. Porém, o volume, variedade e velocidade (Big Data) de dados gerados atualmente são tão grandes que inviabilizam as análises e absorções por um ser humano, necessitando de apoio de processos específicos para executar estas atividades.

O processo de descoberta de conhecimento em banco de dados possui particularidades que reúnem diversos tipos de disciplinas e expertises. A natureza dos projetos de análise de dados exige uma metodologia especial e diferente das metodologias de projetos de softwares. Felizmente, técnicas de análise exploratória de dados foram desenvolvidas no decorrer dos anos para auxiliar os especialistas a retirar informações a partir dos dados (insight).

Em 1996, o artigo publicado por Fayyad, Piatestsky e Smyth (1996) já apresentava a mineração de dados e a descoberta de conhecimento em bancos de dados (KDD - Knowledge Discovery in Databases) como um tema de grande 
importância para a pesquisa, indústria e mídia. A artigo apresenta uma visão geral deste campo, esclarecendo como a mineração de dados e a descoberta de conhecimento em bancos de dados estão relacionadas, tanto entre si, quanto com campos relacionados, como aprendizado de máquina, estatísticas e bancos de dados. Além disto, o artigo apresenta um modelo sequêncial de cinco etapas, iniciando na seleção dos dados, processamento, transformação, mineração e finalizando com a interpretação e geração do conhecimento, conforme a Figura 20.

Figura 20 - Etapas do processo KDD.

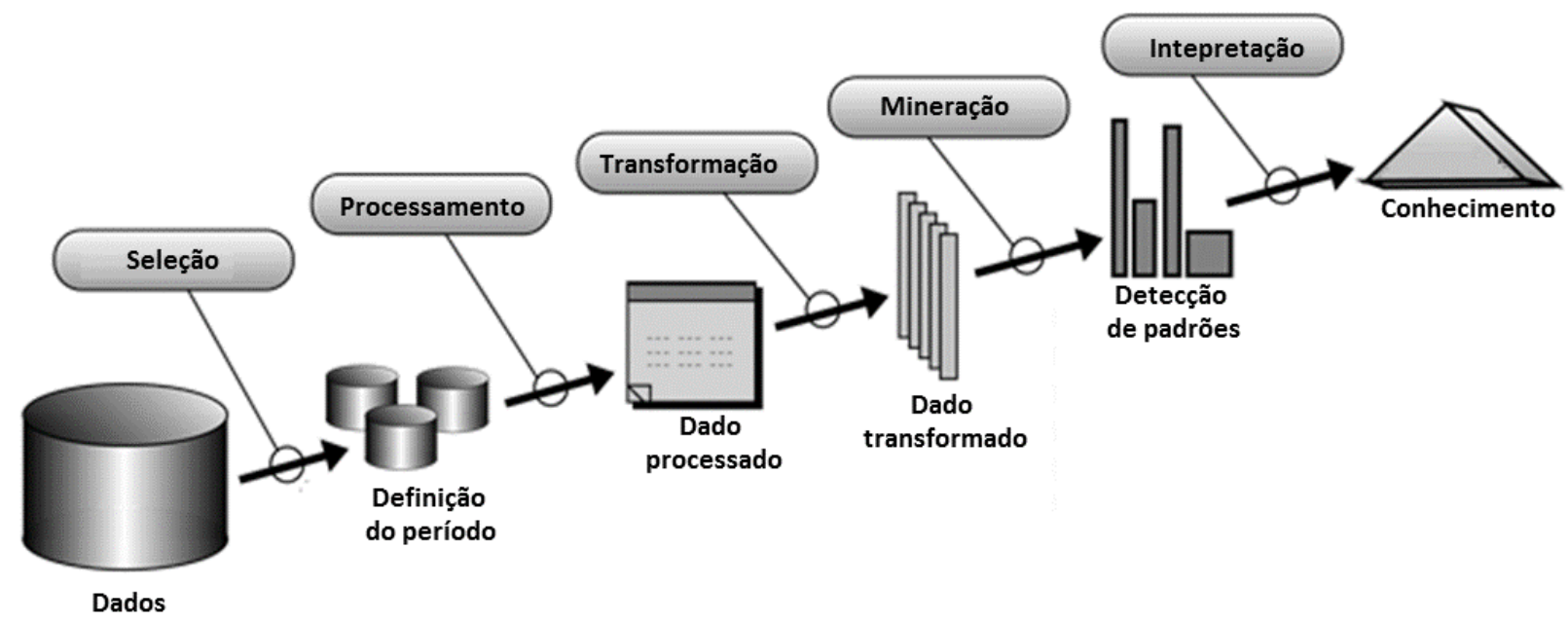

Fonte: adaptado de por Fayyad, Piatestsky e Smyth (1996).

Mais de uma década depois do artigo publicado sobre o processo de descoberta de conhecimento em banco de dados (KDD), Agrawal et al. (2012) apresenta um processo que apresenta as principais etapas para análises de um Big Data. Este processo, igualmente ao anterior ao KDD, possui cinco etapas muito bem relacionadas com a sua precursora. O que reforça que a grande diferença, assim como o abordado nas iniciativas anteriores de DOF (Digital Oil Field) para a Transformação Digital, baseia-se na evolução da tecnologia disponível no momento.

Em sua publicação, que trata especificamente de Big Data with Analytics para a indústria de petróleo, Holdaway (2014) apresenta um processo que reflete uma interação entre as etapas de um Big Data, conforme Figura 21. 
Figura 21 - Processo do Big Data.

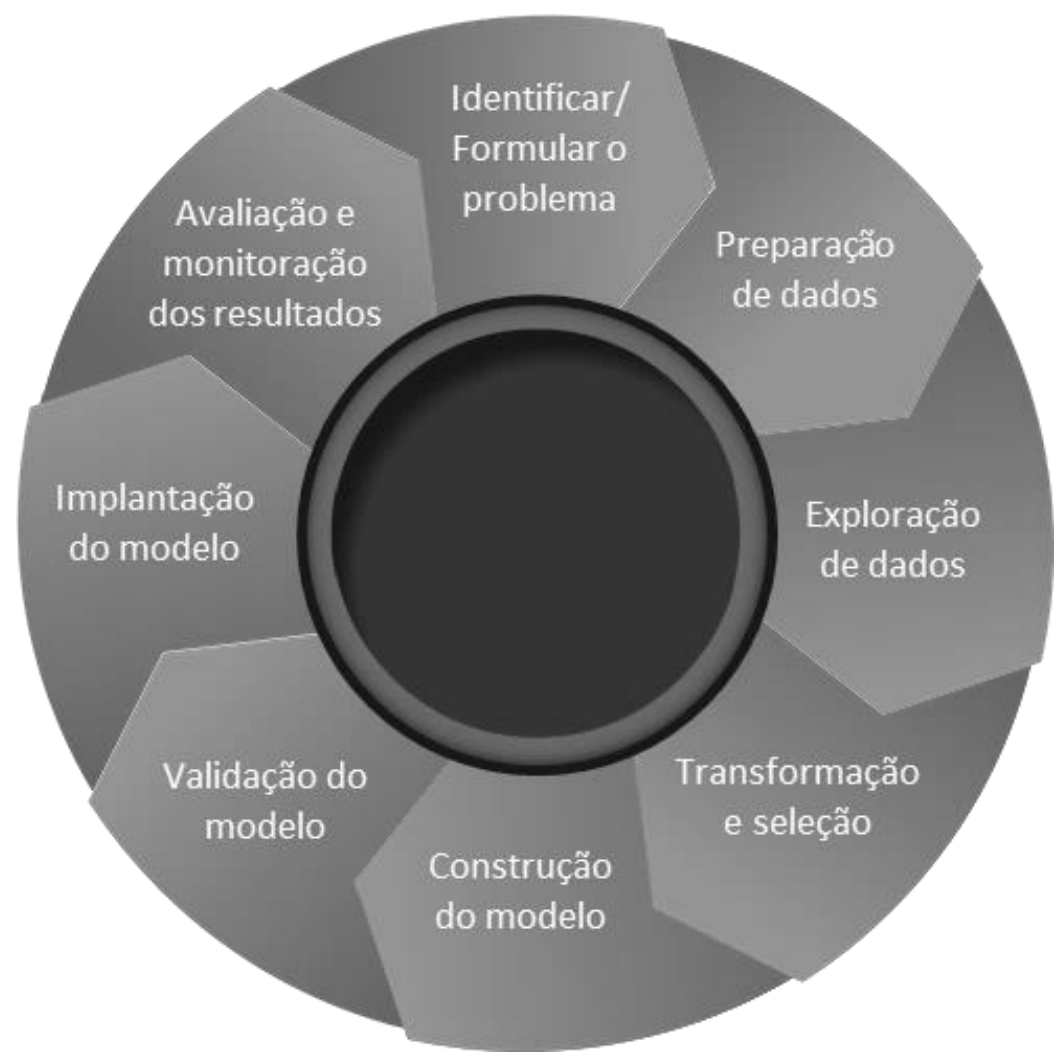

Fonte: adaptado de Holdaway (2014).

O processo apresenta a interação de oito etapas que são brevemente detalhadas abaixo:

- Formular problema: é necessário identificar um problema de negócio de E\&P que integre de forma colaborativa dados de diferentes silos. Big Data abrange dados estruturados, bem como dados não estruturados. O primeiro passo oriente grupo de engenheiros e de especialistas de diferentes áreas do negócio agregue e cruze os dados com base em sua experiência para abordar a questão e para explorar oportunidades úteis à obtenção de valor;

- Preparação de dados: os dados devem ser tratados por meio de alguns fluxos de controle de qualidade de dados, para incluir valores faltantes, segregar outliers, filtrar qualquer ruído (seja coerente ou aleatório) e gerar parâmetros de dados adicionais, a partir dos dados medidos. As questões de tratamento de dados devem ser feitas por engenheiros e/ou especialistas e devem ser encapsuladas nos processos;

- Exploração de dados: durante a etapa de análise de dados exploratórios, devem ser empregados vários fluxos de trabalho para disponibilizar 
conjuntos de representações e gráficos de visualização e identificação de correlações. É necessário entender os parâmetros que têm maior influência e impactos estatísticos, por uma ou mais variáveis dependentes;

○ Transformação e seleção: esta etapa complementa o fluxo de trabalho de preparação de dados, após a análise de dados exploratórios. O passo de seleção nos permite aprimorar as variáveis independentes mais importantes;

- Construção do modelo: múltiplas soluções devem ser avaliadas para determinar o modelo mais apropriado. Esses modelos são orientados a dados, incorporando quaisquer restrições introduzidas. Diversos modelos podem ser testados e implementados, tais como: regressão, redes neurais, regressões não-lineares, modelos lineares mistos, random forest e arvore de decisão;

- Validação do modelo: é de suma importância desenvolver uma estrutura para gerenciar os modelos preditivos e garantir a validade de todos os modelos, especialmente após cada modelo ser atualizado com novos dados;

- Implantação do modelo: o modelo é aplicado com dados em tempo real que, por sua vez, são comparados com os modelos simulados. Lacunas de desempenho do modelo podem ser identificadas, além dos resultados do modelo propriamente dito e alarmes preditivos. As lacunas de desempenho do modelo são revisadas por especialistas. Já os alarmes preditivos levam a um processo de tomada de decisão.

- Avaliação e monitoração dos resultados: a monitoração do desempenho do modelo preditivo deve ser dinâmica através da apresentação de indicadores que reflitam as regras de negócio estabelecidas. A distribuição dos resultados deve ser feita aos perfis apropriados para garantir uma efetiva correção e atenção a todos os alertas informados.

De modo mais amplo, para a indústria, duas metodologias para aplicação do processo de KDD são apresentadas, sendo elas CRISP-DM (Cross Industry Standard Process for Data Mining) e a SEMMA (AZEVEDO; SANTOS, 2008; SHAFIQUE; QAISER, 2014). 
O CRISP-DM é uma metodologia abrangente de mineração de dados e um modelo de processo que fornece um plano completo para a condução de um projeto de mineração de dados. O CRISP-DM divide o ciclo de vida de um projeto de mineração de dados em seis etapas. O Capítulo 5 apresenta na prática a adoção desta metodologia, abaixo segue uma breve descrição de cada etapa do ciclo:

1. Compreensão do negócio: compreende o entendimento dos objetivos do projeto, requisitos de negócio, definição de um problema e um plano preliminar para atingir os objetivos;

2. Compreensão dos dados: a etapa de compreende a coleta inicial dos dados, a elaboração do relatório de descrição dos dados, o relatório de exploração de dados e identificação da qualidade (problemas) nos dados;

3. Preparação dos dados: a etapa de preparação dos dados abrange todas as atividades para a construção do conjunto de dados final a partir dos dados brutos iniciais;

4. Modelagem: são selecionadas e aplicadas as técnicas de modelagem de dados;

5. Avaliação: nesta etapa o modelo é avaliado para verificar se os objetivos foram alcançados.

6. Implantação: esta última etapa concentra na obtenção do conhecimento e resultados e também em organizar, relatar e apresentar os conhecimentos adquiridos quando necessário.

A Figura 22 mostra as fases do CRISP-DM. As setas indicam as dependências mais importantes e frequentes entre as fases, enquanto o círculo externo simboliza a natureza cíclica da mineração de dados e ilustra que as lições aprendidas durante o processo de mineração de dados e da solução implantada podem desencadear novas questões de negócios, muitas vezes, mais focadas (CHAPMAN et al., 2000; HEKIMA, 2017; LAKE, 2006; SHEARER et al., 2000; WIRTH, 2000). Montevecchi (2012) apresenta esta metodologia como a mais utilizada. 
Figura 22 - Metodologia CRISP-DM.

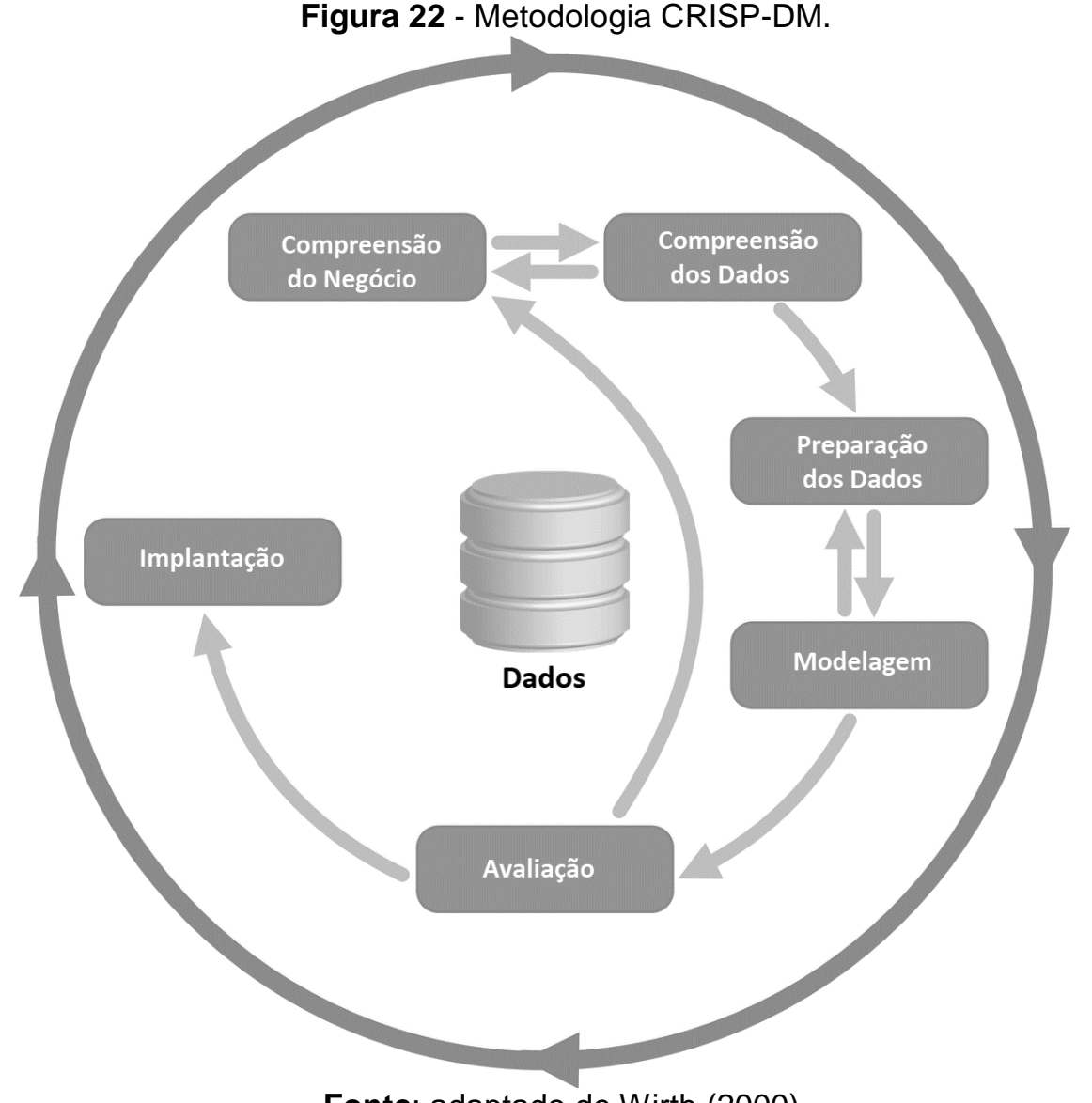

Fonte: adaptado de Wirth (2000).

Por fim, a metodologia SEMMA, desenvolvida pelo SAS Institute, e que significa Amostragem, Exploração, Modificação, Modelagem e Avaliação (Sample, Explore, Modify, Model and Assess) é uma metodologia focada principalmente nas tarefas de criação do modelo, deixando as questões de negócio um pouco de fora. A metodologia inicia com a obtenção de uma amostra estatisticamente representativa da base de dados para iniciar o processo experimental (Sample) de extração de conhecimento. A metodologia SEMMA não apresenta os retornos para as etapas anteriores como a metodologia CRISP-DM, ficando a cargo do conhecimento dos especialistas efetuar este fluxo (HOLDAWAY, 2014; MONTEVECCHI, 2012; SAS, 2017). 
Figura 23 - Metodologia SEMMA.

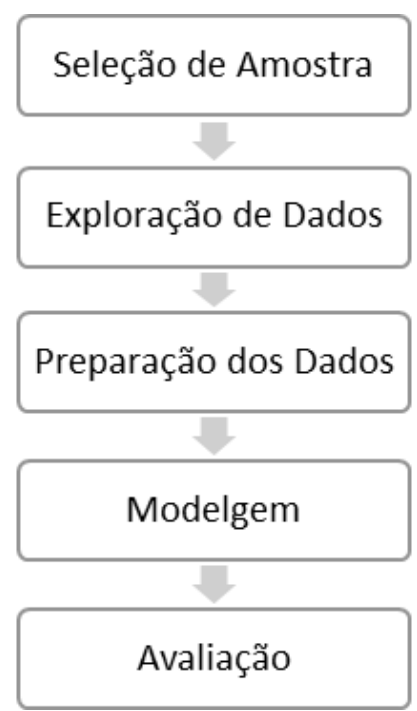

Fonte: adaptado de Montevecchi (2012).

Segundo Azevedo e Santos (2008), o SEMMA oferece um processo de fácil compreensão, permitindo um desenvolvimento organizado e a manutenção de projetos de data mining. As etapas apresentadas na Figura 23, são descritas a seguir (SHAFIQUE; QAISER, 2014):

1. Amostra: concentra-se na amostragem de dados. Uma parte de um grande conjunto de dados é considerada grande o suficiente para extrair informações significativas e pequena o suficiente para manipular rapidamente;

2. Explorar: concentra-se na exploração de dados. Isso pode ajudar na compreensão e nas ideias, bem como refinar o processo de descoberta, procurando tendências e anomalias;

3. Modificar: concentra-se na modificação de dados através da criação, seleção e transformação de variáveis para o processo de seleção do modelo de foco. Esse estágio também pode procurar outliers e reduzir o número de variáveis;

4. Modelo: concentra-se na modelagem de dados. O software para isso procura automaticamente pela combinação de dados. Existem diferentes técnicas de modelagem presentes e cada tipo de modelo tem sua própria força e é apropriado para situações específicas nos dados para mineração de dados;

5. Avaliar: concentra-se na avaliação da confiabilidade e utilidade dos resultados e estima o desempenho. 


\section{REVISÃO DA LITERATURA}

Este capítulo objetiva apresentar a revisão da literatura que foi desenvolvida a partir da pesquisa acadêmica e científica no portal de periódicos CAPES, particularmente nas bases SCOPUS, ScienceDirect e Engineering Village. No contexto da pesquisa tecnológica a base de pesquisa foi a OnePetro da The Society of Petroleum Engineers (SPE).

Segundo Salminen et. al. (2017), uma das primeiras publicações propondo o uso de métodos estatísticos para análise de dados buscando a identificação e predição de eventos de prisão de coluna foi a de Hempkins et. al. (1987). Conforme mencionado anteriormente, esta pesquisa pretende fazer uso do método estatístico de regressão, utilizado por alguns autores (HESS, 2016; SHORAKA; SHADIZADEH; SHAHRI, 2011), com o objetivo de buscar a identificação e previsibilidade em ocorrências de prisão de coluna em um conjunto de dados de poços perfurados.

A fim de analisar a aplicação deste mesmo método em outros trabalhos referentes de perfuração ou operação de poços de petróleo, foi desenvolvida esta pesquisa utilizando as palavras chaves em dois momentos distintos. Para as bases SCOPUS, ScienceDirect e Engineering Village, que não são bases específicas da indústria do petróleo foram utilizadas para pesquisa as palavras: "Regression", "Drilling", "Petroleum or Oil" e "stuck pipe". Para a base tecnológica da OnePetro foram utilizadas as palavras chaves "Regression", "Drilling", e "stuck pipe".

As palavras de pesquisa utilizados em cada base foram:

- OnePetro: "regression" AND "drilling" AND "stuck pipe";

- ScienceDirect, SCOPUS e Engineering Village: "regression" AND "drilling" AND "stuck pipe" AND ("Petroleum" OR "Oil");

As pesquisas nestas bases retornaram cerca de 240 publicações (188 originadas da base técnica OnePetro e o restante das demais bases) originadas de diversas fontes de publicações e congressos. Com o intuito de apresentar a distribuição desses estudos pelo mundo, foi elaborada uma carta geográfica, utilizando as informações contidas nas referências. Estas referências foram obtidas nos periódicos através da exportação dos dados da bibliografia, no formato RIS (Research Information Systems). Com o uso de técnicas de estatística espacial 
(geoestatística) os dados foram apresentados no mapa conforme a Figura 24. Não foi possível apresentar cerca de $20 \%$ das publicações, por não terem em sua referência a informação de local de publicação.

Figura 24 - Publicações pelo mundo.

Fonte: o autor.

As publicações encontradas nas pesquisas foram filtradas em duas etapas. A primeira análise foi direcionada aos títulos e abstracts das publicações, buscando a relevância com o método da pesquisa. Posteriormente, uma análise mais criteriosa, detalhada, foi efetuada, para buscar e selecionar os trabalhos com maior aderência. O Quadro 6 apresenta as 25 publicações classificadas com maior relevância, agrupadas de acordo com o tema principal do artigo. Apesar das palavras chaves selecionadas direcionarem para publicações referentes a perfuração de poços, diferentes objetivos (questão principal) foram encontrados relacionados a temas, como: confiabilidade de equipamentos, estabilidade do poço, otimização de taxa de perfuração, intervenção de poços, otimização de parâmetros, transporte de resíduos de perfuração, pressão de formação, dentre outros temas técnicos e tecnológicos. 
Quadro 6 - Publicações relacionadas a regressão em Perfuração de Poços.

\begin{tabular}{|c|c|c|}
\hline REFERÊNCIA & APLICAÇÃO & RESUMO \\
\hline $\begin{array}{c}\text { (HESS, 2016; SHORAKA; } \\
\text { SHADIZADEH; SHAHRI, } \\
\text { 2011) }\end{array}$ & $\begin{array}{l}\text { Previsão de prisão de } \\
\text { coluna de perfuração } \\
\text { usando estatística } \\
\text { multivariada }\end{array}$ & $\begin{array}{l}\text { Os trabalhos apresentam propostas de identificação previa } \\
\text { de riscos de prisão de coluna de perfuração em poço, } \\
\text { utilizando método estáticos de regressão múltipla. } \\
\text { modelo sugerido fornece indicações da necessidade de } \\
\text { aplicar medidas para mitigar a situação antes que o } \\
\text { problema ocorra ou, no mínimo, forneça informações } \\
\text { adicionais para a tomada de decisões, reduzir o tempo } \\
\text { improdutivo (NPT). }\end{array}$ \\
\hline (HOLAND, 2001) & $\begin{array}{c}\text { Confiabilidade dos BOPs } \\
\text { em Águas Profundas }\end{array}$ & $\begin{array}{l}\text { Análise de confiabilidade dos equipamentos preventores de } \\
\text { blowout submarino em águas profundas. Utilizando método } \\
\text { de regressão foi avaliado que a confiabilidade geral dos } \\
\text { equipamentos não sobre grandes mudanças em relação ao } \\
\text { uso em águas profundas e não profundas. Para a análise } \\
\text { forma considerados dados de prisão de coluna. }\end{array}$ \\
\hline $\begin{array}{l}\text { (D. LUO ET AL., 2014; } \\
\text { KADYROV; TUTUNCU, } \\
\text { 2012; LIKRAMA; DIAZ, } \\
\text { 2015; MITCHELL; } \\
\text { SWEATMAN, 2013) }\end{array}$ & $\begin{array}{l}\text { Análises da estabilidade } \\
\text { do poço }\end{array}$ & $\begin{array}{l}\text { Os autores indicam em seus trabalhos que a instabilidade } \\
\text { do poço pode causa prisões de coluna, perda de circulação, } \\
\text { colapso do poço, entre outros problemas que resultam em } \\
\text { altos custos de perfuração e significativo NTP. Modelos } \\
\text { numéricos de regressão são empregados para } \\
\text { determinação de pressão mínima do poço (utilizada pelos } \\
\text { engenheiros para definirem a densidade adequada da lama } \\
\text { de perfuração), identificação de intervalos de perfuração } \\
\text { problemáticos, análise de fluido de perfuração (para revelar } \\
\text { mudanças nas condições do poço) e estudo de prevenção } \\
\text { de influxo de gás de formação. Os estudos serviram para a } \\
\text { geração de recomendações para operação resultando } \\
\text { redução de NPT e custos na operação. }\end{array}$ \\
\hline $\begin{array}{l}\text { (AMJAD ET AL., 2015; } \\
\text { JIANG; SAMUEL, 2016; } \\
\text { MANTHA; SAMUEL, 2016; } \\
\text { PEREZ-TELLEZ ET AL., } \\
\text { 2010; WIKTORSKI; } \\
\text { KUZNETCOV; SUI, 2017; } \\
\text { YAZIDI, 2013) }\end{array}$ & $\begin{array}{l}\text { Otimização de taxa de } \\
\text { penetração (ROP) } \\
\text { usando técnicas } \\
\text { estatística de regressão }\end{array}$ & $\begin{array}{l}\text { De acordo com os autores a otimização de perfuração é } \\
\text { uma estratégia de engenharia para perfurar os poços de } \\
\text { forma mais produtiva e eficiente. As publicações estão } \\
\text { relacionadas com o uso de técnicas estatísticas objetivando } \\
\text { a otimização e estimativa de taxas razoáveis de penetração } \\
\text { (ROP) para reduzir o tempo de perfuração, o custo e, } \\
\text { consequentemente, a descoberta precoce de petróleo e } \\
\text { gás. Os estudos destacaram o uso de regressão para } \\
\text { planejamento de trajetória de poço, estimar e determinar } \\
\text { parâmetros otimizados para a perfuração e vida útil das } \\
\text { brocas. Apresentam também os benefícios do uso de novas } \\
\text { tecnologias, na coleta de dados, combinadas com } \\
\text { diferentes campos da ciência, tais como, mineração de } \\
\text { dados, inteligência artificial e estatística, auxiliando na } \\
\text { tomada de decisão. }\end{array}$ \\
\hline
\end{tabular}

Fonte: 0 autor. 
Quadro 6 - Publicações relacionadas a regressão em Perfuração de Poços (continuação).

\begin{tabular}{|c|c|c|}
\hline REFERÊNCIA & APLICAÇÃO & RESUMO \\
\hline $\begin{array}{l}\text { (APONTE; TRUJILLO; } \\
\text { PRIMERA, 2016) }\end{array}$ & $\begin{array}{l}\text { Metodologia Aplicada } \\
\text { para Otimizar a } \\
\text { Sequência de } \\
\text { Intervenção em um } \\
\text { Campo de Petróleo } \\
\text { Maduro no Mar do Norte }\end{array}$ & $\begin{array}{l}0 \text { artigo apresenta uma metodologia para análises de } \\
\text { incertezas relacionadas com as intervenções em poços de } \\
\text { petróleo em campos maduros, buscando a maximizçãa da } \\
\text { produção através da seleção de uma sequência de } \\
\text { intervenções de workover (manutenção em poços). É } \\
\text { apresentado uma sequencias de atividades que passam } \\
\text { pela identificação de oportunidades, análise de viabilidades } \\
\text { econômicas e geração de modelos através regressão } \\
\text { multivariadas. }\end{array}$ \\
\hline $\begin{array}{c}\text { (EREN; OZBAYOGLU, } \\
\text { 2010) }\end{array}$ & $\begin{array}{c}\text { Otimização em Tempo } \\
\text { Real dos Parâmetros de } \\
\text { Perfuração Durante } \\
\text { Operações de } \\
\text { Perfuração }\end{array}$ & $\begin{array}{l}\text { De acordo com o autor a otimização em tempo real dos } \\
\text { parâmetros de perfuração visa reduzir os custos de } \\
\text { perfuração através da taxa máxima de perfuração. } \\
\text { Apresenta o uso de técnica de regressão linear múltipla, } \\
\text { para gerar uma taxa de penetração otimizada. Apresenta } \\
\text { uma questão de infraestrutura e processo, onde um } \\
\text { computador central fica continuamente recebendo os dados } \\
\text { e calculando os parâmetros do modelo e retornando os } \\
\text { resultados a equipe de campo. Assim, todo o processo é } \\
\text { otimizado em tempo real proporcionando tomadas de } \\
\text { decisões mais rápidas. }\end{array}$ \\
\hline (BELLO ET AL., 2016) & $\begin{array}{l}\text { Aplicação de Técnicas } \\
\text { de Inteligência Artificial } \\
\text { no Projeto e Operação } \\
\text { de Sistemas de } \\
\text { Perfuração }\end{array}$ & $\begin{array}{l}\text { O artigo ressalta o uso da Inteligência Artificial (IA) para a } \\
\text { simplificação de procedimentos complexos de tomada de } \\
\text { decisão, envolvendo o uso de ferramentas de rede } \\
\text { sofisticadas e algoritmos na solução de problemas. } 0 \text { autor } \\
\text { sugere que as técnicas, incluindo as de regressão, vem para } \\
\text { atender a lacuna tecnológica que impedem a execução } \\
\text { automatizada e monitoramento dos principais } \\
\text { procedimentos de simulação, perfuração e completação de } \\
\text { reservatórios, diagnóstico de brocas, estimativa de queda } \\
\text { de pressão, otimização de produção de poços, projeção de } \\
\text { desempenho de poços, entre outros. Agregando assim par } \\
\text { a uma tomada de decisão rápida e lógica em operações de } \\
\text { perfuração críticas e caras. }\end{array}$ \\
\hline (WILSON, 2017) & $\begin{array}{c}\text { Técnicas de } \\
\text { processamento de } \\
\text { linguagem natural para } \\
\text { dados de perfuração de } \\
\text { petróleo e gás }\end{array}$ & $\begin{array}{l}\text { O artigo aborda sobre que os avanços recentes em } \\
\text { pesquisa, aprendizado de máquina e processamento de } \\
\text { linguagem natural tornaram possível extrair informações } \\
\text { estruturadas de texto livre, fornecendo uma nova e } \\
\text { amplamente inexplorada fonte de insights para o } \\
\text { planejamento de poços e reservatórios. Apresenta um } \\
\text { método, de classificação utilizado regressão logística, para } \\
\text { comparar a distribuição de riscos hipotéticos e realizados } \\
\text { para poços de petróleo descritos em dois conjuntos de } \\
\text { dados que contêm descrições de riscos em texto livre. }\end{array}$ \\
\hline
\end{tabular}

Fonte: 0 autor. 
Quadro 6 - Publicações relacionadas a regressão em Perfuração de Poços (continuação).

\begin{tabular}{|c|c|c|}
\hline REFERÊNCIA & APLICAÇÃO & RESUMO \\
\hline $\begin{array}{l}\text { (Ll; KURU, 2004; } \\
\text { PETERSEN, 2015) }\end{array}$ & $\begin{array}{l}\text { Previsão da velocidade } \\
\text { de transporte de } \\
\text { resíduos }\end{array}$ & $\begin{array}{l}\text { A limpeza do poço é uma das principais preocupações e } \\
\text { desafios durante a perfuração de poços. Limpeza } \\
\text { insuficiente dos poços pode causar vários problemas, como } \\
\text { aumento do ECD, torque excessivo, empilhamento, } \\
\text { problemas de cimentação, prisão de coluna, entre outros. } \\
\text { Os artigos apresentam estudos, baseados em estáticas, } \\
\text { para determinas a velocidade do fluido de transporte } \\
\text { exigida. Os efeitos dos principais parâmetros de perfuração } \\
\text { na velocidade do fluido também foram investigados. }\end{array}$ \\
\hline (WISNIE; ZHU, 1994) & $\begin{array}{l}\text { Quantificação do risco } \\
\text { de prisão de coluna }\end{array}$ & $\begin{array}{l}\text { A prisão de coluna é um dos riscos mais dispendiosos da } \\
\text { perfuração, segundo o autor. } 0 \text { artigo descreve um método } \\
\text { para a quantificação econômica para serem incorporado } \\
\text { nos projetos. O método envolve a coleta de dados e a partir } \\
\text { desses dados é aplicada uma regressão logística para } \\
\text { construir modelos de probabilidade que são incorporados } \\
\text { outra simulação de Monte Carlo. }\end{array}$ \\
\hline (DAVID, 2016) & $\begin{array}{c}\text { Abordagem para } \\
\text { estabelecer o ambiente } \\
\text { de análise de dados } \\
\text { para permitir decisões } \\
\text { de operações orientadas } \\
\text { a dados }\end{array}$ & $\begin{array}{l}\text { O artigo apresenta como uma plataforma integrada de } \\
\text { análise de dados permite a integração de fluxos de trabalho } \\
\text { de E\&P e análise de dados para melhorar o monitoramento } \\
\text { das operações, prever a produtividade de poços, identificar } \\
\text { padrões de desempenho e } \mathrm{KPI} \text {, melhorar o fator de } \\
\text { recuperação do reservatório e prever falhas de } \\
\text { equipamentos, para atingir o objetivo de otimização } \\
\text { contínua do desempenho do campo petrolífero. }\end{array}$ \\
\hline $\begin{array}{c}\text { (ABALIOGLU ET AL., } \\
\text { 2011; DRAOU; } \\
\text { OSISANYA, 2000) }\end{array}$ & $\begin{array}{l}\text { Estimar das pressões de } \\
\text { formaçãa }\end{array}$ & $\begin{array}{l}\text { A previsão de pressões de poros é essencial para a } \\
\text { perfuração de poços profundos com pressões de poros } \\
\text { maiores do que o normal. Os trabalhos relacionados fazem } \\
\text { o uso de técnicas de regressão para definição destas } \\
\text { estimativas de pressão. Como resultados os custos e } \\
\text { problemas de perfuração podem ser reduzidos } \\
\text { substancialmente pelo reconhecimento precoce de } \\
\text { pressões de poros anormalmente altas. }\end{array}$ \\
\hline $\begin{array}{c}\text { (AL-HAMEEDI ET AL., } \\
\text { 2017) }\end{array}$ & $\begin{array}{l}\text { Controle das perdas de } \\
\text { fluido de perfuração }\end{array}$ & $\begin{array}{l}\text { A perda de circulação é um problema desafiador segundo o } \\
\text { autor. Os engenheiros de perfuração são desafiados a } \\
\text { selecionar o valor ideal para os principais parâmetros de } \\
\text { perfuração para mitigar as perdas do fluido. Muitos desses } \\
\text { parâmetros de perfuração estão inter-relacionados e o } \\
\text { impacto geral da alteração dos parâmetros-chave requer } \\
\text { uma experiência de perfuração ou estudo extensivo. O autor } \\
\text { apresenta um estudo baseado e uma análise de regressão } \\
\text { múltipla com dados de eventos de perda de fluido de } \\
\text { perfuração e a partir dessa análise, um modelo foi } \\
\text { desenvolvido para prever perdas totais de lama. }\end{array}$ \\
\hline (ORIJI; DOSUNMU, 2012) & $\begin{array}{l}\text { Projeto e aplicação de } \\
\text { fluidos de perfuração } \\
\text { para poço com alta } \\
\text { pressão e alta } \\
\text { temperatura (HPHT) }\end{array}$ & $\begin{array}{l}\text { O autor ressalta a importância de se projetar um sistema de } \\
\text { fluido de perfuração para poços HPHT (High Pressure, High } \\
\text { Temperature) de maneira econômica e com problemas } \\
\text { operacionais mínimos. No estudo, as práticas } \\
\text { convencionais de projetos foram revisadas sendo muitas } \\
\text { consideradas inadequadas para a perfuração de HPHT. As } \\
\text { equações modelos derivadas da análise de regressão } \\
\text { múltipla foram usadas para prever e classificar as melhores } \\
\text { propriedades reológicas para o campo. }\end{array}$ \\
\hline
\end{tabular}

Fonte: 0 autor. 
Métodos computacionais trazem um grande auxílio na análise e interpretação de dados de perfuração, podendo integrar dados de diversas bases e formatos em tempo quase real. Isto permite um maior acesso a informações, possibilitando ajustes contínuos nas operações e uma tomada de decisão mais precisa e rápida. A utilização de métodos de regressão para estimar tendências e propriedades é uma realidade de em diversos segmentos da área de E\&P (Exploração e Produção). Novos métodos e tecnologias são catalizadores para o emprego de ciência de dados (Data Science) na indústria do petróleo.

Conforme demonstrado, muitos estudos mostram um boa aplicabilidade de técnicas de análise estatística multivariada no processo de interpretação de dados de perfuração, buscando melhores números para os processos, como, por exemplo, na redução dos custos de perfuração, por meio da otimização do tempo gasto nas fases da construção de poços, (MANTHA; SAMUEL, 2016). Outros estudos, em que também são aplicadas técnicas de estatística multivariada, estão relacionados a busca na otimização nos parâmetros de perfuração (EREN; OZBAYOGLU, 2010). Conforme Jovic (2013), o uso de métodos estatísticos com dados corretamente identificados, pode ajudar as empresas a impulsionar seus negócios com base em uma tomada de decisão mais qualificada. 


\section{DESENVOLVIMENTO DA SOLUÇÃO CRISP-DM}

Este capítulo apresenta os procedimentos e metodologias adotados para 0 desenvolvimento da dissertação, descrevendo a abordagem seguida para desenvolvimento da solução computacional.

A natureza da dissertação, de descoberta de conhecimento em dados, pode remeter inicialmente à ideia da utilização de uma metodologia tradicional para o planejamento e desenvolvimento de softwares, porém a descoberta de conhecimentos em base de dados possui características próprias. Existem especificidades quando o trabalho é relacionado para Big Data e demais cenários que envolvam processos conexos à análise de grandes volumes de dados. Algumas metodologias, que visam cobrir estas lacunas dos processos tradicionais, foram destacadas no Capítulo 3.

Para o desenvolvimento desta dissertação foi selecionada uma metodologia desenhada para processos de mineração de dados, a CRISP-DM (Cross Industry Standard Process for Data Mining). A seleção se deu principalmente pelo seu caráter interativo entre as 6 (seis) etapas salientadas no item 3.4, quais sejam: compreensão do negócio, compreensão dos dados, preparação dos dados, modelagem, avaliação e implantação.

Para efetuar as manipulações de dados nas etapas compreensão dos dados, preparação dos dados, modelagem e avaliação, foi utilizada a linguagem de programação $\operatorname{Python}^{\circledR}$, na versão 3.6, além de alguns pacotes predefinidos de manipulação de dados e tratamento de dados estatísticos. Uma versão inicial da solução é apresentada no item 5.6.1, onde também estão concentrados os códigos de programação. Importante ressaltar que não foi o foco da pesquisa o uso da tecnologia. Desta forma, não serão detalhados ou explicados tecnicamente os comandos e/ou funcionalidades da linguagem de programação utilizada.

Este capítulo está organizado de acordo com os processos da metodologia, conforme o Quadro 7, as interações entre as etapas estão detalhadas dentro de cada tópico, mais especificamente entre as etapas de preparação dos dados e modelagem. 
Quadro 7 - Processo no desenvolvimento da solução.

\begin{tabular}{|c|c|}
\hline $\begin{array}{c}\text { Compreensão } \\
\text { do Negócio }\end{array}$ & $\begin{array}{l}\text { - Descreve o problema estudado; } \\
\text { - O problema de prisão de coluna de perfuração e o impacto no negócio; } \\
\text { - Método utilizado para avaliação dos resultados. }\end{array}$ \\
\hline & $\begin{array}{l}\text { - Descreve a fonte de dados (dataset) utilizado para o desenvovimento; } \\
\text { - Detalhamento das variáveis existentes na amostra; } \\
\text { - Análise exploratória dos dados, considerando dados faltantes, balanceamento } \\
\text { da variáveis alvo, escalas dos dados e distrinuição dos valores e análise de } \\
\text { correlações. }\end{array}$ \\
\hline & $\begin{array}{l}\text { - Detalha os procedimentos adotados para o tratamento dos dados, de acordo } \\
\text { com as decobertas na fase de compreensão dos dados; } \\
\text { - Descreve as interações com a fase de modelagem; } \\
\text { - Processo e detalhamento das principais variáveis para o modelo. }\end{array}$ \\
\hline Model & $\begin{array}{l}\text { - Apresenta as interações executadas com a etapa anterior de preparação dos } \\
\text { dados; } \\
\text { - Informa procedimento de validação do modelo adotado com as variáveis } \\
\text { selecionadas e descreve os resultados. }\end{array}$ \\
\hline Avaliação & $\begin{array}{l}\text { - Expõe os resultados quantidativos do modelo apresentados para avaliação; } \\
\text {-Apresenta a análise dos coeficientes de acurácia e precisão do modelo, } \\
\text { assim como uma discussão sobre os resultados para o negócio. }\end{array}$ \\
\hline Implantação & $\begin{array}{l}\text {-Apresentada a solução computacional gerada, versão inicial (protótipo); } \\
\text { - Apresenta atividades que podem ser aplicadas para a melhoria no modelo de } \\
\text { classificação e atividades para a implantação da solução sistemica; } \\
\text {-Apresenta os códigos gerados pelo estudo. }\end{array}$ \\
\hline
\end{tabular}

Fonte: o autor.

A dissertação apresentou algumas interações entre as etapas de preparação dos dados e a etapa de modelagem. Porém, a metodologia, conforme informado anteriormente, proporciona a possibilidade de outras interações. Ainda na etapa de compreensão do negócio, a interação entre compreensão dos dados e a compreensão do negócio é fundamental para a identificação das principais fontes de dados e dos próprios dados que serão utilizados. A interação entre a preparação dos dados e a modelagem, conforme foi utilizada nesta pesquisa, tem uma função importante de busca do melhor resultado para o modelo com o tratamento dos dados. A interação 
entre a avalição dos resultados e o entendimento do negócio está relacionada com a análise dos objetivos do negócio. Por fim, após a implantação, o processo pode se repetir como um ciclo PDCA (Plan, Do, Check, Act/Adjust), que pode levar à geração de outros projetos e/ou versões do mesmo.

\subsection{COMPREENSÃO DO NEGÓCIO}

A primeira etapa do projeto de descoberta de conhecimento em dados, utilizando a metodologia CRISP-DM, está focada no entendimento do negócio e dos objetivos pretendidos. Deve-se detalhar qual o problema que se quer resolver e porque isto é importante para o negócio.

Conforme Provost e Fawcett (2013), para os projetos de ciência de dados agregarem valor para as organizações, é importante que os cientistas de dados avaliem o que gostariam de alcançar com a mineração de dados e conectar os resultados com as metas das organizações.

Como descrito nos objetivos desta dissertaçaõ, o problema a ser trabalhado está relacionado com prisão de coluna de perfuração, de um modo geral, na fase de construção de um poço de petróleo marítimo perfurado no polígono do pré-sal. Os impactos de anormalidades nesta fase podem ser catastróficos de acordo com os riscos envolvidos, conforme visto no item 2.6. A prisão de coluna é um evento que pode causar atrasos e custos extras nas tentativas de retomar a perfuração gerando NPT.

Segundo Muqeen, Weekse e Al-Hajji (2012), a prisão de coluna corresponde a $25 \%$ do NPT, pois são necessárias diversas manobras não planejadas para tentar liberar a coluna, assim como equipamentos e serviços especiais. Em casos mais extremos, pode levar à necessidade de abandono do poço definitivamente. Além disto, custos diários de sonda representam uma parcela considerável do gasto total na construção de um poço, principalmente em operações offshore; desta forma a eliminação ou a minimização do NPT é algo desejável em todas as operações.

De acordo com as diversas possibilidades e técnicas de aplicação de IA disponibilizadas para análise do problema em estudo, esta dissertação está delimitada à avaliação de aplicabilidade da técnica de regressão na identificação de padrões de anomalias do tipo prisão de coluna, na fase de perfuração. A revisão, da literatura, da aplicação desta técnica no contexto estudado encontra-se detalhada no Capítulo 4. 
Conforme destacado, anteriormente, a fase de perfuração de um poço é uma das mais onerosas financeiramente no processo de extração de petróleo. Qualquer iniciativa que possa reduzir os NTP, diretamente ligados aos custos de construção, agregam valor para a indústria do petróleo. A avalição dos resultados obtidos com este modelo se dará pela precisão do classificador e com uma matriz de confusão, que visa decompor e contar os acertos e erros do modelo, como será visto na etapa de avaliação.

\subsection{COMPREENSÃO DOS DADOS}

A fase de compreensão dos dados é fundamental para alcançar os objetivos pretendidos da pesquisa, pois estes dados são a matéria-prima sobre a qual a solução vai ser construída. Os processos de coleta de dados nas organizações são, na maioria das vezes, genéricos, ou seja, coletam a maior quantidade de dados dos mais diversos sistemas. Estes dados, então, são disponibilizados para diversos fins, desde acompanhamento e análises operacionais até análises de gestão e custo. Portanto, é importante mapear os dados que realmente fazem relação com a questão que se pretende resolver, seus pontos fortes e correspondências com os objetivos pretendidos. Para este fim, a visão do especialista é fundamental com o auxílio de técnicas estatísticas.

Para esta dissertação, foi utilizada uma base de dados disponibilizada pela Agência Nacional do Petróleo, Gás Natural e Biocombustíveis (ANP), por meio de um projeto de pesquisa de desenvolvimento e inovação (PD\&I), contendo um conjunto de dados de perfuração de poços de petróleo do polígono do pré-sal, na costa brasileira. Por questões de confidencialidade de dados, os nomes dos poços foram omitidos neste estudo, sendo classificados como amostra 1 a 7.

O conjunto de dados disponibilizado para a pesquisa foi submetido a tratamento prévio, conforme indicado nos itens a seguir.

\subsubsection{Fontes de Dados}

Foram identificadas duas principais fontes de dados para o estudo, a primeira relacionada com os registros de dados operacionais em tempo real, responsável pela coleta das informações dos sistemas de Superfície e Poço (Sondagem, MWD, 
Mudlogging e LWD) e do sistema responsável para registro dos boletins diários de perfuração.

Os arquivos foram disponibilizados em formato CSV (comma-separated values), arquivos formato texto com os campos separados por virgulas. Cada arquivo contém os dados de um poço específico, totalizando 7 (sete) poços. Os dados referentes aos boletins diários de operação não foram utilizados, pois, conforme será visto no item 5.2.3, a necessidade deles foi incorporada na amostragem disponibilizada.

\subsubsection{Limpeza dos dados faltantes}

No contexto de dados de superfície e poço, a quantidade de dados é oriunda de sistemas e sensores diversos. Como se trata de um ambiente em que alguns sistemas podem falhar ou até mesmo não existir, em alguns casos não é possível garantir que, para todas as amostras (poços) coletadas, todos os dados estarão disponíveis. Assim, faz-se necessária uma análise para identificar quais variáveis (features), a serem trabalhadas no modelo, estarão realmente presentes.

Para esta análise, foi empregada a estratégia de exame dos dados existentes em todas as amostras apresentadas (dados de poços perfurados), eliminando previamente as variáveis que excedessem mais de $70 \%$ de dados faltantes.

No final desta etapa, seguindo esta condição, restaram, em todas as amostras apresentadas, 23 variáveis mais a variável de registro da data e hora. A variável de data e hora foi essencial para os tratamentos da próxima etapa, identificação do dado de estudo (variável alvo).

\subsubsection{Identificação do dado de estudo (variável alvo)}

Uma outra atividade executada previamente no conjunto de dados (dataset) disponibilizado foi a identificação, em cada amostra dos poços, dos registros relativos ao evento de prisão de coluna. Na extensão dos dados, oriundos dos sistemas de Sondagem, MWD, Mudlogging e LWD, normalmente disponibilizados em intervalos de 5 segundos, se encontram os dados relativos ao estudo. Para treinamento do método computacional selecionado, é imperativo que estes dados sejam devidamente identificados. Por um outro lado, o sistema de registro de boletim diário (Item 2.5.1) 
possui esta informação descritivamente informada pelo operador da Sonda. A granularidade desta informação é diferente da encontrada nos sistemas de tempo real geradores dos dados para o estudo. A maioria dos dados indicam que os registros são armazenados em intervalos maiores que 5 segundos, sendo 10 minutos, 30 minutos e até mesmo na escala de horas.

Para solucionar esta questão, o conjunto de dados foi trabalhado por especialista em perfuração, em um processo no qual os dados oriundos dos sistemas de tempo real foram analisados e cruzados com os dados de boletins diários. Com este cruzamento foi possível reduzir a quantidade necessária para efetuar a análise e identificar os pontos em que se encontravam os dados de prisão de coluna.

A identificação do dado foi efetuada através da criação de uma variável para efetuar registro de eventos de prisão, chamada binary_class. Os valores atribuídos para esta variável foram "1" (um) e "2" (dois), respectivamente para "operação normal” e "coluna presa".

\subsubsection{Análise qualitativa da amostra}

Para o melhor entendimento, o Quadro 8 apresenta uma breve descrição de cada variável recebida no conjunto de dados.

Quadro 8 - Descrição das variáveis da amostra.

\begin{tabular}{|c|c|c|c|c|}
\hline Variável & $\begin{array}{l}\text { Variável na } \\
\text { amostra }\end{array}$ & Grupo & Sistema & Descrição da Variável \\
\hline Pressão no anular & $\begin{array}{l}\text { annulus_pressure_ } \\
\text { filtered }\end{array}$ & $\begin{array}{c}\text { Poço } \\
\text { (Downhole) }\end{array}$ & MWD & $\begin{array}{l}\text { Pressão do fluido no anular entre o tubo e } 0 \\
\text { revestimento ou entre duas cadeias de } \\
\text { revestimento. }\end{array}$ \\
\hline $\begin{array}{c}\text { Frequência de rotação } \\
\text { da broca } \\
\text { (RPM - Rotation per } \\
\text { minute })\end{array}$ & bit_rotary_speed & $\begin{array}{c}\text { Poço } \\
\text { (Downhole) }\end{array}$ & MWD & $\begin{array}{l}\text { Variável é uma composição entre o número de } \\
\text { rotações da coluna somado com o número de } \\
\text { rotações do motor de fundo ou turbina, por } \\
\text { unidade de tempo. }\end{array}$ \\
\hline $\begin{array}{l}\text { Altura do bloco/gancho } \\
\text { (Block/Hook Height) }\end{array}$ & $\begin{array}{l}\text { block_position_ } \\
\text { filtered }\end{array}$ & Superfície & $\begin{array}{l}\text { Sondagem, } \\
\text { MWD, } \\
\text { Mudlogging }\end{array}$ & $\begin{array}{l}\text { Variável mede a altura do bloco em relação a } \\
\text { mesa rotativa. }\end{array}$ \\
\hline $\begin{array}{l}\text { Torque no fundo } \\
\text { (TOB - Torque on } \\
\text { Bottom) }\end{array}$ & $\begin{array}{l}\text { bottom_torque_ } \\
\text { filtered }\end{array}$ & $\begin{array}{c}\text { Poço } \\
(\text { Downhole })\end{array}$ & MWD & Torque na broca medido no fundo do poço. \\
\hline $\begin{array}{l}\text { Peso sobre a broca no } \\
\text { fundo } \\
\text { (WOB - Weight on Bit) }\end{array}$ & $\begin{array}{l}\text { bottom_weight_ } \\
\text { on_bit_filtered }\end{array}$ & $\begin{array}{c}\text { Poço } \\
\text { (Downhole) }\end{array}$ & MWD & $\begin{array}{l}\text { Peso dos tubos e equipamentos sobre a broca } \\
\text { medido no fundo do poço }\end{array}$ \\
\hline
\end{tabular}

Fonte: (IBP et al., 2018; PETROWIKI, 2018; SCHLUMBERGER, 2018). 
Quadro 8 - Descrição das variáveis da amostra (continuação).

\begin{tabular}{|c|c|c|c|c|}
\hline Variável & $\begin{array}{c}\text { Variável na } \\
\text { amostra }\end{array}$ & Grupo & Sistema & Descrição da Variável \\
\hline $\begin{array}{l}\text { Densidade equivalente } \\
\text { durante circulação } \\
\text { (ECD - Equivalent } \\
\text { Circulating Density) }\end{array}$ & $\begin{array}{l}\text { equivalent_ } \\
\text { circulating_ } \\
\text { density }\end{array}$ & $\begin{array}{c}\text { Poço } \\
\text { (Downhole) }\end{array}$ & MWD & $\begin{array}{l}\text { Densidade efetiva exercida pelo fluido circulante } \\
\text { contra a formação que leva em consideração a } \\
\text { queda de pressão no anular acima do ponto } \\
\text { considerado. O ECD é um parâmetro importante } \\
\text { para evitar kicks e perdas, particularmente em } \\
\text { poços que possuem uma janela estreita entre o } \\
\text { gradiente de fratura e o gradiente de pressão de } \\
\text { poros. }\end{array}$ \\
\hline Vazão total & fluid_flow_filtered & Superfície & $\begin{array}{l}\text { Sondagem, } \\
\text { MWD, } \\
\text { Mudlogging }\end{array}$ & Vazão total do fluido de perfuração do poço. \\
\hline $\begin{array}{l}\text { Temperatura do fluido de } \\
\text { perfuração na saída do } \\
\text { poço } \\
\text { (Temperature inlet and } \\
\text { outlet) }\end{array}$ & $\begin{array}{l}\text { fluid_output_ } \\
\text { temperature_filtered }\end{array}$ & Superfície & Mudlogging & $\begin{array}{l}\text { Temperatura medida na saída dos tanques de } \\
\text { lama para o poço. }\end{array}$ \\
\hline $\begin{array}{l}\text { Profundidade medida } \\
\text { da broca compensada } \\
\text { pelo heave } \\
\text { (Heave Compensator) }\end{array}$ & heave_bit_depth & Superfície & $\begin{array}{l}\text { Sondagem, } \\
\text { MWD, } \\
\text { Mudlogging }\end{array}$ & $\begin{array}{l}\text { Variável indica a profundidade atual da broca } \\
\text { descontando as oscilações verticais ocorridas } \\
\text { na sonda devido a maré e onda do mar. }\end{array}$ \\
\hline $\begin{array}{l}\text { Profundidade medida do } \\
\text { poço } \\
\text { (MD - Measured Depth) }\end{array}$ & hole_depth_filtered & Superfície & $\begin{array}{l}\text { Sondagem, } \\
\text { MWD, } \\
\text { Mudlogging }\end{array}$ & $\begin{array}{l}\text { Variável indica a profundidade atual do poço de } \\
\text { acordo com a distância perfurada desde a } \\
\text { origem. O acompanhamento do avanço da } \\
\text { operação de perfuração é realizado através } \\
\text { deste parâmetro. }\end{array}$ \\
\hline $\begin{array}{l}\text { Frequência de rotação } \\
\text { da turbina } \\
\text { (RPM - Rotation per } \\
\text { minute) }\end{array}$ & $\begin{array}{l}\text { Iwd_rotary_speed_ } \\
\text { filtered }\end{array}$ & $\begin{array}{c}\text { Poço } \\
\text { (Downhole) }\end{array}$ & MWD & Rotação da turbina por minuto. \\
\hline $\begin{array}{l}\text { Volume de fluido de } \\
\text { perfuração nos tanques } \\
\text { (Mud Pit) }\end{array}$ & pit_volume_filtered & Superfície & Mudlogging & $\begin{array}{l}\text { Combina todos os indicadores individuais de } \\
\text { volume total de fluido de perfuração nos } \\
\text { tanques. }\end{array}$ \\
\hline $\begin{array}{l}\text { Contador de pulsos da } \\
\text { bomba } 1\end{array}$ & $\begin{array}{l}\text { pump_strokes_ } \\
\text { 1_filtered }\end{array}$ & Superfície & $\begin{array}{l}\text { Sondagem, } \\
\text { MWD, } \\
\text { Mudlogging }\end{array}$ & Número de pulsos gerados pela primeira bomba. \\
\hline $\begin{array}{l}\text { Contador de pulsos da } \\
\text { bomba } 2\end{array}$ & $\begin{array}{l}\text { pump_strokes_ } \\
\text { 2_filtered }\end{array}$ & Superfície & $\begin{array}{l}\text { Sondagem, } \\
\text { MWD, } \\
\text { Mudlogging }\end{array}$ & $\begin{array}{l}\text { Número de pulsos gerados pela segunda } \\
\text { bomba. }\end{array}$ \\
\hline $\begin{array}{l}\text { Contador de pulsos da } \\
\text { bomba } 3\end{array}$ & $\begin{array}{l}\text { pump_strokes_ } \\
\text { 3_filtered }\end{array}$ & Superfície & $\begin{array}{l}\text { Sondagem, } \\
\text { MWD, } \\
\text { Mudlogging }\end{array}$ & Número de pulsos gerados pela terceira bomba. \\
\hline $\begin{array}{c}\text { Taxa de penetração } \\
\text { (ROP-Rate of } \\
\text { Penetration) }\end{array}$ & rate_of_penetration & Superfície & $\begin{array}{l}\text { Sondagem, } \\
\text { MWD, } \\
\text { Mudlogging }\end{array}$ & $\begin{array}{l}\text { Variável representa a taxa de perfuração do } \\
\text { poço, medida em unidades de comprimento por } \\
\text { unidades de tempo. }\end{array}$ \\
\hline $\begin{array}{c}\text { Frequência de rotação } \\
\text { da coluna de perfuração } \\
\text { (RPM - Rotation per } \\
\text { minute) }\end{array}$ & $\begin{array}{l}\text { rotary_speed_ } \\
\quad \text { filtered }\end{array}$ & Superfície & Sondagem & $\begin{array}{l}\text { Variável indica o número de rotações da coluna } \\
\text { na superfície por unidade de tempo. }\end{array}$ \\
\hline
\end{tabular}

Fonte: (IBP et al., 2018; PETROWIKI, 2018; SCHLUMBERGER, 2018). 
Quadro 8 - Descrição das variáveis da amostra (continuação).

\begin{tabular}{|c|c|c|c|c|}
\hline Variável & $\begin{array}{c}\text { Variável na } \\
\text { amostra }\end{array}$ & Grupo & Sistema & Descrição da Variável \\
\hline $\begin{array}{l}\text { Pressão nas linhas de } \\
\text { superfície } \\
\text { (SPP - Stand Pipe } \\
\text { Pressure) }\end{array}$ & $\begin{array}{l}\text { standpipe_pressure_ } \\
\text { filtered }\end{array}$ & Superfície & $\begin{array}{l}\text { Sondagem, } \\
\text { MWD, } \\
\text { Mudlogging }\end{array}$ & $\begin{array}{l}\text { Variável mede a pressão nas linhas de } \\
\text { superfície da sonda, qualquer variação no poço } \\
\text { ou na superfície pode ser identificado por esta } \\
\text { medição, pois o sistema de fluido é fechado. }\end{array}$ \\
\hline Vibração stick slip & stick_slip_filtered & $\begin{array}{c}\text { Poço } \\
(\text { Downhole })\end{array}$ & MWD & $\begin{array}{l}\text { Condição caracterizada por flutuações na } \\
\text { velocidade de rotação do BHA. }\end{array}$ \\
\hline Torque na superfície & torque_filtered & Superfície & Sondagem & $\begin{array}{l}\text { Variável mede o torque aplicado na coluna para } \\
\text { retirar a mesma da inércia e aplicar rotação } \\
\text { necessária para operação. }\end{array}$ \\
\hline $\begin{array}{l}\text { Volume de fluido de } \\
\text { perfuração nos tanques } \\
\text { (Mud Pit) }\end{array}$ & $\begin{array}{l}\text { total_pit_volume_ } \\
\text { filtered }\end{array}$ & Superfície & Mudlogging & $\begin{array}{l}\text { Volume total de fluido de perfuração nos } \\
\text { tanques. }\end{array}$ \\
\hline $\begin{array}{l}\text { Peso sobre a broca } \\
\text { (WOB - Weight on Bit) }\end{array}$ & $\begin{array}{l}\text { weight_on_bit_ } \\
\text { filtered }\end{array}$ & Superfície & $\begin{array}{l}\text { Sondagem, } \\
\text { MWD, } \\
\text { Mudlogging }\end{array}$ & Peso sobre a broca, medido na superfície. \\
\hline $\begin{array}{l}\text { Peso no gancho } \\
\text { (Hook load) }\end{array}$ & $\begin{array}{l}\text { weight_on_hook_ } \\
\text { filtered }\end{array}$ & Superfície & $\begin{array}{l}\text { Sondagem, } \\
\text { MWD, } \\
\text { Mudlogging }\end{array}$ & $\begin{array}{l}\text { A força total de puxo para baixo no gancho. } \\
\text { Inclui o peso da coluna de perfuração no ar, os } \\
\text { colares de perfuração e qualquer equipamento } \\
\text { auxiliar. }\end{array}$ \\
\hline Data e hora do registro & time & $\begin{array}{l}\text { Superfície e } \\
\quad \text { Poço } \\
\text { (Downhole) }\end{array}$ & $\begin{array}{l}\text { Sondagem, } \\
\text { MWD, } \\
\text { Mudlogging }\end{array}$ & $\begin{array}{l}\text { Registro data e hora do evento registrado. Existe } \\
\text { um para cada sistema e estes devem estar } \\
\text { devidamente sincronizados. }\end{array}$ \\
\hline $\begin{array}{l}\text { Identifica o registro de } \\
\text { Prisão }\end{array}$ & binary_class & Gerada & Gerada & $\begin{array}{l}\text { Valores correspondentes para classificação dos } \\
\text { dados em: } 1 \text { (um) "operação normal" e } 2 \text { (dois) } \\
\text { "coluna presa". }\end{array}$ \\
\hline
\end{tabular}

Fonte: (IBP et al., 2018; PETROWIKI, 2018; SCHLUMBERGER, 2018).

\subsubsection{Análise quantitativa da amostra}

A amostra disponibilizada de dados de tempo real foi relativa a 7 poços com dados de perfuração em campos da costa brasileira do polígono do Pré-sal. A Figura 25 apresenta quantitativamente a distribuição destes dados.

Figura 25 - Quantidade de registro da amostra.

\section{Quatidade de Registros}

358.634

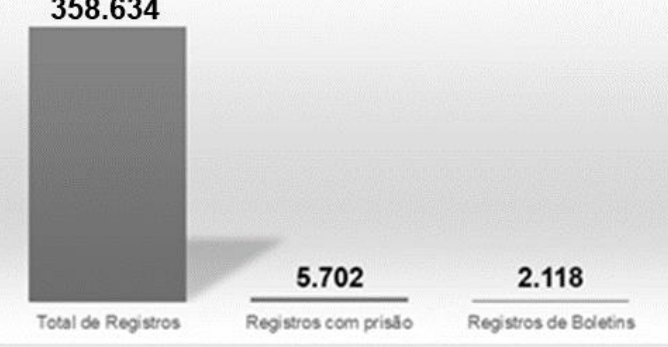

Fonte: $\mathrm{O}$ autor. 
Pode se notar que, apesar de o impacto do evento prisão de coluna ser grande para a operação e o NPT, a quantidade de registros identificados com prisão de coluna são muito inferiores, se comparados com o total de registros da amostra. Se comparados com os dados de boletins diários, também é comprovada a grande diferença na granularidade das informações. Vale destacar que os registros totais são referentes a somente à fase de perfuração no sal e os registros dos boletins estão relacionados a todas as fases de perfuração.

\subsubsection{Análise exploratória dos dados}

A análise exploratória de dados é uma abordagem descritiva para obter um maior entendimento dos dados, por meio da análise dos conjuntos dos dados, de modo a resumir suas características principais.

Somente foram analisados os dados oriundos dos sensores de superfície e poço (downhole). Os dados referentes aos boletins diários de operação apenas foram utilizados para a identificação dos registros alusivos à prisão de coluna de perfuração, conforme descrito no item 5.2.3.

As variáveis são apresentadas como quantitativas (numéricas) e contínuas, a exceção da variável "Identifica o registro de Prisão", que aponta os registros com prisão de coluna (identificada como binary_class no conjunto de dados). Apesar do conteúdo numérico, esta variável é utilizada para classificar os registros em operação normal (representado pelo número 1 - um) e coluna presa (representado pelo número 2-dois). Um ponto importante foi a transposição desta variável para classificação binária, assim representando a ocorrência de eventos de prisão o valor 1 (um) e para os eventos de operação normal, ou seja, sem prisão o valor 0 (zero).

Também foram efetuadas análises no conjunto de dados para efetuar a identificação do quantitativo de variáveis nulas na amostragem disponibilizada, a análise de balanceamento da variável alvo, o entendimento das escalas dos dados e correlações destas variáveis. As análises são dispostas a seguir.

\subsubsection{Análise de variáveis nulas e faltantes}

A Figura 26 apresenta a análise das variáveis nulas ou faltantes do conjunto de dados. O resultado desta análise define o método de tratamento a ser dado aos 
dados nulos ou inválidos para a fase de Preparação dos Dados. Pode se observar que, apesar do conjunto de dados já ter sido previamente trabalhado, existe uma considerável ausência de dados que devem ser tratados.

Figura 26- Análise de dados nulos e faltantes.

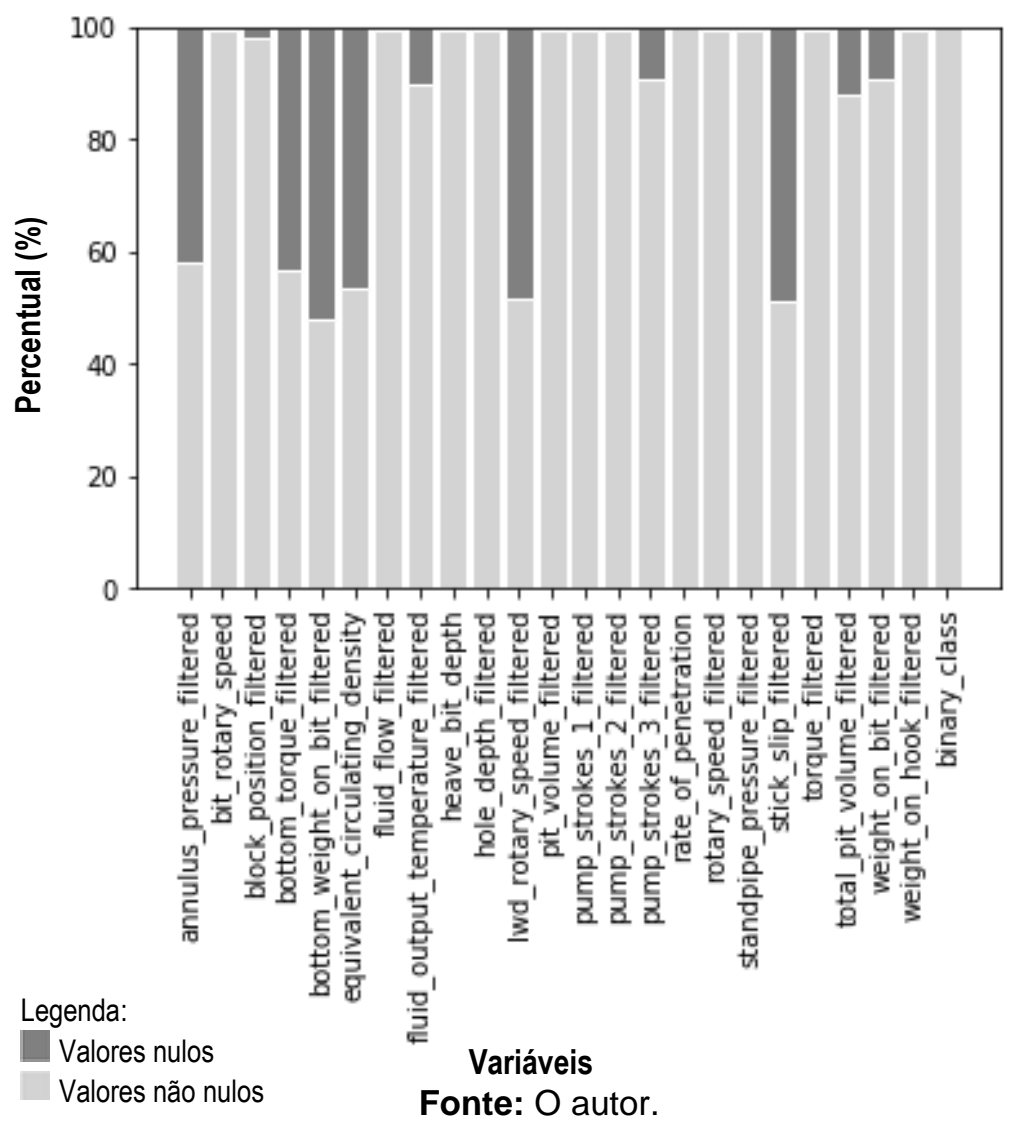

5.2.6.2. Análise de balanceamento da variável alvo

Outro aspecto observado nos dados, conforme a Figura 27, está relacionado com a análise de balanceamento da variável alvo, comparando com o total de registros. A quantidade de registros selecionados como registros de prisão de coluna é cerca de somente $2 \%$ do total de registros da amostra. Isto indica uma possível necessidade de tratamento do dataset para não prejudicar os resultados na fase da modelagem. 
Figura 27 - Análise de balanceamento da variável alvo.

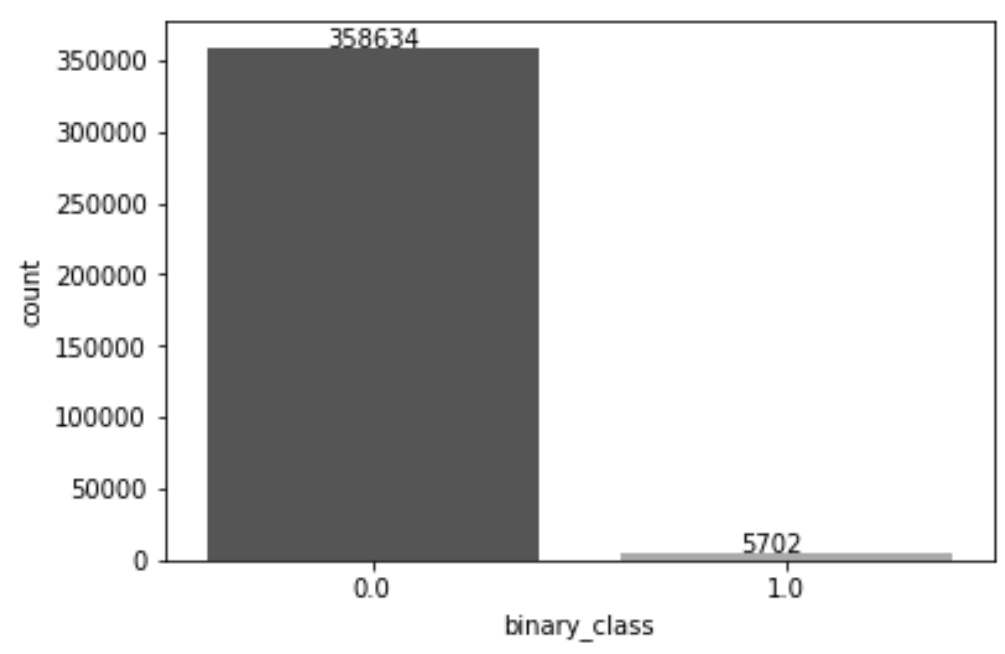

Fonte: O autor.

\subsubsection{3. $\quad$ Análise de distribuição dos dados}

A análise da distribuição dos valores de cada variável é importante para entender as suas escalas no conjunto de dados a ser utilizado e analisar os intervalos que as variáveis podem trabalhar. A natureza dos dados, relacionada a poços distintos, pode impor grandezas diferentes de valores de um poço para o outro, colocando um dado normal em uma amostragem como anormal em outra amostragem. A Figura 28 apresenta o resultado desta análise. O resultado desta análise apresenta a escala de cada variável, recebida no conjunto de dados, com relação a dados marcados com prisão de coluna ou sem prisão de coluna, identificados pela variável binária (binary_class). É possível perceber que algumas variáveis têm distribuições muito distintas, como por exemplo Torque no fundo (bottom_torque), com escala na casa dos 10000, Frequência de rotação da coluna de perfuração (rotary_speed) na cada de 1000 e algumas na cada das dezenas. Através desta análise, também é possível delinear alguns tratamentos a serem dados para os dados na próxima fase do trabalho, a preparação dos dados. 
Figura 28 - Boxplot de análise de distribuição dos dados.
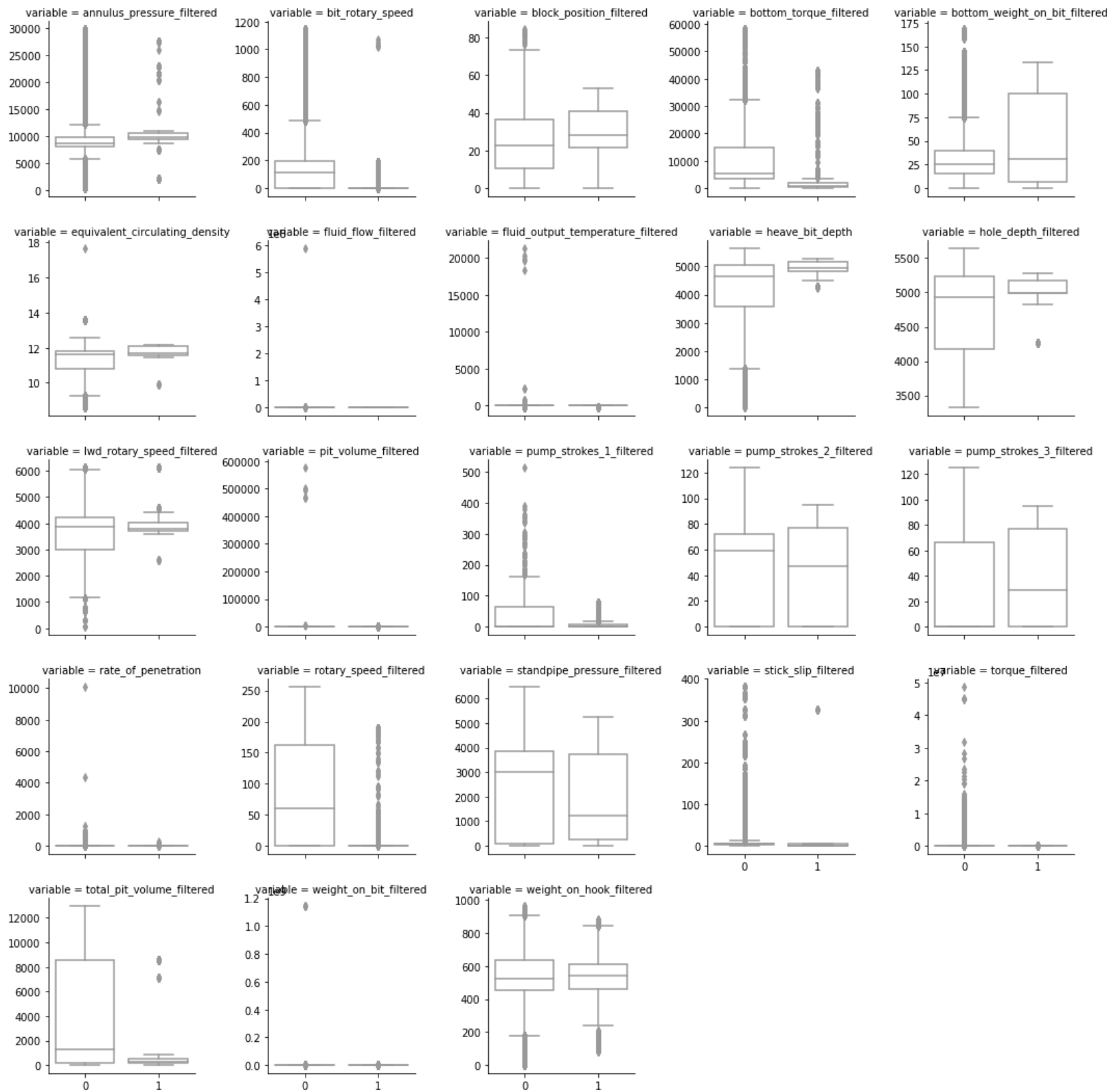

Fonte: $\mathrm{O}$ autor.

\subsection{PREPARAÇÃO DOS DADOS}

As tecnologias analíticas impõem determinados requisitos sobre os dados que são analisados. A verificação da qualidade dos dados é uma das etapas mais críticas em qualquer análise estatística. Juntamente com a fase de entendimento, a preparação dos dados o trabalho que pode tomar mais tempo no processo de descoberta de conhecimento em base de dados, como apresentado no tópico Qualidade de Dados, item 3.2. 
Esta etapa, conforme descrito da metodologia CRISP-DM, a depender dos resultados obtidos na fase de modelagem, pode ser revisitada constantemente. Logo, são descritos alguns tratamentos e preparação de dados, que não foram efetuados sequencialmente e, sim, após algumas interações com a fase de modelagem.

\subsubsection{Seleção de variáveis}

Após uma primeira modelagem, utilizando o conjunto de dados com as 23 variáveis disponibilizadas, após a uma análise dos resultados ${ }^{3}$, optou-se por efetuar uma análise de importância por intermédio da seleção de variáveis (feature selection). O processo consiste na seleção de um subconjunto de variáveis relevantes (variáveis) para uso na construção de modelos. Isto permite a simplificação dos modelos, tornando-os mais fáceis de interpretação, além de proporcionar menores tempos de treinamentos e, dentre outras razões, a redução do chamado overfitting ${ }^{3}$ (sobre ajuste).

Para a seleção de variáveis foi utilizado uma função de um pacote do Python ${ }^{\circledR}$, de computação científica, baseado no método estatístico de Randon Forest. Método este utilizado para problemas de classificação e regressão, porém com grande precisão na identificação de variáveis informativas (GENUER; POGGl; TULEAUMALOT, 2010; HAPFELMEIER; ULM, 2013). A Figura 29 apresenta o resultado da análise de relevâncias das variáveis do dataset apresentado.

Os resultados da análise do conjunto de dados (dataset) mostram que 8 variáveis estão acima dos $5 \%$ de relevância. O valor de corte foi definido pelo pesquisador para inicio de testes das variáveis. A seleção das variáveis se deu pela utilização das variáveis indicadas, através de interações com a fase seguinte: Modelagem. As variáveis foram sendo incluídas uma a uma, respeitando-se a ordem de importância da Figura 29, e buscando-se o melhor ganho ao modelo. Após diversas análises, observou-se que o melhor resultado para o modelo foi obtido com a não utilização das variáveis com maior número de dados faltantes, dentre as oito indicadas.

\footnotetext{
${ }^{3}$ Overfitting é o termo utilizado para descrever quando um modelo se ajusta demasiadamente ao conjunto de dados observado e, assim, tornando-o ineficaz de prever novos resultados.
} 
Figura 29 - Seleção de variáveis.
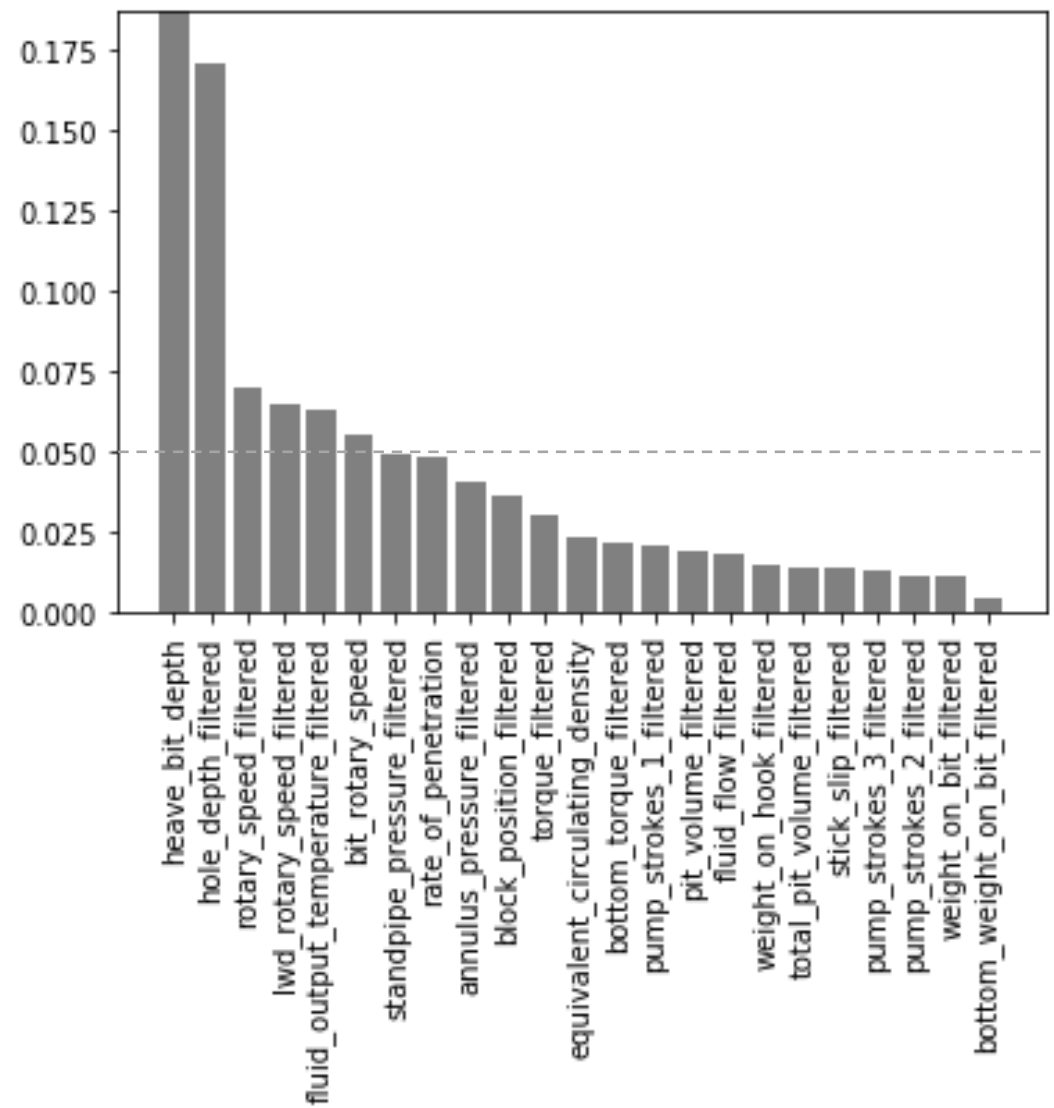

Fonte: $\mathrm{O}$ autor.

O Quadro 9 apresenta as variáveis destacadas como as mais relevantes para o modelo de acordo com o método estatístico e o processo sequencial de testes da fase de modelagem.

Quadro 9 - Variáveis relevantes selecionados.

\begin{tabular}{|cccc|}
\hline Variável & $\begin{array}{c}\text { Variável na } \\
\text { amostra }\end{array}$ & Grupo & Sistema \\
\hline $\begin{array}{c}\text { Pressão nas linhas de superficie } \\
\text { (SPP - Stand Pipe Pressure) }\end{array}$ & $\begin{array}{c}\text { standpipe_pressure_ } \\
\text { filtered }\end{array}$ & Superfície & $\begin{array}{c}\text { Sondagem, MWD, } \\
\text { Mudlogging }\end{array}$ \\
\hline $\begin{array}{c}\text { Frequência de rotação da broca } \\
(R P M-\text { Rotation per minute })\end{array}$ & bit_rotary_speed & $\begin{array}{c}\text { Poço } \\
(\text { Downhole) })\end{array}$ & MWD \\
\hline $\begin{array}{c}\text { Frequência de rotação da coluna de perfuração } \\
\text { (RPM - Rotation per minute) }\end{array}$ & rotary_speed_filtered & Superfície & Sondagem \\
\hline $\begin{array}{c}\text { Profundidade medida do poço } \\
\text { (MD - Measured Depth) }\end{array}$ & hole_depth_filtered & Superfície & $\begin{array}{c}\text { Sondagem, MWD, } \\
\text { Mudlogging }\end{array}$ \\
\hline $\begin{array}{c}\text { Profundidade medida } \\
\text { da broca compensada pelo heave } \\
\text { (Heave Compensator) }\end{array}$ & heave_bit_depth & Superfície & $\begin{array}{c}\text { Sondagem, MWD, } \\
\text { Mudlogging }\end{array}$ \\
\hline
\end{tabular}

Fonte: $\mathrm{O}$ autor. 


\subsubsection{Tratamento para dados nulos e faltantes}

Outro ponto de tratamento, conforme visto na fase anterior, está relacionado com os dados nulos e faltantes. Algumas possibilidades foram levadas para 0 tratamento da questão de dados faltantes, como por exemplo o preenchimento com o último valor, com a média, com a mediana ou, até mesmo, com a interpolação de valores. Porém, qualquer uma destas soluções poderia levar a um erro, pois, cada uma das variáveis da amostra possui uma especificidade própria. Assim, a mesma regra não poderia ser aplicada uniformemente. Por exemplo, para um dado de profundidade poderia ser adequada uma interpolação, mas já para um dado de rotação faltante poderia ser assumido qualquer valor, inclusive um valor fora da amostra. Devido a um número consideravelmente pequeno de dados, optou-se pela não atualização e/ou correção destes dados. A abordagem adotada para estes, conforme visto nos resultados, foi a eliminação das variáveis com dados faltantes.

\subsubsection{Tratamento para dispersão de valores}

Outro ponto trabalhado nos dados, conforme previamente identificado na etapa de Compreensão dos Dados, está relacionado com a alta dispersão dos valores de algumas variáveis. Para resolver esta questão optou-se por usar o valor de desvio padrão para efetuar as análises. Isso é útil quando se deseja comparar dados que correspondem a diferentes unidades. O objetivo principal é normalizar e padronizar as variáveis, antes de serem aplicadas técnicas de aprendizado de máquina. A Figura 30 apresenta o bloxplot das variáveis selecionadas. Utilizando os valores de desvio padrão para as variáveis selecionadas os valores são ajustados para uma mesma escala eliminando a dispersão das variáveis do conjunto de dados disponibilizados, como é apresenta no eixo: y com valores entre -3 a 2 e o eixo x com valores 0.0 para dados sem prisão coluna e para 1.0 dados com prisão de coluna. 
Figura 30 - Boxplot das variáveis selecionadas (desvio padrão).
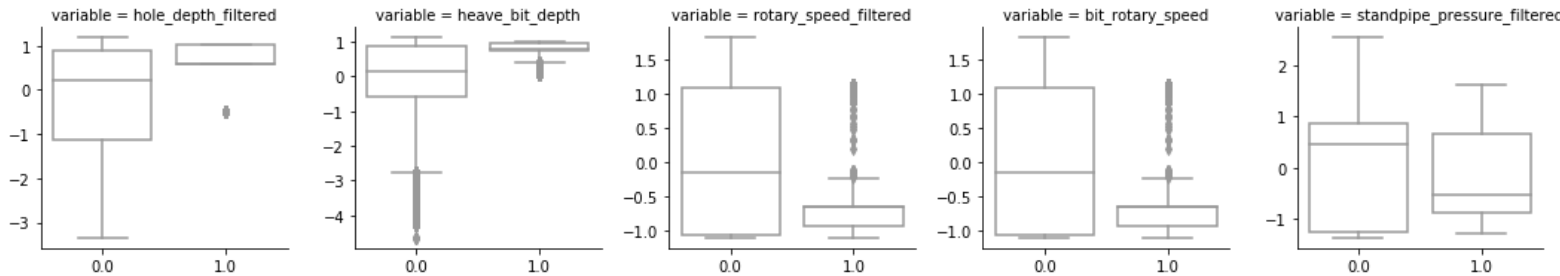

Fonte: $\mathrm{O}$ autor.

\subsubsection{Tratamento da variável alvo}

A variável alvo, disponibilizada no conjunto de dados foi atualizada, como detalhado anteriormente, para representar a ocorrência de eventos de prisão com o valor 1 (um) e para os eventos de operação normal, sem prisão, o valor 0 (zero).

Outro ponto identificado na etapa de entendimento dos dados está relacionado com o balanceamento da variável alvo com relação ao conjunto de dados disponibilizado. Para o tratamento deste ponto, a estratégia utilizada foi a utilização do pacote suplemento para Python ${ }^{\circledR}$ chamado SKLEARN (função "class_weight = balanced"), que calcula automaticamente um peso, inversamente proporcional à frequência, para cada classe da variável alvo e multiplica pelo peso da amostra do caso especificado (SCIKITLEARN, 2018).

Com a execução dos tratamentos e transformações, o conjunto de dados ficou pronto para o trabalho de modelagem propriamente dito, conforme será visto no próximo tópico.

\subsection{MODELAGEM}

Nesta etapa é aplicada a técnica de análise adequada, ao objetivo estabelecido. No caso desta dissertação foi selecionada a técnica de regressão.

A análise de regressão é usada principalmente para prever valores da variável alvo em relação aos valores das variáveis preditoras e estimar como as mudanças nas variáveis preditoras afetam a variável resposta (WEISBERG, 2005) .

No decorrer da dissertação, foram analisados estudos na área de perfuração que utilizaram análises de regressão, conforme Capítulo 4. Como por exemplo, Gupta et al. (2016) busca, com o uso de regressão linear múltipla, a previsão de valores de 
produção de poços de petróleo. A regressão múltipla é o método de análise apropriado, quando o problema de pesquisa envolve uma única variável dependente métrica, considerada como relacionada a duas ou mais variáveis independentes métricas. O objetivo da análise de regressão múltipla é prever as mudanças na variável dependente como resposta a mudanças nas variáveis independentes (HAIR et al., 2009).

Hess (2016) utiliza a regressão linear múltipla para a previsão de prisão de coluna, por meio de uma variável alvo, igualmente utilizada na presente dissertação. Um aspecto que deve ser destacado no modelo de regressão linear múltipla é que a variável deve ser métrica. No estudo de Hess (2016), a variável preditora, mesmo sendo numérica, assumindo valores 0 (zero) para eventos de não prisão e 1 (um) para eventos de prisão, pode ser considerada qualitativa pois estes números (0 e 1) não qualificam a variável, são apenas referências ao cálculo matemático. Por outro lado, para o modelo de previsão de produção, descrito por Gupta et al. (2016), já está adequado o uso de regressão linear múltipla, pois o valor de produção de petróleo é um valor métrico e contínuo.

O modelo que se adequa para a análise de regressão, quando a variável de resposta é binária, é o modelo de regressão logística (HAIR et al., 2009). Este modelo, que será usado na presente dissertação, é semelhante ao modelo de regressão linear. Como na regressão múltipla, as variáveis independentes são métricas, mas a variável dependente é não métrica (HAIR et al., 2009).

No presente caso, a variável binária dependente "Identifica o registro de Prisão" assume dois valores: sendo 0 (zero), para registros de dados de não prisão de coluna, e 1 (um), para registros de prisão de coluna.

Seguindo com o estudo de análise da prisão de coluna, para determinar o valor da variável dependente "Identifica o registro de Prisão", em função das demais 23 variáveis independentes métricas incorporadas ao modelo, as técnicas estatísticas de regressão logística foram aplicadas ao conjunto de dados analítico preparado na etapa anterior, a partir dos dados disponibilizados.

Conforme mencionado anteriormente, esta etapa tem uma grande interação com as fases de preparação, pois análises prévias nos resultados podem apontar para a necessidade de correções e mudanças nos dados disponibilizados, em função de uma melhor adequação aos métodos selecionados. 
Na etapa de modelagem, é necessária que seja definida a estratégia para teste do modelo. Umas das opções disponíveis seria efetuar a técnica de validação cruzada (cross validation), que corresponde ao procedimento do próprio algoritmo selecionar uma coleção de dados de testes. Porém, esta opção foi descartada peloque fato que o algoritmo poderia selecionar somente dados sem prisão, tendo em vista a grande quantidade de dados disponíveis com esta classificação. Assim, foi escolhido dividir a amostra, em poços para o treinamento e poços para os testes do modelo. A partir da amostra contendo sete poços, optou-se por utilizar cinco, amostragens nomeadas como: Poço_1, Poço_2, Poço_3, Poço_4 e Poço_5, para treinamento do modelo e 2 (dois) para teste do modelo, amostragem nomeada como: Poço_6, Poço_7.

Na primeira rodada, na etapa de modelagem, foi considerada a utilização das 23 variáveis disponibilizadas no conjunto de dados, com resultados não adequados às expectativas. Conforme já previsto, foi necessária a utilização de algumas técnicas de otimização de seleção de variáveis. Como resultado, o processo foi modelado novamente com as principais variáveis, de acordo com o método de seleção de variáveis (Feature Selection), utilizando o Random Forest. Com a lista das variáveis foi adotado o processo de aplicação das variáveis uma a uma até que o modelo parasse de apresentar ganho. Por fim, foram selecionadas cinco variáveis que foram aplicadas ao modelo.

O resultado da modelagem sumarizado é apresentado na Figura 31.

Figura 31 - Sumarização do método de regressão logística.

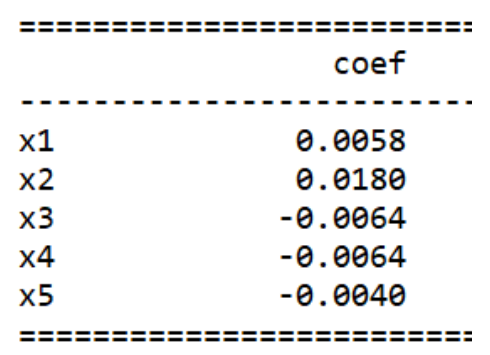

Fonte: $\mathrm{O}$ autor.

O resultado da modelagem apresenta, para cada variável selecionada, um coeficiente de relação positiva e negativa. Positivamente, são relacionadas as variáveis $X 1$ e $X 2$. Sendo as demais com uma correlação negativa. A variável mais representativa para o modelo é a X2 e a menos representativa é a X4. Respectivamente, as variáveis são: 
$\phi \quad$ x1: Profundidade medida do poço

(MD - Measured Depth) - Variável: Hole_depth_filtered

\$ $\mathbf{x 2}$ : Profundidade medida da broca compensada pelo heave (Heave Compensator) - Variável: Heave_bit_deaph

\$ x3: Frequência de rotação da coluna de perfuração (RPM - Rotation per minute) - Variável: Rotary_speed_filtered

x4: Frequência de rotação da broca (RPM - Rotation per minute) - Variável: Bit_rotary_speed

x5: Pressão nas linhas de superfície (SPP - Stand Pipe Pressure) - Variável: Standpipe_pressure_filtered

\subsection{AVALIAÇÃO}

A fase de avaliação serve para garantir que os resultados obtidos estejam adequados aos objetivos do negócio propriamente dito, ou seja, que os resultados apoiem a tomada de decisão da organização (PROVOST; FAWCETT, 2013).

Os resultados de um trabalho de ciência de dados, em sua grande maioria, não resolvem um problema sozinho, pois estão alinhados a um contexto maior, ou seja, a um objetivo. Especificamente no caso desta dissertação, a possibilidade de identificação de um evento de prisão antecipadamente, juntamente com as atividades executadas "pós alarme" (após a ocorrência do evento), pode evitar ou mitigar a ocorrência de um problema que resulte em um gasto de milhares de dólares e, em determinados casos, pode evitar eventos mais indesejáveis como acidentes.

Os resultados da modelagem estão apresentados na matriz de confusão, Quadro 10. Os valores desta matriz são calculados com os valores: população (population), número de dados relacionados com a ocorrência de prisão de coluna (P), número de dados relacionados sem prisão de coluna $(\mathrm{N})$ e número de testes executados positivamente e negarivamente (Positive Test e Negative Test). A matriz e montada com os valores de: acerto de dados de não prisão (TN- True Negative), acerto de dados de prisão (TP- True Positive), erros de dados de prisão (FN - False Negative) e erro de dados de não prisão (FT- False Positive). 
Quadro 10 - Matriz de confusão.

\begin{tabular}{|c|c|c|c|}
\hline & Classifi & ção & $\begin{array}{l}\text { population: } 124151 \\
\text { P: } 1453 \\
\text { N: } 122698 \\
\text { PositiveTest: } 15453 \\
\text { NegativeTest: } 108698\end{array}$ \\
\hline Real & Não Prisão & Prisão & $\begin{array}{l}\text { IP: } 1444 \\
\text { TN: } 10868\end{array}$ \\
\hline Não Prisão & 108689 (TN) & 14009 (FP) & FP: 14009 \\
\hline Prisão & 9 (FN) & 1444 (TP) & FN: 9 \\
\hline & & & $\begin{array}{l}\text { FPR: } 0.115 \\
\text { ACC: } 0.887\end{array}$ \\
\hline
\end{tabular}

Fonte: $\mathrm{O}$ autor.

Conforme Provost e Fawcett (2013), a atividade avaliação de um modelo está, ou deveria estar, contatada com as metas dos empreendimento estudados. Os autores complementam que é crucial pensar no que é realmente necessário mensurar.

A matriz de confusão é uma ferramenta que auxilia na avaliação dos resultados, pois separa as decisões tomadas pelo classificador, tornando explícito como uma classe está sendo confundida com outra. Assim, diferentes tipos de erros podem ser tratados separadamente. Na matriz de confusão, a diagonal principal contém as contagens das decisões corretas. Os erros do classificador são os falsos positivos (dados negativos classificados como positivos) e falsos negativos (dados positivos classificados como negativos) (PROVOST; FAWCETT, 2013).

O modelo apresentou uma acurácia $(\mathrm{ACC}=(\mathrm{TN}+\mathrm{TP}) /$ population $)$ de $89 \%$ e uma taxa de precisão de (TPR=1-FN/(FN+TP)) 99\%. A taxa de erro de falso positivos (FPR $=1-\mathrm{TN} /(\mathrm{TN}+\mathrm{FP})$ ) ficou em $11 \%$. A análise deste parâmetro pode ser relativa a cada negócio, devendo ser estudado o impacto versus os benefícios.

A realização de uma análise para buscar o entendimento dos custos destes falsos positivos para o negócio demandaria o cálculo do custo de quantas vezes um operador iria verificar um alarme falso, em comparação com a taxa de acerto de um alarme verdadeiro, tendo assim o custo evitado de um evento de prisão de coluna. Como visto durante a pesquisa, a prisão de coluna pode elevar os valores da construção de um poço de petróleo. Assim, evitar um evento como este, em comparação a uma análise do operador em um alarme falso, pode ser considerado praticamente irrelevante.

Outra análise estatística para avaliar o classificador é a interpretação útil da área abaixo da curva ROC, ou AUROC (Area under Receiver Operating Characteristic 
Curve). O gráfico para geração desta curva é derivado de parâmetros calculados a partir da matriz de confusão e relaciona a taxa de verdadeiros positivos (TPR) com a taxa de falsos positivos (FPR), para um mesmo modelo essa relação pode variar de acordo com o limite (threshold) de decisão selecionado. Esse parâmetro representa o valor de probabilidade, a partir do qual se considera a ocorrência do evento analisado. Geralmente acima, de 0,5 considera-se que o evento ocorreu, porém é possível realizar uma análise de sensibilidade e selecionar outro valor de acordo com os objetivos do negócio (OWEN, 2013).

Os valores da estimativa AUROC podem variar entre zero e um, onde o menor valor representa um modelo que nunca obtém sucesso (nesse caso pode-se aplicar um fator negativo para inverter todos os valores previstos) e o maior valor representa um modelo que obtém sucesso em todos os eventos aleatoriamente observados. Desta maneira, pode-se sugerir que valores de AUROC abaixo de 0,5 não são relevantes para estudos de classificadores, pois um modelo totalmente aleatório, com probabilidades iguais de sucesso e fracasso, poderia produzir um AUROC de 0,5, como por exemplo jogar uma moeda para prever se um evento irá ou não ocorrer. Valores ideais de AUC estão geralmente acima de 0,7.

A Figura 32 mostra a área abaixo da curva ROC para o modelo analisado, que representa a probabilidade de um evento selecionado aleatoriamente ser positivo em relação a um evento negativo.

Figura 32 - Interpretação útil da área.

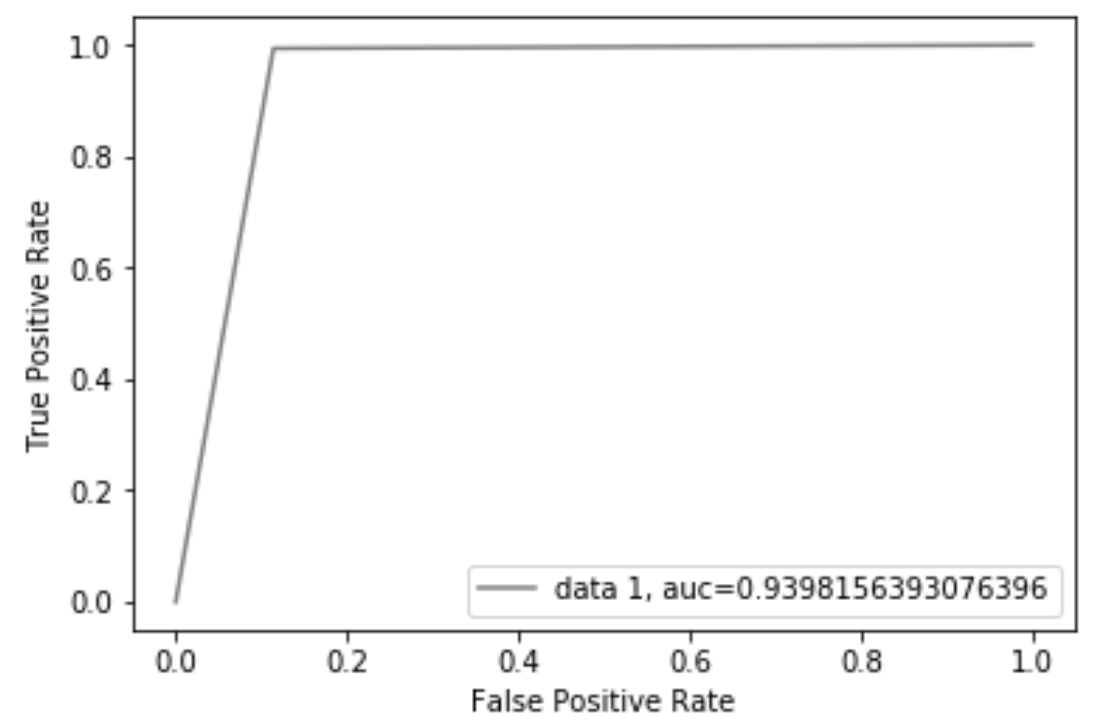

Fonte: $\mathrm{O}$ autor. 
O resultado do modelo apresenta um AUC de $94 \%$, para um limite padrão de 0,5. A taxa de verdadeiros positivos (TPR) se aproxima do valor máximo e para o estudo em questão este é o parâmetro mais relevante, ainda que a taxa de falsos positivos (FPR) possa ser minimizada, alterando o valor do limite. Isso não seria indicado, pois o custo de não previsão da ocorrência do evento é muito maior do que o custo de verificação gerado por alarmes falsos durante a operação de perfuração, conforme explicitado anteriormente.

\subsection{IMPLANTAÇÃO}

Por fim, a última fase do CRISP-DM está relacionada à disponibilização do conhecimento obtido durante o trabalho no ambiente de negócios. De acordo com Provost e Fawcett (2013), a implantação de um modelo no sistema de produção normalmente requer que o modelo seja recodificado para o ambiente de produção, geralmente para maior velocidade ou compatibilidade com os sistemas existentes, podendo em alguns casos, a equipe que desenvolveu o trabalho ter que participar do desenvolvimento de protótipos integrados aos sistemas existentes na organização.

Com o objetivo de proporcionar uma primeira versão da solução o código gerado nas etapas de tratamento dos dados, modelagem e avaliação, foram encapsulados para a geração de uma solução computacional protótipo executável, conforme será apresentado mais adiante.

A execução da solução está condicionada a algumas premissas de formato de dados definidas na etapa de compreensão de dados. Além disto, a pesquisa foi conduzida com um número reduzido de dados. Para melhorar o modelo, é imperativo que ele seja submetido a um conjunto mais volumoso de dados, com o intuito de melhorar o dataset de treinamento do modelo.

Outro ponto que pode ser evoluído, é a análise de outros métodos estatísticos na fase de Modelagem. Conforme definido, esta dissertação limitou-se à aplicação do método de regressão logística para buscar a previsão do evento prisão de coluna de perfuração. Porém, conforme visto no Capítulo 3, mais precisamente no item Aprendizado de Máquina, existe uma variedade de algoritmos de aprendizado supervisionados que podem ser empregados para a classificação de valores. Assim, é coerente que sejam aprofundados estudos e os valores sejam comparados a fim de 
serem identificados os melhores métodos para atendimento ao problema proposto na primeira fase, ou seja, no entendimento do negócio.

Existem ainda outras atividades que devem ser definidas para a colocação dos métodos em ambiente de produção, tais como, definição de conexões com bases de dados ou arquivos, automação dos processos de extração, codificações de serviços automáticos - API (Application Programming Interface), entre outros que não são escopo desta dissertação.

Por fim, para auxiliar as pesquisas futuras, são disponibilizados os códigos, elaborados em Python $^{\circledR}$, escritos e utilizados para: i. Executar as análises exploratórias dos dados durante a compreensão dos dados, ii. Preparar os dados, iii. Modelar, iv. Avaliar os resultados, e, finalmente, v. implantação (protótipo de solução computacional), nos Apêndice $B$, Apêndice $C$, Apêndice $D$ e Apêndice $E$.

A solução computacional é apresentada a seguir, assim como, a estrutura de diretórios utilizada para a disponibilização dos arquivos de treinamento e testes.

\subsubsection{Solução computacional (protótipo)}

Conforme informado anteriormente, a solução computacional foi baseada nos códigos gerados nas etapas da metodologia CRISP-DM. Porém, nem todas as atividades são passiveis, ou necessárias, de serem aplicadas na fase de implantação. Por exemplo, a análise exploratória dos dados é muito importante para efetuar o entendimento das variáveis e do dataset disponibilizado, mas é necessário a aplicação de todos os métodos ou análises na implantação.

Logo, a solução é fundamentada no processo de seleção da amostra (para treinamento e testes), análise dos dados, seleção das variáveis e execução do modelo e análise dos resultados, como demostrado a seguir:

\subsubsection{Seleção da Amostra}

Os dados disponibilizados são apresentados na Figura 33, contendo as amostras para o treinamento e testes. 
Figura 33 - Diretório com dataset.

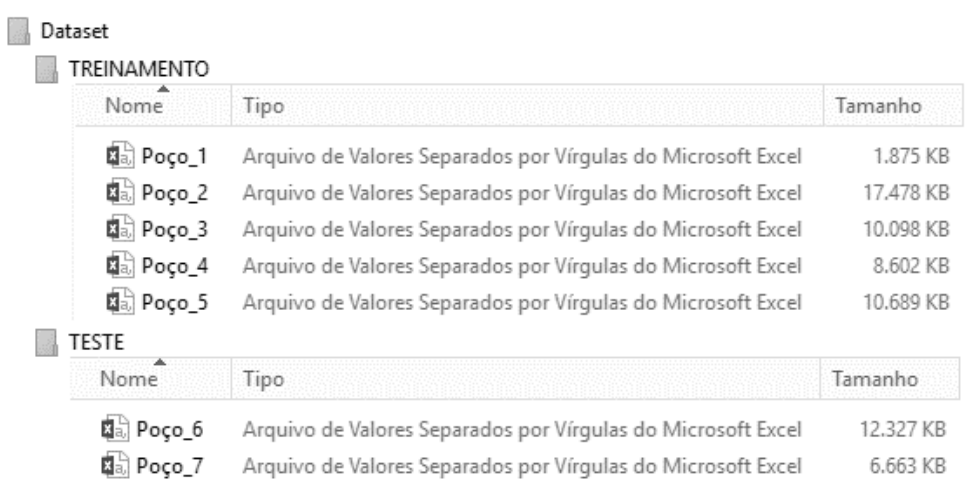

Fonte: $\mathrm{O}$ autor.

As amostras estão disponibilizadas conforme foram utilizadas na fase de modelagem, sendo as cinco primeiras amostras definidas para o treinamento e as demais para o teste do modelo.

Ao rodar o executável, é apresentada a opção para a configuração das fontes de dados. Esta primeira funcionalidade disponibiliza a opção de não efetuar a configuração dos diretórios das amostra de treinamento e testes, se estes já tenham sido configurados anteriormente, Figura 34. Caso seja respondido que não são as mesmas pastas do estudo anterior, será solicitada a informação dos caminhos de ambas as pastas, de treinamento e seguida para os testes.

Figura 34 - Seleção dos dados.

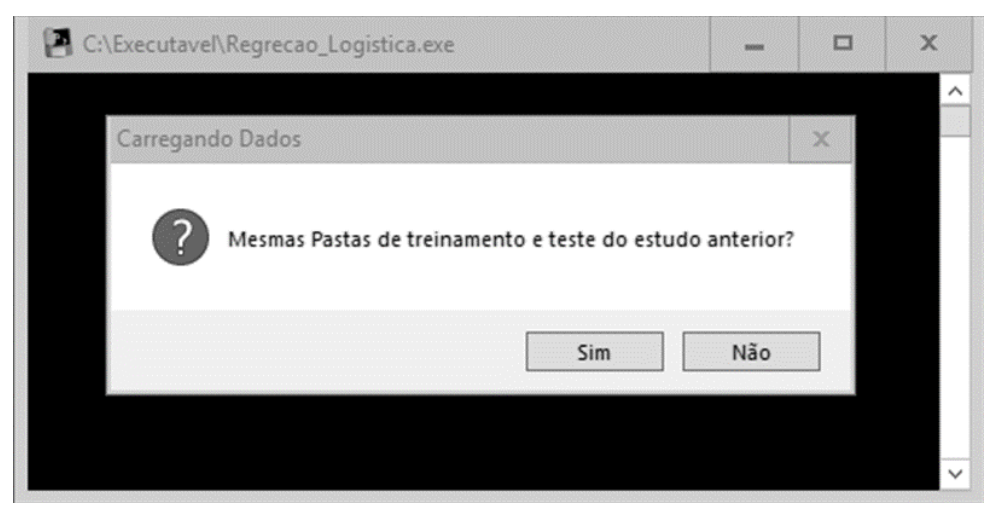

Fonte: O autor.

Ao selecionar a opção para configurar as pastas novamente, a solução apresenta a caixa de seleção dos arquivos tipo CSV para o treinamento, conforme Figura 35. 
Figura 35 - Seleção dos dados para Treinamento.

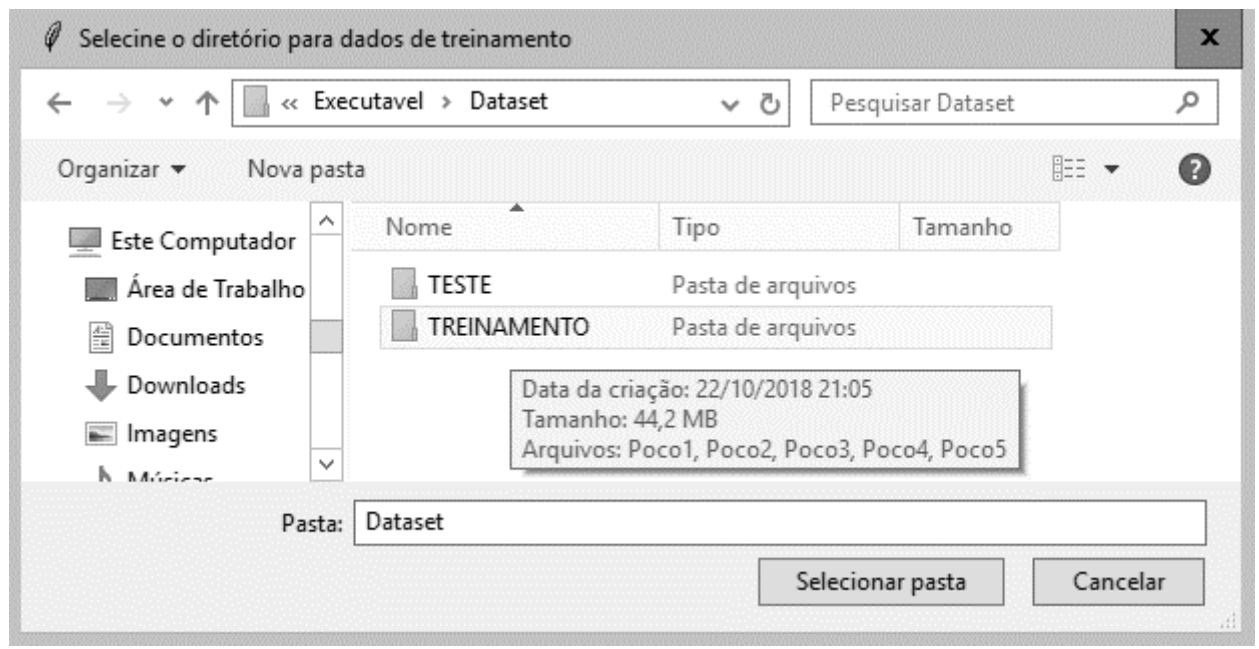

Fonte: $\mathrm{O}$ autor.

Após a seleção dos dados de treinamento o processo dever ser repetido para os dados para o treinamento, conforme Figura 36.

Figura 36 - Seleção dos dados para Teste

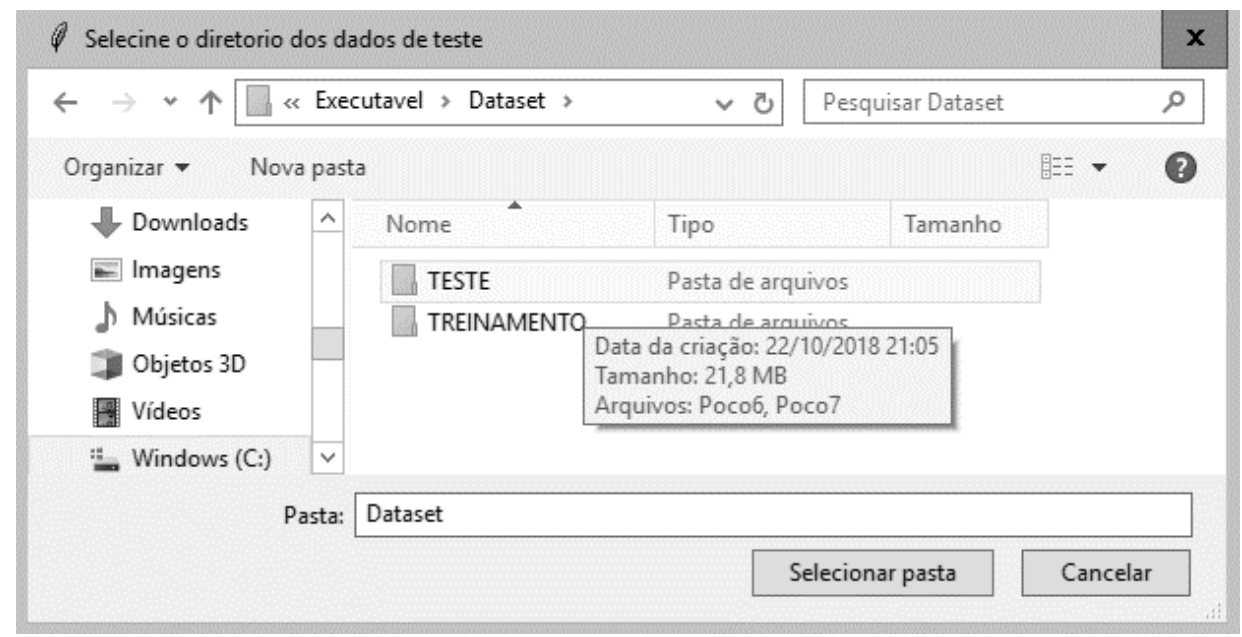

Fonte: O autor.

Os arquivos de origem, amostras, devem respeitar algumas premissas conforme analisadas na etapa de entendimento dos dados da metodologia. Caso sejam encontrados erros nos arquivos, a solução informará e não prosseguirá com a análise dos dados. 


\subsubsection{2. $\quad$ Análise dos dados}

Após a seleção das amostras é executada uma análise nos dados, conforme os métodos definidos nas fases de análise exploratórios. É apresentada uma análise de dados faltantes e/ou nulos e variáveis importantes para o modelo (relevância), conforme Figura 37.

Figura 37 - Análise dos dados.

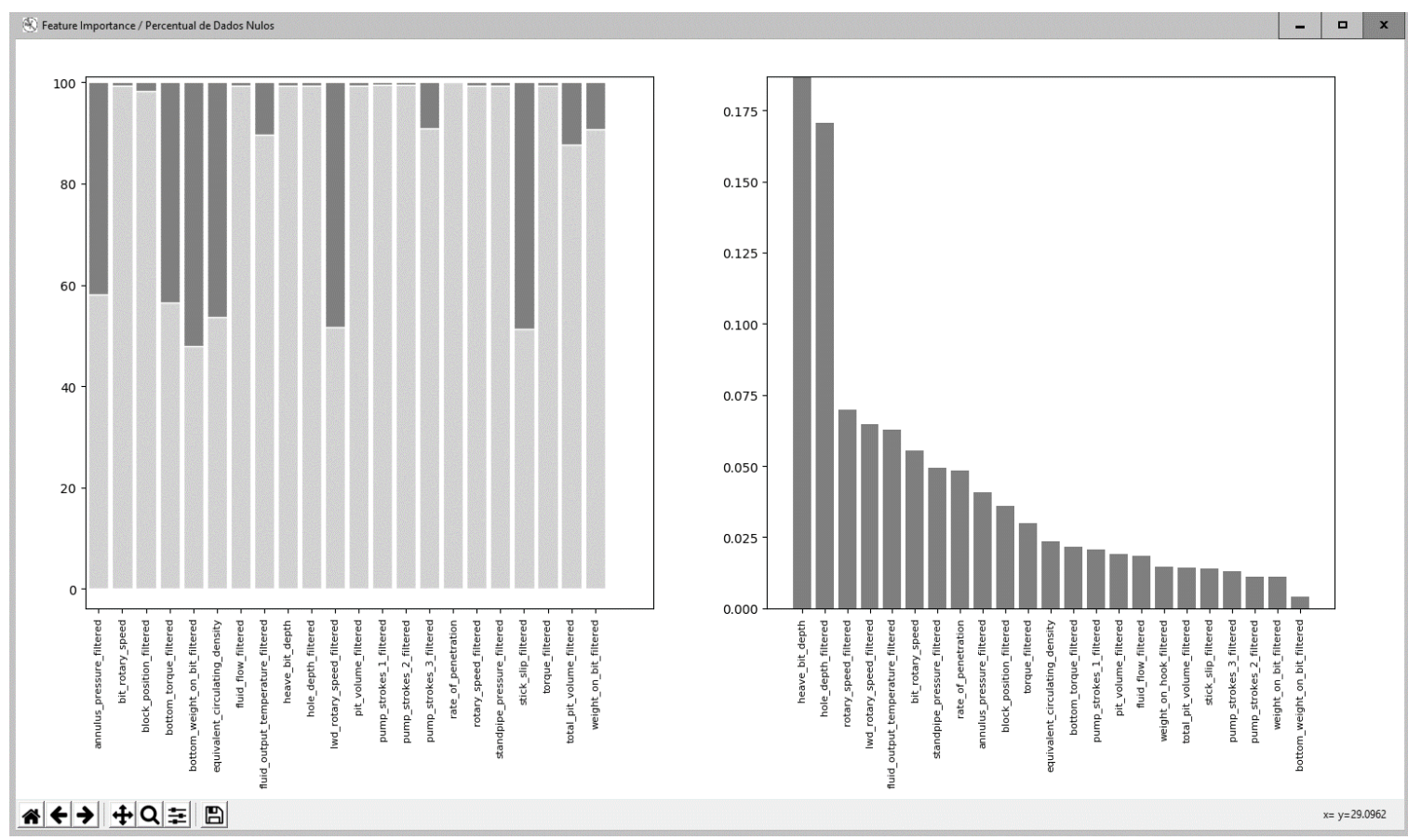

Fonte: $\mathrm{O}$ autor.

\subsubsection{Seleção das variáveis}

A etapa seguinte, no uso da solução, é relacionada com a seleção das variáveis a serem utilizadas no modelo. Como visto nas etapas de entendimento e preparação dos dados, na metodologia CRISP-DM, optou-se pelo o uso das variáveis que tivessem relevância acima de $5 \%$. O resultado indicou que 8 variáveis estavam acima de $5 \%$. De acordo com os resultados das modelagens, retirando as variáveis com dados nulos (3 delas) foi possível melhorar o resultado. Desta forma foram selecionadas 5 (cinco) variáveis para serem utilizadas no modelo. Sendo: "standpipe_pressure_filtered", "bit_rotary_speed", "rotary_speed_filtered", "hole_depth_filtered" e "heave_bit_depth". 
Com o intuito de prover um protótipo mais flexível a solução foi desenvolvida para apresentar e disponibilizar, para seleção, todas as variáveis disponíveis no dataset. A variável alvo "binary_class" responsável por sinalizar os dados de prisão de coluna e não prisão, foi suprimida pois se trata da variável alvo. Conforme pode ser visto na Figura 38.

Figura 38 - Seleção das variáveis.

\begin{tabular}{|c|c|c|c|}
\hline 4 Selecione as Variaveis & - & ㅁ & $\mathbf{x}$ \\
\hline \multicolumn{4}{|l|}{ Variaveis: } \\
\hline \multicolumn{4}{|l|}{$\Gamma$ annulus_pressure_filtered } \\
\hline \multicolumn{4}{|l|}{$\sqrt{\nabla}$ bit_rotary_speed } \\
\hline \multicolumn{4}{|l|}{$\Gamma$ block_position_filtered } \\
\hline \multicolumn{4}{|l|}{$\Gamma$ bottom_torque_filtered } \\
\hline \multicolumn{4}{|c|}{ Г bottom_weight_on_bit_filtered } \\
\hline \multicolumn{4}{|c|}{$\Gamma$ equivalent_circulating_density } \\
\hline \multicolumn{4}{|l|}{$\Gamma$ fluid_flow_filtered } \\
\hline \multicolumn{4}{|c|}{$\Gamma$ fluid_output_temperature_filtered } \\
\hline \multicolumn{4}{|l|}{$\sqrt{\checkmark}$ heave_bit_depth } \\
\hline \multicolumn{4}{|l|}{$\sqrt{ }$ hole_depth_filtered } \\
\hline \multicolumn{4}{|l|}{$\Gamma$ Iwd_rotary_speed_filtered } \\
\hline \multicolumn{4}{|l|}{$\Gamma$ pit_volume_filtered } \\
\hline \multicolumn{4}{|l|}{ Г pump_strokes_1_filtered } \\
\hline \multicolumn{4}{|l|}{$\Gamma$ pump_strokes_2_filtered } \\
\hline \multicolumn{4}{|l|}{$\Gamma$ pump_strokes_3_filtered } \\
\hline \multicolumn{4}{|l|}{$\Gamma$ rate_of_penetration } \\
\hline \multicolumn{4}{|l|}{$\sqrt{ }$ rotary_speed_filtered } \\
\hline \multicolumn{4}{|c|}{$\sqrt{ }$ standpipe_pressure_filtered } \\
\hline \multicolumn{4}{|l|}{$\Gamma$ stick_slip_filtered } \\
\hline \multicolumn{4}{|l|}{$\Gamma$ torque_filtered } \\
\hline \multicolumn{4}{|l|}{$\Gamma$ total_pit_volume_filtered } \\
\hline$\Gamma$ weight_on_bit_filtered & & & \\
\hline
\end{tabular}

Fonte: $\mathrm{O}$ autor.

\subsubsection{Análise dos resultados}

Com a seleção das variáveis efetuada, o modelo de regressão logística é aplicado apresentando o resultado conforme a fase de avaliação, apresentando uma curva ROC e uma matriz de confusão, conforme Figura 39. 
Figura 39 - Análise de resultados.

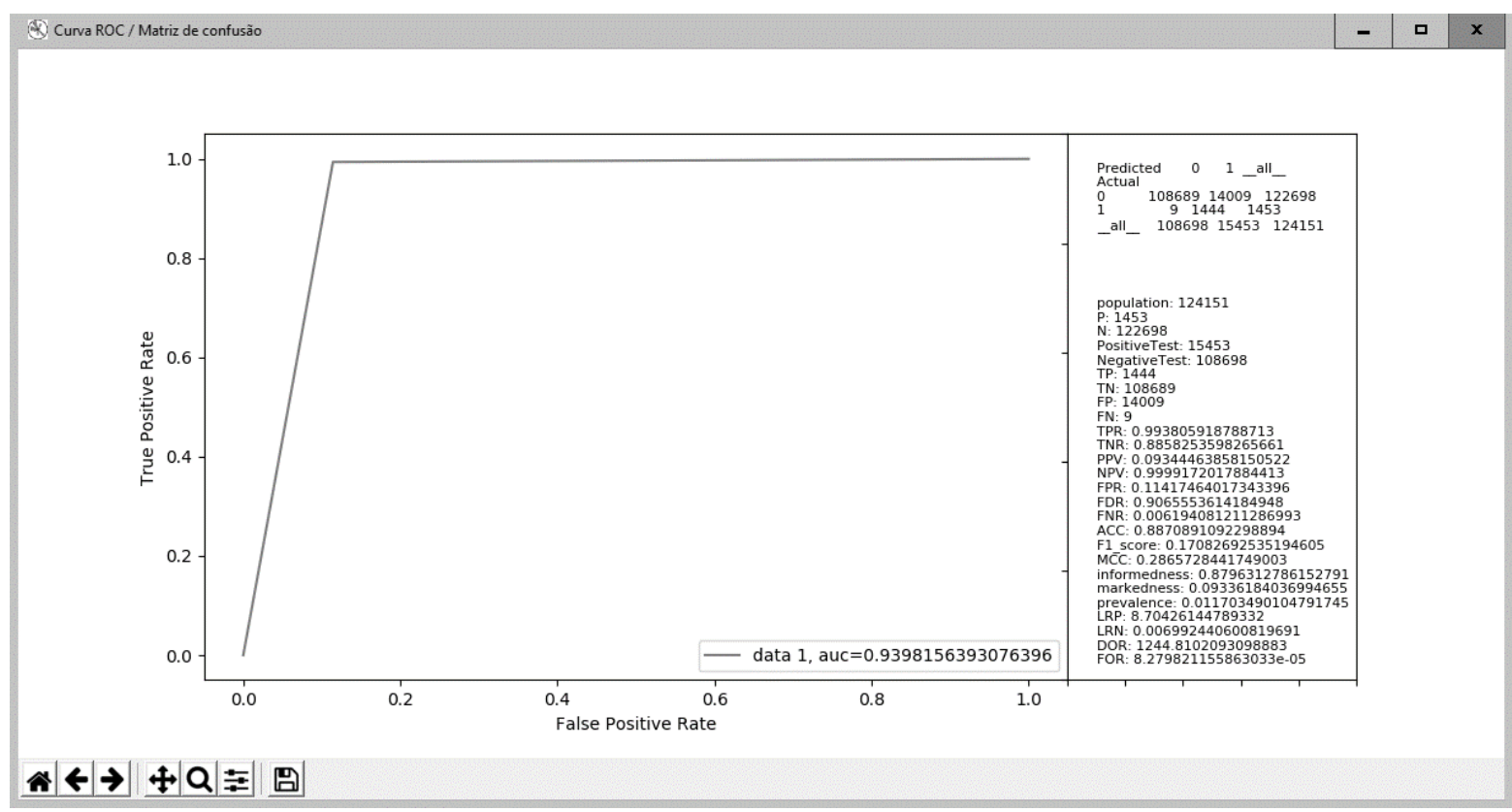

Fonte: $\mathrm{O}$ autor.

A amostragem de dados, de acordo com o informado, é relativamente pequena. Desta forma, o resultado das análises é altamente impactado pela seleção dos dados de treinamento e testes. Esta variação pode tender a diminuir com a disponibilização de uma gama maior de dados. 


\section{CONCLUSÕES}

O objetivo desta dissertação foi apresentar o desenvolvimento de uma solução de descoberta de dados utilizando uma metodologia, CRISP-DM, para delinear os processos afim de obter resultados para o negócio. A pesquisa partiu da necessidade de obter melhores ferramentas, através das iniciativas de transformação digital, para apoiar o processo de tomada de decisão na perfuração de poços marítimos, considerado uma das fases mais dispendiosa de recursos financeiros do processo de exploração e produção (E\&P).

Para um melhor entendimento do processo de perfuração, a dissertação abordou no referencial teórico os sistemas utilizados nas operações de perfuração assim como as principais anomalias geradoras dos NPT, nos processos ligados a estes sistemas.

O Capítulo 3 apresentou uma visão geral do que está sendo considerado atualmente a quarta revolução industrial, fazendo o uso de tecnologias disruptivas, para apoio aos processos de trabalho na indústria com ênfase mais direta na indústria do petróleo. Este capitulo também trouxe uma visão das técnicas utilizadas para a condução de projetos de análise de dados incluindo neste, a metodologia utilizada na presente dissertação.

Para exemplificar a aplicação da metodologia, a seleção de um caso de negócios se fez necessário. Para tal, foi selecionado um problema de coluna de perfuração durante o referido processo. A técnica escolhida foi a modelagem de Regressão.

A tarefa de extrair informações de bases de dados pode ser árdua, considerando a quantidade de dados estruturados e não estruturados. Além disso, o problema de mineração de dados envolve diferentes métodos estatísticos, linguagens e algoritmos de programação, entre outras atividades que podem estar desconexas com efeito desejado pelo cliente.

Para tentar atenuar este problema, a metodologia CRISP-DM descreve as principais fases a seguir para problemas relacionados com à análise de dados. Nesta dissertação foram apresentadas diversas técnicas que podem ser empregadas em cada fase da metodologia. Exemplificando com o uso de códigos elaborados com a linguagem de programação Python ${ }^{\circledR}$. 
O marco inicial do método está relacionado com o entendimento do negócio, o grande resultado desta fase é poder entender o negócio buscando alinhar os possíveis resultados aos objetivos do negócio.

Outro ponto positivo da metodologia foi a interação entre fases, que podem ser sequenciais, como exemplo, da fase compreensão dos dados, onde foram identificadas questões que apontavam à necessidade de preparação e tratamentos que deveriam ser efetuadas na fase subsequente. Ou em interação com as etapas anteriores, como por exemplo, na análise dos primeiros resultados da modelagem apontaram para a necessidade de uma melhor preparação nos dados, retornando para o estágio anterior.

A etapa de avaliação proporciona o momento para a tomada de decisão relacionando os resultados obtidos com o entendimento do negócio. Nesta pesquisa foi utilizada uma matriz de confusão. Os resultados alcançados para exemplificar o modelo demonstram uma acurácia de $89 \%$ e uma taxa de precisão de $99 \%$.

Por fim, como resultado a dissertação apresenta um método exemplificado contribuindo a profissionais e empresas que necessitem aplicar métodos de ciência de dados em casos semelhantes ou com outras características.

\subsection{TRABALHOS FUTUROS}

Durante a pesquisa forma vislumbradas algumas lacunas ou limitações que podem ser desdobradas em trabalhos futuros, melhorando os resultados do próprio tema da dissertação, assim como, a abertura de novas linhas de pesquisas.

Relacionado ao tema da dissertação, alguns pontos foram previamente destacados para serem melhorados na etapa de implantação, item 5.6, mas que podem ser reacionados aqui, como trabalhos futuros. Destacam-se dois, a necessidade de submeter o modelo a um número mais volumoso de dados, assim como, a verificação de outros métodos estatísticos na fase de modelagem.

O método estatístico de Randon Forest, utilizado para a seleção de variáveis nesta pesquisa, também é uma outra linha para aprimoramento do modelo. Verificando a sua aplicação para na etapa de modelagem do CRISP-DM. Nesta linha também pode ser completada com a eleboração de uma revisão da literatua de uso do método para análise de dados de perfuração de poços de petróleo. 
Outro trabalho que pode agregar valor ao negocio, relaciona-se a atividade efetuada no conjuto de dados, amostra, para realiza a identificação dos dados com prisão de coluna, item 5. 2.3 (Identificação do dado de estudo - variável alvo). A utilização de métodos avançados de IA, classificação, podem trazer um grau de automação para o processo com o cruzamento de dados dos sistemas de tempo real com os dados de boletins operacionais, com o intuito de identificar os registros relacionados aos momentos de ocorrência dos eventos de prisão de coluna.

Por fim, uma aplicação voltarda para a análise financeita do NPT pode ser uma outra linha de pesquisa. Buscando identificar através dos dados de boletíns os tempos perdidos e as atividades relacionadas, no momento da prisão, cruzando-os com dados financeiros. Obtendo assim uma correlação exata de tempo parado versus custos. 


\section{BIBLIOGRAFIA}

ABALIOGLU, I. et al. The Role of Geomechanics in diagnosing Drilling Hazards and providing solutions to the Northern Iraq fields. SPE Middle East Oil and Gas Show and Conference.Society of Petroleum Engineers, 4 abr. 2011

ABLARD, P. et al. The Expanding Role of Mud Logging. Oilfield Review, 2012.

ADAMS, A.; GIBSON, C.; SMITH, R. G. Probabilistic Well-Time Estimation Revisited. SPE Drilling \& Completion, v. 25, n. 04, p. 472-499, 1 dez. 2010.

AGRAWAL, D. et al. Challenges and Opportunities with Big Data. Computing Community Consortium committee of the Computing Research Association, p. 1-17, 2012.

AL-HAMEEDI, A. T. et al. Limiting Drilling Parameters to Control Mud Losses in the Dammam Formation, South Rumaila Field, Iraq. 28 ago. 2017.

AMJAD, Q. B. et al. Drilling Optimization of Kohat/Potohar Region by Mathematical Model (Using Matlab) and Comparative Method - A Case Study. SPE/PAPG Pakistan section Annual Technical Conference. Anais...Society of Petroleum Engineers, $17 \mathrm{fev}$. 2015

APONTE, J.; TRUJILLO, M.; PRIMERA, A. Applied Methodology to Optimize the Intervention Sequence in a Mature Water-Flood Oil Field in the North Sea. SPE Europec featured at 78th EAGE Conference and Exhibition. Anais...Society of Petroleum Engineers, 30 maio 2016

ASLAN, J. F. Segurança: Aspectos de Segurança na Cimentação de Poços de Petróleo. Disponível em: <https://www.petroleoenergia.com.br/6041/>. Acesso em: 28 maio. 2018.

AZAR, J. J.; SAMUEL, G. R. Drilling engineering. [s.I.] PennWell Corp, 2007.

AZEVEDO, A.; SANTOS, M. F. KDD, SEMMA and CRISP-DM: a parallel overview. IADIS European Conference Data Mining, n. January, p. 182-185, 2008.

AZEVEDO, M. T. DE. Transformação digital na indústria: indústria 4.0 e a rede de água inteligente no Brasil. 10 mar. 2017.

AZUAGA, D.; ROCHA, L. A. S.; VIEIRA, J. L. B. Perfuração Direcional. [s.l: s.n.].

BAY, Q.; BAY, Y. Sistemas Marítimos de Produção de Petróleo: Processos, Tecnologias e Equipamentos Offshore. [s.I.] Campus, 2016.

BELLO, O. et al. Application of Artificial Intelligence Techniques in Drilling System Design and Operations: A State of the Art Review and Future Research Pathways. SPE Nigeria Annual International Conference and Exhibition. Anais...Society of Petroleum Engineers, 2 ago. 2016

BOMAN, K. Study: Low Oil Price Gives Industry Chance to Pursue Digital Transformation / Rigzone. Disponível em: $<$ https://www.rigzone.com/news/oil_gas/a/138503/study_low_oil_price_gives_industr y_chance_to_pursue_digital_transformation/?all=hg2>. Acesso em: 20 jan. 2018.

BOURGOYNE, A. T. et al. Applied Drilling Engineering. [s.l: s.n.]. v. 2

BUSHNELL-WATSON, Y. M.; PANESAR, S. S. Differential Sticking Laboratory Tests 
Can Improve Mud Design. SPE Annual Technical Conference and Exhibition. Anais...Society of Petroleum Engineers, 4 abr. 1991

CARTER, K. M.; VAN OORT, E.; BARENDRECHT, A. Improved Regulatory Oversight using Real-Time Data Monitoring Technologies in the Wake of Macondo. SPE Deepwater Drilling and Completions Conference. Anais...Society of Petroleum Engineers, 10 set. 2014

CCPS. Diretrizes Para Segurança de Processo Baseada em Risco. 1. ed. [s.I.] Interciência, 2014.

CHAPMAN, P. et al. CRISP-DM 1.0 (Step-by-step data mining guide) CRISP-DM Consortium. [s.I: s.n.].

CHIEZA, C. P. Diagnósticos de problemas operacionais durante a perfuração de poços de petróleo. [s.I.] PUC-RIO, 2011.

CHIPALAVELA, A. F. Análise e Discussão das Operações de Perfuração e Completação em Poços Petrolíferos. [s.l.] Técnico Lisboa, 2013.

CRAMER, R. et al. A Measure of The Digital Oil Field Status - Is It The End of The Beginning? SPE Intelligent Energy International. Anais...Society of Petroleum Engineers, 4 abr. 2012

CRISTOFARO, R. A. L. et al. Artificial Intelligence Strategy Minimizes Lost Circulation Non-Productive Time in Brazilian Deep Water Pre-Salt. OTC Brasil. Anais...Offshore Technology Conference, 24 out. 2017

D. LUO et al. Simulation and Analysis of Wellbore Stability Using FLAC for Horizontal Well Drilling in Shale Formations. American Rock Mechanics Association, 18 ago. 2014

DAMODARAN, A. The Oil Price Shock: Primary, Secondary, And Collateral Effects / Seeking Alpha. Disponível em: <https://seekingalpha.com/article/2774365-the-oilprice-shock-primary-secondary-and-collateral-effects>. Acesso em: 21 set. 2017.

DAVENPORT, T. H. Big Data no Trabalho Derrubando mitos e descobrindo oportunidades. [s.l.] Elsevier , 2014.

DAVID, R. M. Approach towards Establishing Unified Petroleum Data Analytics Environment to Enable Data Driven Operations Decisions. SPE Annual Technical Conference and Exhibition. Anais...Society of Petroleum Engineers, 26 set. 2016.

DEVEREUX, S. Drilling technology in nontechnical language. [s.I.] PennWell Corp, 2012.

DRAOU, A.; OSISANYA, S. O. New Methods for Estimating of Formation Pressures and Fracture Gradients from Well Logs. SPE Annual Technical Conference and Exhibition. Anais...Society of Petroleum Engineers, 4 abr. 2000.

EREN, T. Real-Time-Optimization of Drilling Parameters During Drilling Operations. Middle East Technical University, 2010.

EREN, T.; OZBAYOGLU, M. E. Real Time Optimization of Drilling Parameters During Drilling Operations. SPE Oil and Gas India Conference and Exhibition. Anais...Society of Petroleum Engineers, 4 abr. 2010

FAYYAD, U.; PIATETSKY-SHAPIRO, G.; SMYTH, P. From Data Mining to Knowledge Discovery in Databases. Al Magazine, v. 17, n. 3, p. 37, 15 mar. 1996. 
GALLAGHER, K. S. et al. Trends in investments in global energy research, development, and demonstration. Wiley Interdisciplinary Reviews: Climate Change, v. 2, n. 3, p. 373-396, 1 maio 2011.

GALP. Perfuração - Galp. Disponível em: $<$ http://www.galpenergia.com/PT/investidor/ConhecerGalpEnergia/Os-nossosnegocios/Exploracao-Producao/fundamentos-engenhariapetroleo/Paginas/Perfuracao.aspx>. Acesso em: 14 fev. 2018.

GAURINA-MEDJIMUREC, B. Risk Due to Wellbore Instability. In: Risk Analysis for Prevention of Hazardous Situations in Petroleum and Natural Gas Engineering. [s.l: s.n.]. v. ip. 23-46.

GENS, F. et al. IDC FutureScape: Worldwide IT Industry 2017 Predictions - Printerfriendly - US41883016. [s.l: $\quad$ s.n.]. Disponível em: $<$ https://www.idc.com/getdoc.jsp?containerld=US41883016\&pageType=PRINTFRIE NDLY>. Acesso em: 26 jan. 2018.

GENUER, R.; POGGI, J.-M.; TULEAU-MALOT, C. Variable selection using random forests. Pattern Recognition Letters, 2010.

GHILARDI, P. et al. Real Time Drilling Data Diagnosis Implemented In Deepwater Wells - A Reality. OTC Brasil. Anais...Offshore Technology Conference, 29 out. 2013.

GOLA, G. et al. Improving Management and Control of Drilling Operations with Artificial Intelligence. SPE Intelligent Energy International. Anais...Society of Petroleum Engineers, 4 abr. 2012

GOMES, J. S. et al. O universo da indústria petrolífera : da pesquisa à refinação. [s.I.] Fundação Calouste Gulbenkian. Serviço de Educação e Bolsas, 2011.

GPO. Macondo: the Gulf oil disaster: Chief Counsel's report. [s.I.] National Commission on the BP Deepwater Horizon Oil Spill and Offshore Drilling, 2011.

GUPTA, M. et al. Role of Multivariate Analysis to Define the Key Driver's Governing the Well Productivity in Marcellus Shale Play. Proceedings of the 4th Unconventional Resources Technology Conference. Anais...Tulsa, OK, USA: American Association of Petroleum Geologists, 1 ago. 2016.

HAIR, J. F. et al. Análise Multivariada de Dados - 6a Edição. [s.l: s.n.].

HALL, P. et al. An Overview of Machine Learning with SAS \& Enterprise Miner TM. An Overview of Machine Learning with SAS® Enterprise Miner ${ }^{\mathrm{TM}}$, n. Rosenblatt 1958, p. 1-24, 2014.

HALLIBURTON. OpenWells® Operations Reporting Software. Disponível em: <https://www.landmark.solutions/OpenWells>. Acesso em: 14 jun. 2018.

HAPFELMEIER, A.; ULM, K. A new variable selection approach using Random Forests. Computational Statistics and Data Analysis, 2013.

HEKIMA. Se você se interessa por Big Data, precisa entender o CRISP-DM. Disponível em: <http://www.bigdatabusiness.com.br/se-voce-se-interessa-por-bigdata-precisa-entender-o-crisp-dm/>. Acesso em: 5 jun. 2018.

HEMPKINS, W. B. et al. Multivariate Statistical Analysis of Stuck Drillpipe Situations. SPE Drilling Engineering, v. 2, n. 03, p. 237-244, 1 set. 1987.

HESS, J. Pipe Sticking Prediction Using LWD Real-Time Measurements. IADC/SPE 
Drilling Conference and Exhibition. Anais...Society of Petroleum Engineers, 1 mar. 2016

HOLAND, P. Reliability of Deepwater Subsea Blowout Preventers. SPE Drilling \& Completion, v. 16, n. 01, p. 12-18, 1 mar. 2001.

HOLDAWAY, K. R. Harness oil and gas big data with analytics : optimize exploration and production with data driven models. 1st. ed. [s.l.] Wiley Publishing, 2014.

HOLDAWAY, K. R.; IRVING, D. H. B. Enhance Oil and Gas Exploration with DataDriven Geophysical and Petrophysical Models. [s.I.] John Wiley \& Sons, 2017.

IBP et al. Dicionário do Petróleo. Disponível em: <http://dicionariodopetroleo.com.br/>. Acesso em: 4 mar. 2018.

JIANG, W.; SAMUEL, R. Optimization of Rate of Penetration in a Convoluted Drilling Framework using Ant Colony Optimization. IADC/SPE Drilling Conference and Exhibition. Anais...Society of Petroleum Engineers, 1 mar. 2016.

JOVIC, M. Statistical Decision Making: Improving the Decision Process in the Oil and Gas Industry. SPE Annual Technical Conference and Exhibition. Anais...Society of Petroleum Engineers, 30 set. 2013.

KADYROV, T.; TUTUNCU, A. N. Integrated Wellbore Stability Analysis For Well Trajectory Optimization And Field Development In the West Kazakhstan Field. 1 jan. 2012.

KANE, G. C. et al. Strategy, not Technology, Drives Digital Transformation. [s.I: s.n.]. Disponível em: <https://sloanreview.mit.edu/projects/strategy-drives-digitaltransformation/>. Acesso em: 20 jan. 2018.

KUEHN, A. L. T. Técnicas de Perfuração com Gerenciamento de Pressão Aplicáveis aos Reservatórios Carbonáticos do Pré-Sal Brasileiro. [s.I.] UFRJ, 2014.

KUMAR, H. SPE Web Events: Digital technologies- opportunities in the E\&P sector. Disponível em: <https://webevents.spe.org/products/digital-technologiesopportunities-in-the-ep-sector\#tab-product_tab_overview>. Acesso em: 24 fev. 2018.

LAKE, L. W. Petroleum Engineering Handbook: Volume 2. Drilling Engineering. [s.I.] Society of Petroleum Engineers, 2006. v. 2

LI, Y.; KURU, E. Prediction of Critical Foam Velocity for Effective Cuttings Transport in Horizontal Wells. SPE/ICoTA Coiled Tubing Conference and Exhibition. Anais...Society of Petroleum Engineers, 4 abr. 2004.

LIKRAMA, F.; DIAZ, A. A Practical Log-Based Approach on Assessing and Preventing Wellbore Instability Considering Both Mechanical and Shale Swelling Effects. 13 nov. 2015.

LIMA, C. B. D. C. et al. Drilling Centers Maturity Model Evaluation Based on Integrated Operation Key Elements: A Case Study from Brazil. The Open Petroleum Engineering Journal, v. 9, n. 1, p. 313-323, 30 dez. 2016.

LIMA, C. B. DE C. Abordagem Estratégica Orientada para o Gerenciamento Integrado de Operações: O Caso da Produção de Petróleo do Pré-Sal da Bacia de Santos. [s.I.] UFF, 2013.

MANSANO, R. B. Engenharia de Perfuração e Completação em Poços de Petróleo. Disponível em: <https://pt.slideshare.net/sydman/perfurao-e-completao>. Acesso em: 
3 abr. 2018.

MANTHA, B.; SAMUEL, R. ROP Optimization Using Artificial Intelligence Techniques with Statistical Regression Coupling. SPE Annual Technical Conference and Exhibition. Anais...Society of Petroleum Engineers, 26 set. 2016.

MARR, B. The Complete Beginner's Guide To Big Data In 2017. Disponível em: $<$ https://www.forbes.com/sites/bernardmarr/2017/03/14/the-complete-beginnersguide-to-big-data-in-2017/\#7f786ccf7365>. Acesso em: 21 jan. 2018.

MARTIN, C. A. Wellsite Applications of Integrated MWD and Surface Data. SPE/IADC Drilling Conference. Anais...Society of Petroleum Engineers, 4 abr. 1986.

MATTOS, D. L. A.; CAMPOS, I. M. Riscos da Instabilidade do Poço Durante a Perfuração Offshore. [s.I.] UFF, 2017.

MCLELLAN, P. J. Assessing the risk of wellbore instability in horizontal and inclined wells. Journal of Canadian Petroleum Technology, v. 35, n. 5, p. 21-32, 1996.

MEHTA, A. Tapping the Value From Big Data Analytics. Journal of Petroleum Technology, v. 68, n. 12, p. 40-41, 1 dez. 2016.

MITCHELL, R.; SWEATMAN, R. Wellbore Stability and Integrity Contributors Revealed by Thermal Modeling and Fluid Analysis. Offshore Technology Conference. Anais...Offshore Technology Conference, 6 maio 2013.

MONTEVECCHI, A. L. D. Pictorea: Um método para descoberta de conhecimento em banco de dados convencionais. [s.I.] PUC-MG, 2012.

MORAIS, J. M. DE. Petróleo em Águas Profundas - Uma história tecnológica da PETROBRAS na exploração e produção offshore. [s.l: s.n.].

MOREIRA, A. DOS S. Práticas de Gestão Orientadas para a Melhoria da Segurança de Processos na Atividade de Construção de Poços Marítimos de uma Empresa Petrolífera Brasileira: Uma Proposta. [s.I.] UFF, 2017.

MUQEEM, M. A.; WEEKSE, A. E.; AL-HAJJI, A. A. Stuck Pipe Best Practices - A Challenging Approach to Reducing Stuck Pipe Costs. SPE Saudi Arabia Section Technical Symposium and Exhibition. Anais...Society of Petroleum Engineers, 4 abr. 2012.

NASCIMENTO, R. C. A. M. et al. O Fenômeno de Prisão Diferencial : Uma revisão da Literatura. 2010.

NOV. Integrated Drilling Control Systems. Disponível em: <http://www.nov.com/Segments/Rig_Systems/Land/Control_and_Advisory_Systems/ Integrated_Drilling_Control_Systems/Integrated_Drilling_Control_Systems.aspx>. Acesso em: 15 fev. 2018.

OPEC. OPEC: Basket Price. Disponível em: <http://www.opec.org/opec_web/en/data_graphs/40.htm>. Acesso em: 19 dez. 2016.

ORIJI, A. B.; DOSUNMU, A. Design and Application of Drilling Fluids for HPHT Well A Case Study of Mafia Field. North Africa Technical Conference and Exhibition. Anais...Society of Petroleum Engineers, 4 abr. 2012.

OWEN, S. Machine Learning: What is an intuitive explanation of AUC? Disponível em: $<$ https://www.quora.com/Machine-Learning-What-is-an-intuitive-explanation-ofAUC>. Acesso em: 22 ago. 2018. 
PASCHOA, C. Efficient Drill Bits For The Pre-Salt. Disponível em: $<$ https://www.marinetechnologynews.com/blogs/efficient-drill-bits-for-the-pre-salt700368>. Acesso em: 4 mar. 2018.

PEREIRA, A. F. C. Problemas de estabilização de poços petrolíferos: as questões críticas no onshore e no offshore. [s.I.] Técnico Lisboa, 2014.

PEREZ-TELLEZ, C. et al. Drilling Optimization of Wells From Crater Field: Decreasing Drilling Times and Operational Risks. SPE Latin American and Caribbean Petroleum Engineering Conference. Anais...Society of Petroleum Engineers, 4 abr. 2010.

PETERSEN, J. Determining the Cuttings Critical Transport Fluid Velocity using Simple Geometrical Approximations. SPE Bergen One Day Seminar. Anais...Society of Petroleum Engineers, 22 abr. 2015.

PETROWIKI. PetroWiki. Disponível em: <https://petrowiki.org/PetroWiki>. Acesso em: 21 ago. 2018.

PRIYADARSHY, S. Digital transformation essential for E\&P industry to thrive in new economy. World Oil, v. 238, n. January, p. 66-68, 2017.

PRIYADARSHY, S. E\&P Digital Transformation: Fundamental Next Step in Creating Value. JPT, 2018.

PROVOST, F.; FAWCETT, T. Data Science for Business. Book, 2013.

RABELO, C. A. C. Uma Metodologia para Análise de Dados de Perfuração de Poços de Desenvolvimento. [s.I.] UNICAMP, 2008.

RUSSELL, S. J.; NORVIG, P. Artificial intelligence: a modern approach. [s.I: s.n.].

SALESCHOICE. Difference between Artificial Intelligence \& Machine Learning. Disponível em: <http:/www.saleschoice.com/guest-post-difference-between-artificialintelligence-machine-learning/>. Acesso em: 4 mar. 2018.

SALMINEN, K. et al. Stuck-Pipe Prediction by Use of Automated Real-Time Modeling and Data Analysis. SPE Drilling \& Completion, v. 32, n. 03, p. 184-193, 1 set. 2017.

SAS. SASA: Introduction to SEMMA. Disponível em: <http://documentation.sas.com/?docsetld=emref\&docsetTarget=n061bzurmej4j3n1jnj 8bbjjm1a2.htm\&docsetVersion=14.3\&locale=en>. Acesso em: 5 jun. 2018.

SCHLUMBERGER. Oilfield Review. p. 68, 1999.

SCHLUMBERGER. The Oilfield Glossary: Where the Oil Field Meets the Dictionary. Disponível em: <https://www.glossary.oilfield.slb.com/>. Acesso em: 21 ago. 2018.

SCIKITLEARN. Sklearn Linear Model Logistic Regression scikit learn documentation. Disponível em: <http://scikitlearn.org/stable/modules/generated/sklearn.linear_model.LogisticRegression.html>. Acesso em: 18 ago. 2018.

SHAFIQUE, U.; QAISER, H. A Comparative Study of Data Mining Process Models (KDD, CRISP-DM and SEMMA). International Journal of Innovation and Scientific Research, v. 12, n. 1, p. 217-222, 20 nov. 2014.

SHEARER, C. et al. The CRISP-DM model: The New Blueprint for Data Mining. Journal of Data Warehousing, v. 5, n. 4, p. 13-22, 2000.

SHORAKA, S. A. R.; SHADIZADEH, S. R.; SHAHRI, M. P. Prediction of Stuck Pipe in 
Iranian South Oil Fields Using Multivariate Statistical Analysis. Nigeria Annual International Conference and Exhibition. Anais...Society of Petroleum Engineers, 4 abr. 2011.

TAVARES, R. M. Interpretação e Análise de Dados de Perfuração em Poços de Petróleo. [s.I.] UNICAMP, 2006.

THOMAS, J. E. et al. Fundamentos de Engenharia do Petróleo. [s.l: s.n.].

WEISBERG, S. Applied Linear Regression. [s.l: s.n.].

WHITTAKER, A. H. Mud Logging (1987 PEH Chapter 52). Petroleum Engineering Handbook, 1 jan. 1987.

WIKTORSKI, E.; KUZNETCOV, A.; SUI, D. ROP Optimization and Modeling in Directional Drilling Process. SPE Bergen One Day Seminar. Anais...Society of Petroleum Engineers, 5 abr. 2017.

WILSON, A. Natural-Language-Processing Techniques for Oil and Gas Drilling Data. Journal of Petroleum Technology, v. 69, n. 10, p. 96-97, 1 out. 2017.

WIRTH, R. CRISP-DM: Towards a Standard Process Model for Data Mining. Proceedings of the Fourth International Conference on the Practical Application of Knowledge Discovery and Data Mining, n. 24959, p. 29-39, 2000.

WISNIE, A. P.; ZHU, Z. Quantifying Stuck Pipe Risk in Gulf of Mexico Oil and Gas Drilling. SPE Annual Technical Conference and Exhibition. Anais...Society of Petroleum Engineers, 4 abr. 1994.

WORLD ECONOMIC FORUM. Digital Transformation Initiative Oil and Gas Industry In collaboration with Accenture. p. 36, 2017.

YAZIDI, A. Exploiting The Latent Benefits of Wired Pipes: A Comprehensive Decision Making System. SPE Digital Energy Conference. Anais...Society of Petroleum Engineers, 5 mar. 2013. 


\section{APÊNDICE A - Códigos da análise exploratória}

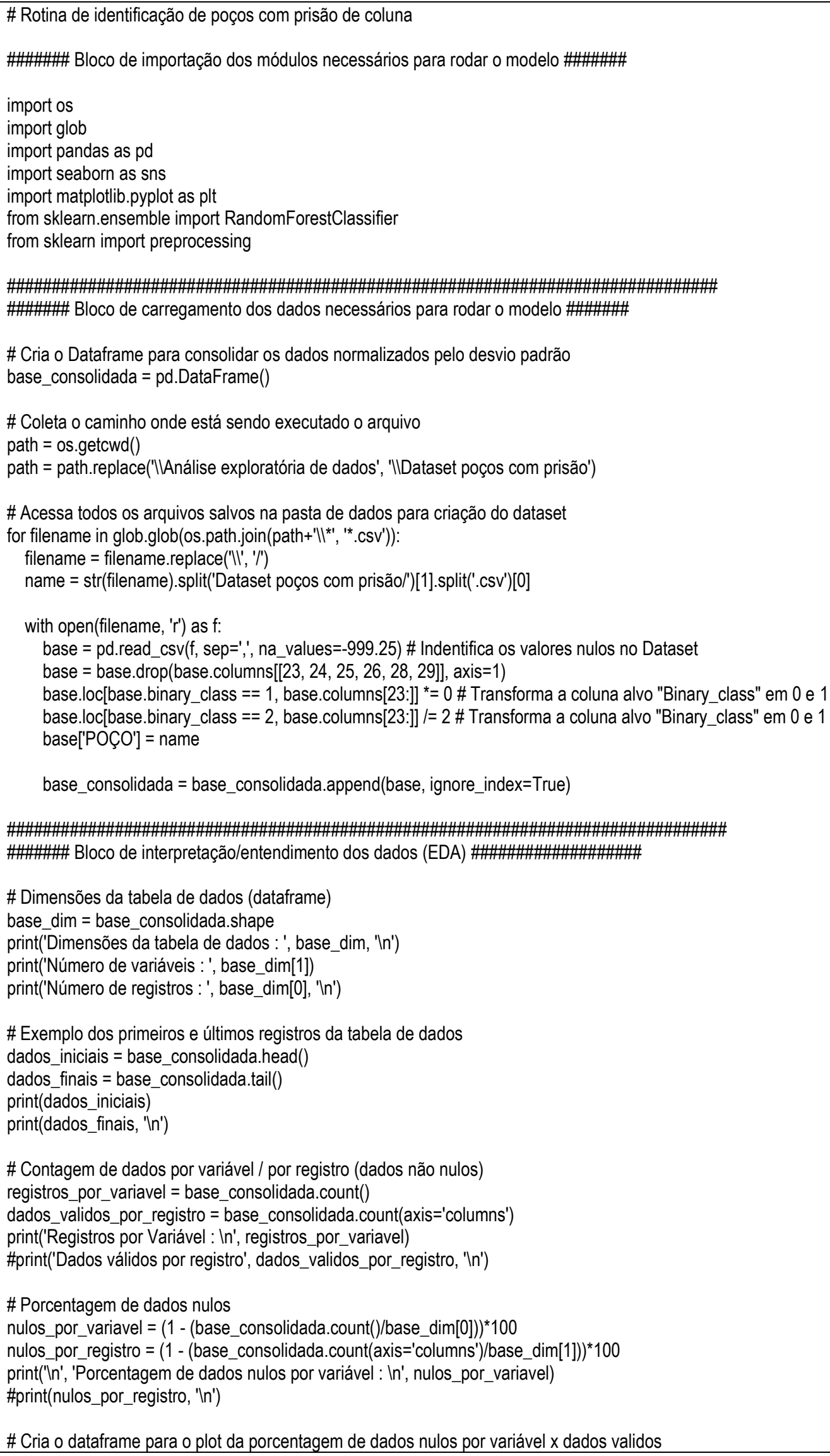


nulos_por_variavel = nulos_por_variavel.to_frame().reset_index()

nulos_por_variavel $=$ nulos_por_variavel[:-1]

nulos_por_variavel.columns $=$ ['VARIAVEL', '\% NULOS']

nulos_por_variavel['\% VALIDOS'] = 100 - nulos_por_variavel['\% NULOS']

\# Informações sobre as variáveis da tabela de dados

info_variaveis = base_consolidada.info()

print('In', info_variaveis)

\#Amostragem desbalanceada para eventos de prisão

$a x=$ sns.countplot $(x=$ "binary_class", data=base_consolidada, palette='gray', saturation=.1)

for $p$, label in zip(ax.patches, base_consolidada["binary_class"].value_counts()):

ax.annotate(label, (p.get_x()+0.290, p.get_height()+0.15))

plt.show()

\# Gráfico de barras indicando a porcentagem de dados nulos por variável

barWidth $=0.85$

names $=$ list(nulos_por_variavel['VARIAVEL'])

$r=[0,1,2,3,4,5,6,7,8,9,10,11,12,13,14,15,16,17,18,19,20,21,22,23]$

plt.bar(r, nulos_por_variavel['\% VALIDOS'], color='lightgray', edgecolor='white', width=barWidth)

plt.bar(r, nulos_por_variavel['\% NULOS'], bottom=nulos_por_variavel['\% VALIDOS'], color='gray', edgecolor='white', width=barWidth)

plt.xticks(r, names, rotation=90)

plt.show()

\# Geração de gráfico de correlação (heatmap) entre as variáveis

fig, ax = plt.subplots $($ figsize $=(16,10))$

sns.heatmap(base_consolidada.iloc[:, :-2].corr(), fmt=".2f", cmap="gray", xticklabels=True, yticklabels=True, annot=True, linewidths=1,

ax=ax)

plt.show()

\# Boxplot de todas as variáveis em relação a variável alvo (binary_class)

$\mathrm{df}=$ base_consolidada.iloc[:, :-1].melt(id_vars=['binary_class'])

$\mathrm{df}=\mathrm{df} . \mathrm{dropna}()$

cols = list(base_consolidada)

cols.pop()

grid = sns. axisgrid.FacetGrid(df[df.variable.isin(cols)], col='variable', sharey=False, col_wrap=5)

grid.map(sns.boxplot, 'binary_class','value', color='white').set_axis_labels(",")

plt.show()

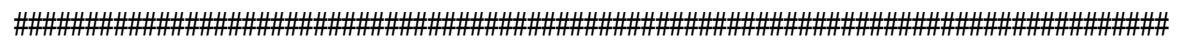




\section{APÊNDICE B - Códigos da preparação dos dados}

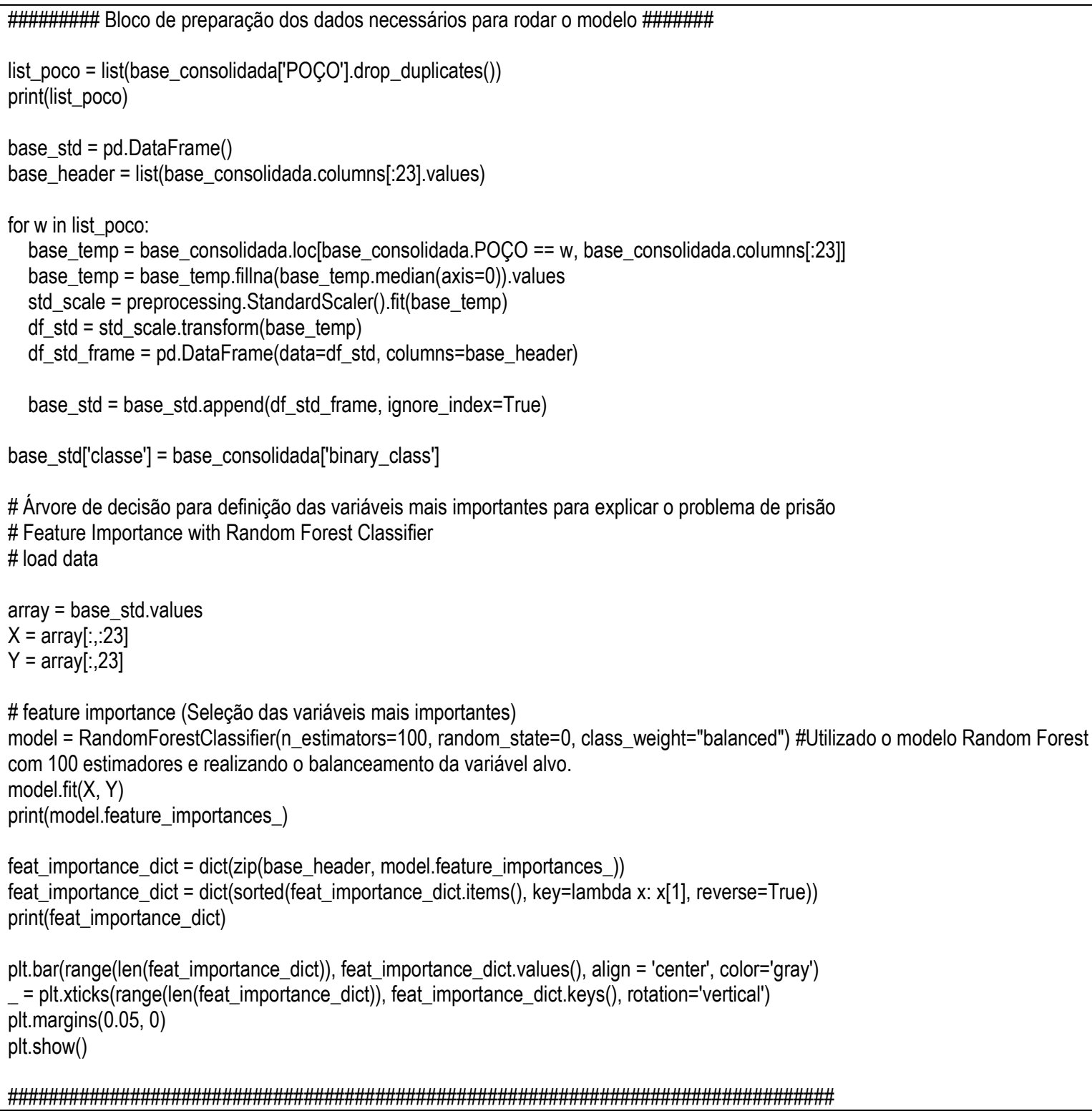




\section{APÊNDICE C - Códigos da modelagem e avaliação}

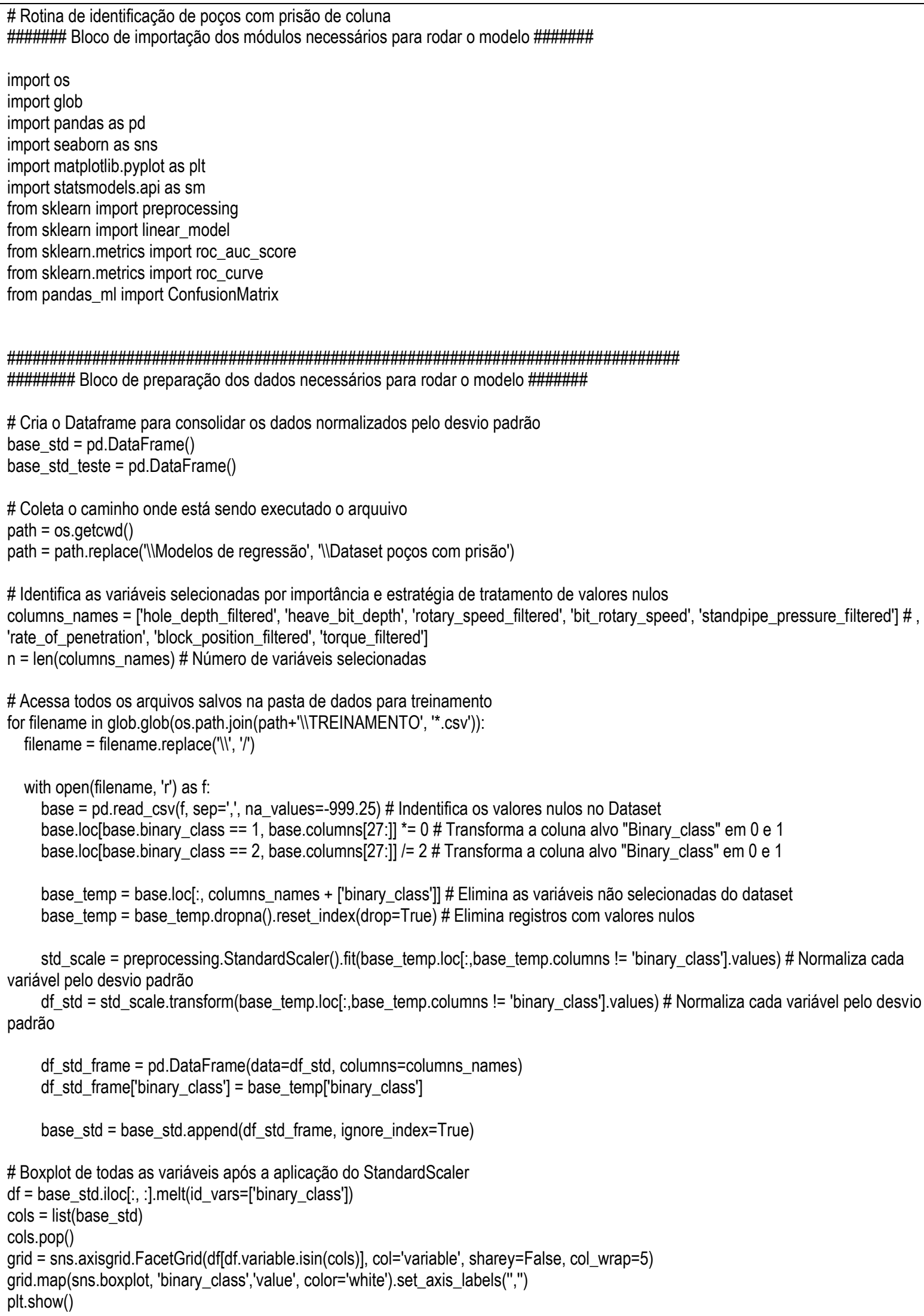




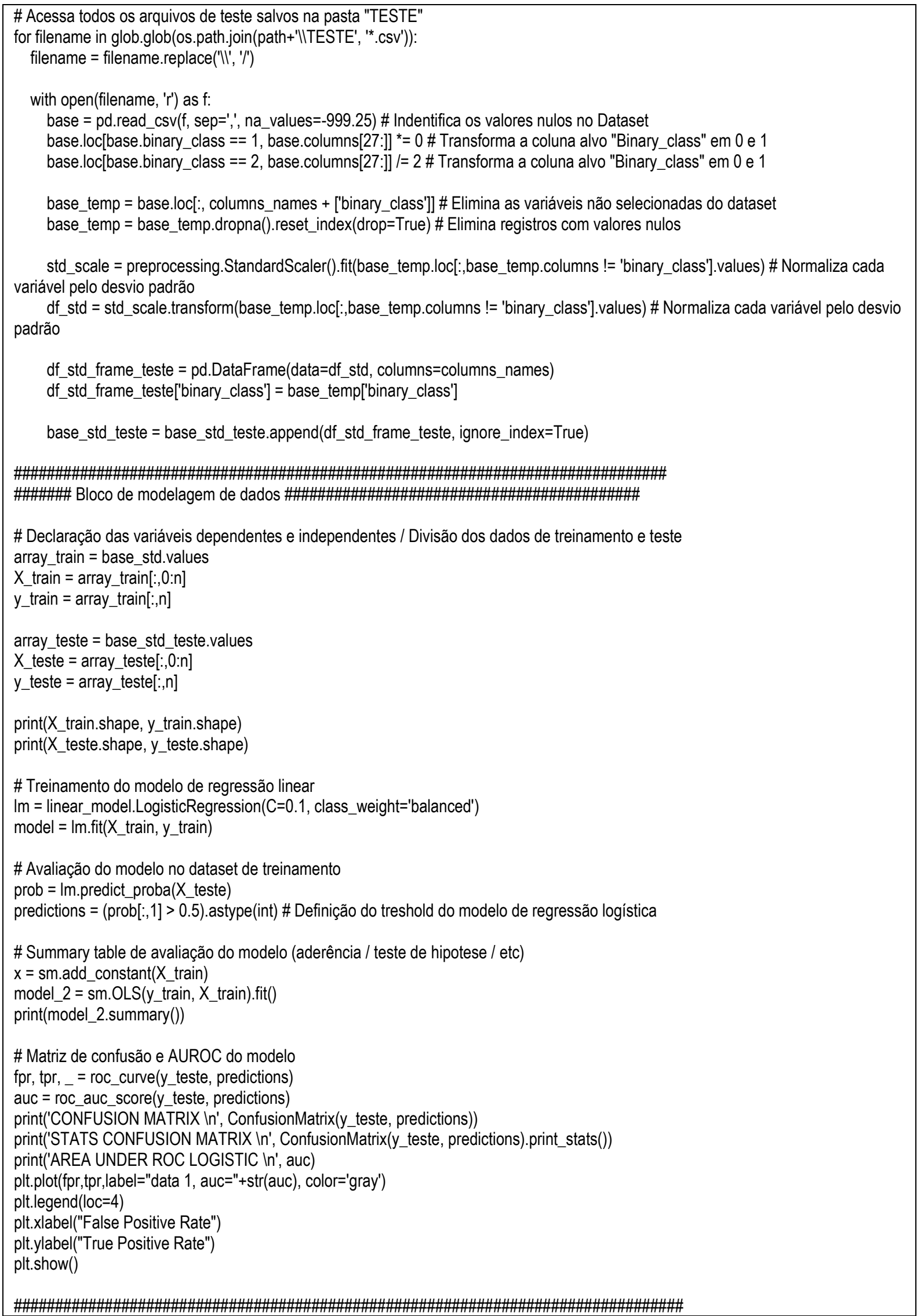




\section{APÊNDICE D - Códigos da solução (protótipo)}

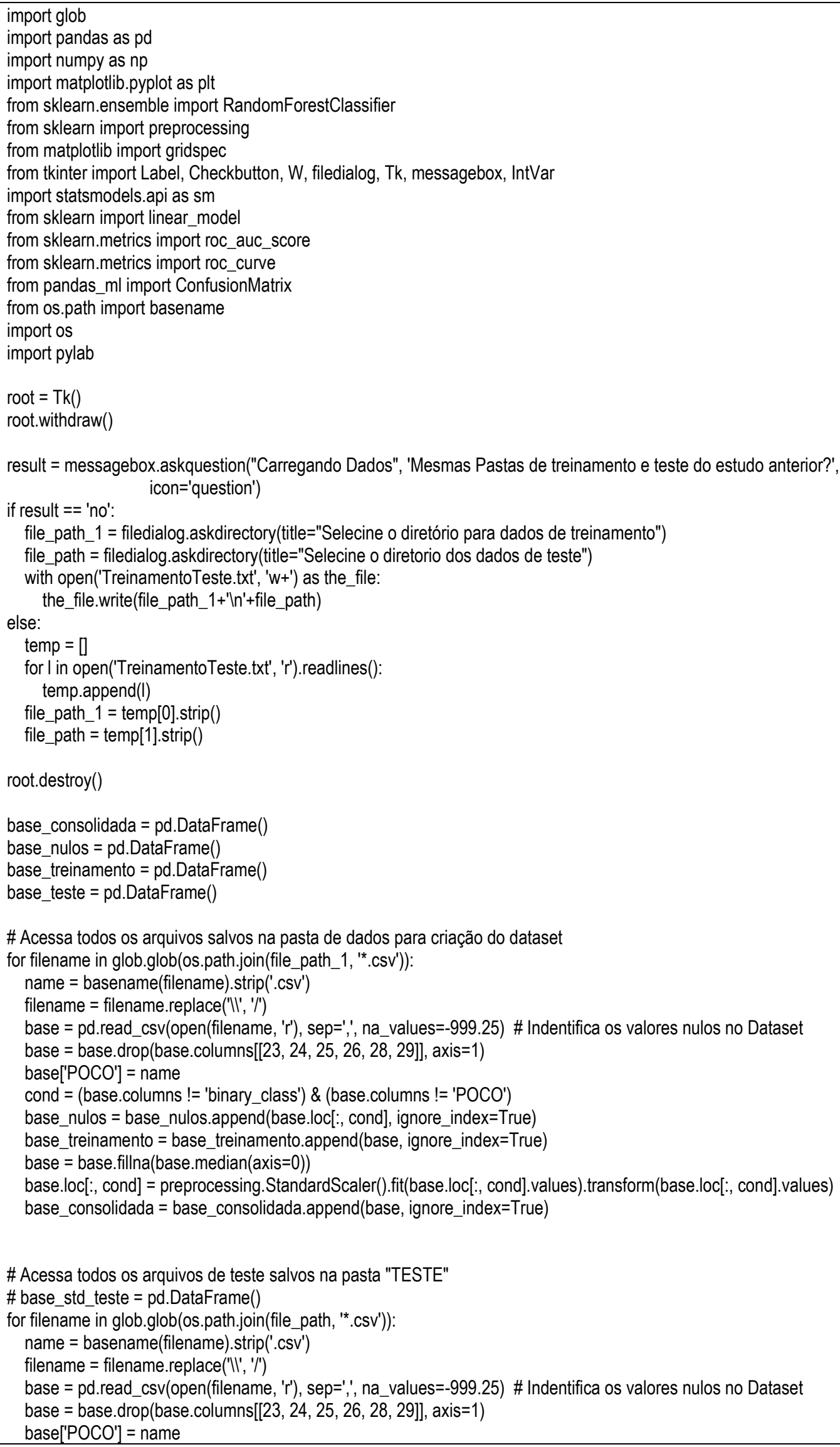


cond = (base.columns != 'binary_class') \& (base.columns != 'POCO')

base_nulos $=$ base_nulos.append $($ base.loc[:, cond], ignore_index=True)

base_teste $=$ base_teste.append (base, ignore_index=True)

base $=$ base . illna $($ base $\cdot$ median $($ axis $=0)$ )

base.loc[:, cond] = preprocessing.StandardScaler().fit(base.loc[:, cond].values).transform(base.loc[:, cond].values)

base_consolidada $=$ base_consolidada.append $($ base, ignore_index $=$ True $)$

\# Transforma a coluna alvo "Binary_class" em 0 e 1

base_treinamento.binary_class $=$ base_treinamento.binary_class.apply(lambda $x: 0$ if $x==1$ else 1$)$

base_teste.binary_class $=$ base_teste.binary_class.apply(lambda $x: 0$ if $x==1$ else 1$)$

base_consolidada.binary_class $=$ base_consolidada.binary_class.apply(lambda $x: 0$ if $x==1$ else 1$)$

\#\#\#\#\#\# Bloco de preparação dos dados necessários para rodar o modelo \#\#\#\#\#

print(base_consolidada['POCO'].drop_duplicates().tolist())

\# feature importance (Seleção das variáveis mais importantes)

\# Utilizado o modelo Random Forest com 100 estimadores e realizando o balanceamento da variável alvo.

model $=$ RandomForestClassifier(n_estimators $=100$, random_state $=0$, class_weight="balanced")

model.fit(base_consolidada.loc[:, base_consolidada.columns != 'POCO'].values[:, :23], base_consolidada.loc[:, base_consolidada.columns != 'POCO'].values[:, 23])

print(model.feature_importances_)

\# Porcentagem de dados nulos

nulos_por_variavel $=(1$ - (base_nulos.count ()$/$ base_nulos.shape[0] $))^{*} 100$

del base_nulos

print('In', 'Porcentagem de dados nulos por variável : In', nulos_por_variavel)

\# Cria o dataframe para o plot da porcentagem de dados nulos por variável $\mathrm{x}$ dados validos

nulos_por_variavel $=$ nulos_por_variavel.to_frame().reset_index()

nulos_por_variavel $=$ nulos_por_variavel[:-1].dropna()

nulos_por_variavel.columns = ['VARIAVEL', 'PERC_NULOS']

nulos_por_variavel['PERC_VALIDOS'] = 100 - nulos_por_variavel['PERC_NULOS']

\# Gráfico de barras indicando a porcentagem de dados nulos por variável

names = nulos_por_variavel['VARIAVEL'].tolist()

$r=$ nulos_por_variavel.index.tolist()

gs = gridspec. $\operatorname{GridSpec}(1,2$, width_ratios=[20,20], wspace=0.2)

ax1 $=$ plt.subplot $(\mathrm{gs}[0])$

ax2 = plt.subplot(gs[1])

ax1.bar(r, nulos_por_variavel['PERC_VALIDOS'].values, color='lightgray', edgecolor='white', width=0.85)

ax1.bar(r, nulos_por_variavel['PERC_NULOS'].values, bottom=nulos_por_variavel['PERC_VALIDOS'].values, color='gray', edgecolor='white', width $=0.85$ )

ax1.set_xticks(r)

ax1.set_xticklabels(names, size=8, rotation=90, multialignment='right')

feat_importance_dict = dict(zip(base_consolidada.columns.tolist(), model.feature_importances_))

feat_importance_dict $=$ dict(sorted(feat_importance_dict.items (), key=lambda x: x[1] , reverse=True))

print(feat_importance_dict)

ax2.bar(range(len(feat_importance_dict)), feat_importance_dict.values(), align='center', color='gray')

ax2.set_xticks(list(range(len(feat_importance_dict))))

ax2.set_xticklabels(list(feat_importance_dict.keys()), size=8, rotation=90, multialignment='right')

ax2.margins $(0.05,0)$

plt.subplots_adjust(top $=0.95$, bottom $=0.25$, left $=0.05$, right $=0.95$ )

fig $=$ pylab.gcf()

fig.canvas.set_window_title('Feature Importance / Percentual de Dados Nulos',) 


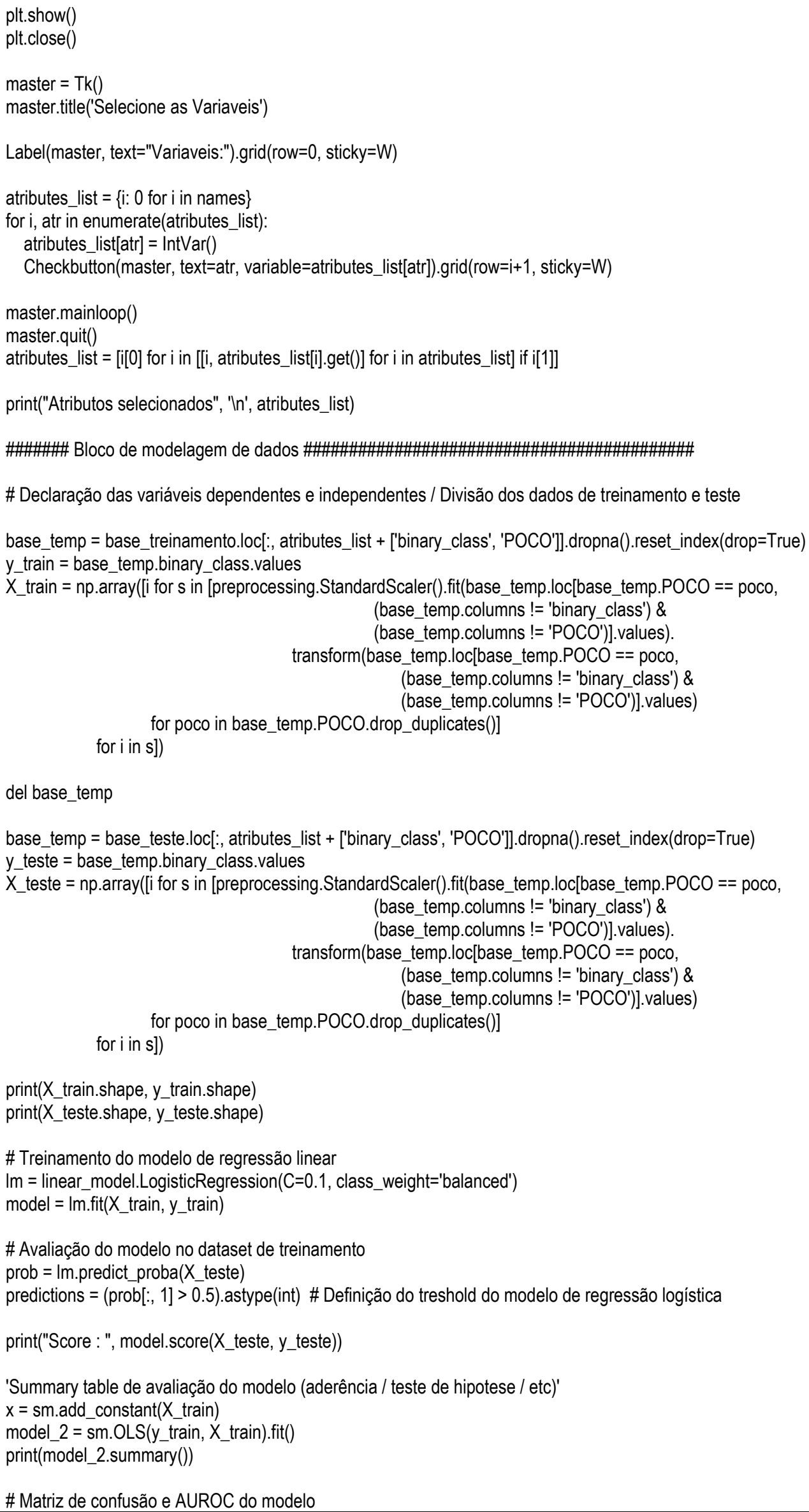

\# Avaliação do modelo no dataset de treinamento prob $=$ Im.predict_proba $\left(X \_\right.$teste $)$ 


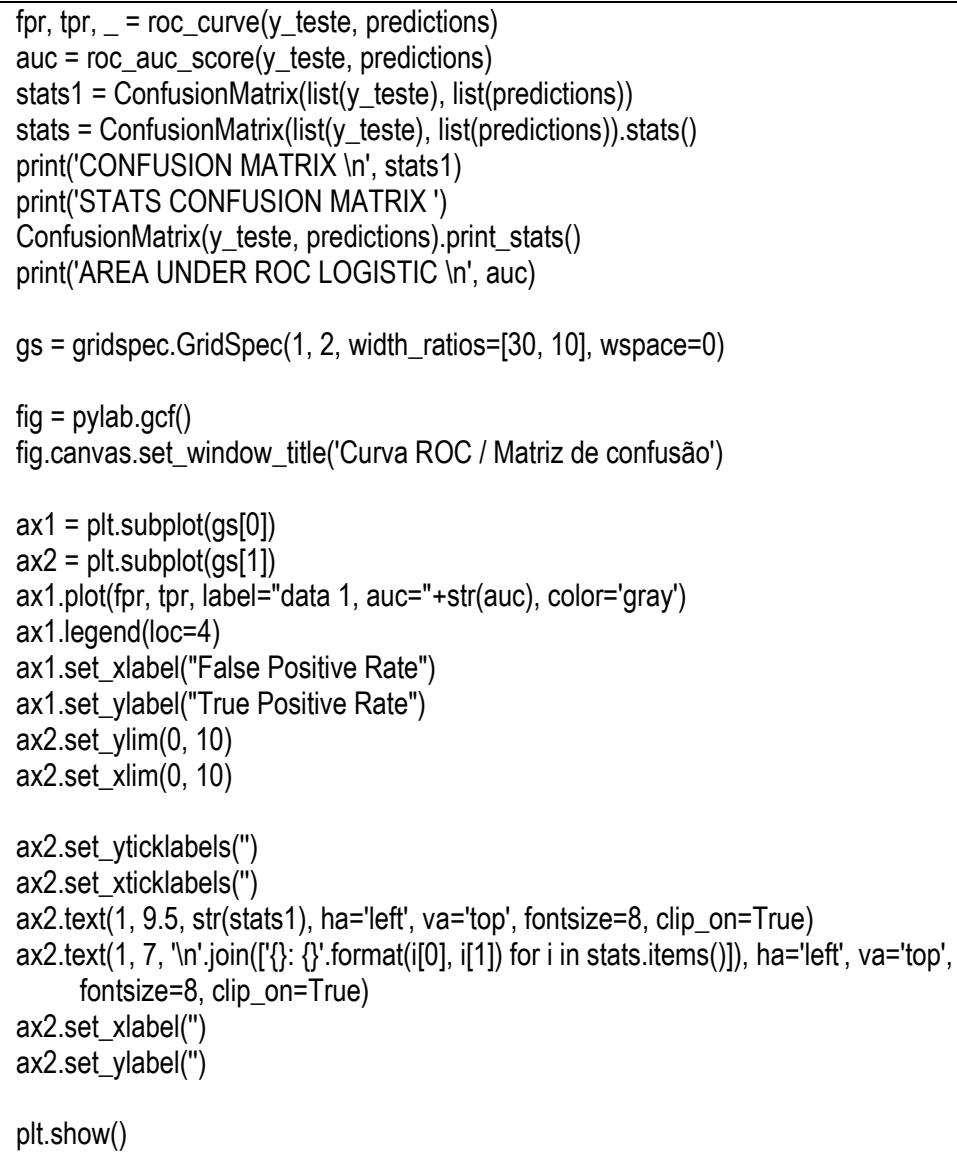

